NBER WORKING PAPER SERIES

LABOR MARKET FRICTIONS, FIRM GROWTH, AND INTERNATIONAL TRADE

\author{
Pablo D. Fajgelbaum \\ Working Paper 19492 \\ http://www.nber.org/papers/w19492 \\ NATIONAL BUREAU OF ECONOMIC RESEARCH \\ 1050 Massachusetts Avenue \\ Cambridge, MA 02138
}

October 2013, Revised November 2019

A previous version of this paper was a chapter from my Ph.D. dissertation. I am thankful to Esteban Rossi-Hansberg and Gene Grossman for their guidance and support. I specially thank Oleg Itskhoki, Nobuhiro Kiyotaki, and Stephen Redding. I also James Tybout for his discussion of the paper. I am also grateful to Andrew Atkeson, Joaquin Blaum, Francisco Buera, Ariel Burstein, Kerem Co ar, Arnaud Costinot, Juan Carlos Hallak, Rasmus Lentz, Guido Menzio, Claudio Michelacci, Maria Jose Prados, Edouard Schaal, Mathieu Taschereau-Dumouchel, and Jon Vogel for useful comments. I thank Andreas Gulyas and Brian Pustilnik for excellent research assistance, as well as Ana Sofía Rojo-Brizuela, Victoria Castillo Videla, and Lucía Tumini at the Argentine Ministry of Labor for providing the data. The views expressed herein are those of the author and do not necessarily reflect the views of the National Bureau of Economic Research.

NBER working papers are circulated for discussion and comment purposes. They have not been peer-reviewed or been subject to the review by the NBER Board of Directors that accompanies official NBER publications.

(C) 2013 by Pablo D. Fajgelbaum. All rights reserved. Short sections of text, not to exceed two paragraphs, may be quoted without explicit permission provided that full credit, including ( $)$ notice, is given to the source. 
Labor Market Frictions, Firm Growth, and International Trade

Pablo D. Fajgelbaum

NBER Working Paper No. 19492

October 2013, Revised November 2019

JEL No. D92,F16,J62,L11

\begin{abstract}
$\underline{\text { ABSTRACT }}$
I study the aggregate effects of labor market frictions in a small open economy where firms grow slowly and make fixed export investments. The model features interactions between dynamic investments in exporting and search frictions with job-to-job mobility. A calibration to Argentina's economy matching data on firm growth, worker transitions between firms, and export dynamics suggests that the real income gains from lowering frictions in job-to-job transitions are about 7 times larger than comparable reductions in frictions from unemployment. Barriers to worker mobility across firms matter for the real income gains of trade-cost reductions.
\end{abstract}

Pablo D. Fajgelbaum

Department of Economics

University of California, Los Angeles

Bunche Hall 8283

315 Portola Plaza

Los Angeles, CA 90095

and NBER

pfajgelbaum@gmail.com 


\section{Introduction}

According to a central view in international trade, the labor allocation and export decisions across heterogeneous firms are important to shape aggregate outcomes (Melitz, 2003). The switch of firms into exporting is also seen as a driver of real income gains in developing countries (Atkin et al., 2017). At the same time, exporting is often described as a discrete decision that can be profitably undertaken only by producers with sufficient scale. Whereas in Melitz (2003) firms instantaneously grow to their desired size, empirically the process of entering export markets occurs slowly, often taking several years before a new firm reaches the scale at which investing in exporting is profitable, if it ever does. ${ }^{1}$

In this context, it is important to understand the role of specific forces that slow down firm growth and therefore may prevent exporting or other fixed revenue-enhancing investments from taking place. Labor market frictions are one such force, as firms operating in more rigid labor markets face larger costs and delays when hiring workers. ${ }^{2}$ It has long been noted that barriers to labor mobility may deter the gains from international integration from fully materializing, ${ }^{3}$ and recent studies of trade liberalization assign an important role to frictions in labor reallocations across sectors (Dix-Carneiro, 2014) or regions (Caliendo et al., 2019). However, less is known about the effects of labor market frictions in open economies through their impact on firm-level growth and export investments. ${ }^{4}$

This paper studies the aggregate impact of labor market frictions in an economy where firms grow slowly and undertake fixed export investments along their life cycle. I develop an openeconomy model combining firm growth subject to adjustment costs, discrete revenue-enhancing investments in exporting, and search and matching frictions with on-the-job search. I then match the model to data from Argentina on firm-level growth, export dynamics, and worker transitions between firms. The theoretical and quantitative results suggest that frictions in job-to-job transitions have a stronger impact on income per worker, investments and growth of the most productive firms compared to frictions in hiring from unemployment. While traditionally the concerns in studies of frictional labor markets are placed on understanding the size of the unemployment pool, my

\footnotetext{
${ }^{1}$ See Bernard et al. (2007) for evidence on exporter size premia and Das et al. (2007) for evidence on fixed costs of exporting and export entry rates.

${ }^{2}$ Kugler (2007) summarizes a body of evidence based on reform episodes that affected specific groups of firms in several countries. As a general finding, a tightening in employment protection reduces net employment adjustments for the affected firms. Hsieh and Klenow (2014) argue that cross-country differences in growth throughout firms' life cycle are important for income differences, and suggest that labor market regulations may be one driver of these differences.

${ }^{3}$ E.g., see Matsuyama (1992) for an early theory of labor market rigidities in a Ricardian environment. The view that labor market barriers are important for the gains from integration was recently stated by Dani Rodrik: "If trade negotiators got around the table and say "what is it that we can do to increase the global consumption possibilities frontier?", they would stop everything that they are doing right now and then go after where the barriers are really large, because that's where the biggest gains are going to be, both at the national level and at the global level.(...) Where the barriers are largest is in labor markets." Trade Talks (www.piie.com/trade-talks), episode 25, March 1, 2018.

${ }^{4}$ The next section reviews recent evidence pointing to a negative relationship between labor market frictions and firm-level exporting decisions.
} 
analysis implies that focusing on determinants of job-to-job transitions is important for income and productivity. ${ }^{5}$

The framework articulates canonical components from the trade and labor search literatures. On the trade side, similarly to Krugman (1980), monopolistically competitive producers can sell at home and internationally. As in Melitz (2003), firms have innate differences in productivity, exporting entails a one-off fixed investment, and firms die continuously due to exogenous shocks, being replaced by entrants to meet zero expected profits. I study a two-country economy, and then extend the analysis to many destinations. On the labor side, firms match randomly with workers who learn about job opportunities both when unemployed and on-the-job. As in Cahuc et al. (2006) and Dey and Flinn (2005), employed workers searching on-the-job use the value of their next-best alternative as outside option in the bargaining with their best potential employer. As in the Pissarides (2000), equilibrium matching rates depend on the effective numbers of workers and firms searching. Finally, in the spirit of Kaas and Kircher (2015), I incorporate a firm-level growth process: firms contact potential employees slowly, subject to a convex cost of search intensity, and discount future profits at a positive rate.

The components of the theory give rise to a firm's life cycle: each new firm starts with no workers, grows by hiring unemployed and employed workers subject to labor market frictions, and at some age may invest in exporting. If many export options are available, firms decide the sequence and timing of entry to each market. In deciding when to export, firms trade off the savings from delaying the fixed cost payment against the foregone revenues and growth from delaying. I refer to this opportunity cost of delaying as a stock effect, because it increases with the stock of labor within the firm. More productive firms invest earlier, and job values increase gradually with age and size conditional on productivity. Thus, in equilibrium, workers flow from smaller and younger firms towards larger and older firms who are more productive and more likely to export, and therefore offer higher-value jobs.

I use the model to characterize and quantify the impact of labor market frictions. Formally, I study comparative statics with respect to the search and matching efficiencies of employed and unemployed workers. This question follows a research tradition asking how search and matching frictions impact income per worker through some form of misallocation. ${ }^{6}$ The matching efficiency parameters capture, in reduced form, country characteristics that impact workers' job-finding rates. A natural interpretation is that they represent labor market regulations. Labor rigidities vary widely across countries due to different reasons such as countries' legal origins or the power of some types of political parties (Botero et al., 2004), and have been historically high in Latin American countries (Heckman and Pages-Serra, 2000; Djankov and Ramalho, 2009). Moreover, measurable

\footnotetext{
${ }^{5}$ In their review of the implications of labor market institutions for economic performance, Nickell and Layard (1999) largely focus on the impact of transitions out of unemployment. Davis and Haltiwanger (2014) have more recently suggested that slow labor reallocations across firms may be important for growth.

${ }^{6}$ Lagos (2006) and Shimer (2005) develop models with a dependence of TFP on search or coordination frictions, while studies such as Shimer and Smith (2000) and Bagger and Lentz (2014) assess the wage and productivity effects of mismatch between heterogeneous workers and firms. Acemoglu and Shimer (2000) explore the impact of labor market frictions on firms' investment decisions in a directed search framework with single-worker firms.
} 
aspects of the employment legislation are visibly correlated with the job-finding rates that I modify in the counterfactuals. ${ }^{7}$ Given my focus on job-to-job transitions, it is worth noting that certain types of employment legislation have a strong impact on job-to-job transitions and job-finding rates of employed workers. ${ }^{8}$ To the extent that my counterfactuals are interpreted as changes in labor market institutions, an important caveat is that they only capture their impacts through workers' job-finding rates, while abstracting from other channels or potential benefits such as enhanced job security.

Frictions in hiring from both employment and unemployment have an impact on income per employed worker through the distributions of export-entry times and growth across heterogeneousproductivity firms. However, I demonstrate that there is an asymmetry in how each type of friction works. Frictions in hiring from unemployment impact these outcomes only through generalequilibrium adjustments in the value of unemployment or revenue per unit sold. This property is in keeping with a well-known property of the canonical matching model (Pissarides, 1985), which is nested within the framework that I study, where increases in firms' meeting rates due to higher matching efficiency are offset by entry unless the value of unemployment adjusts. In contrast, frictions in hiring employed workers impact entry times and firm growth regardless of whether those general-equilibrium variables adjust. Intuitively, given these general-equilibrium variables, a higher contact rate from unemployment increases the size of the employment pool without impacting its composition across firms; the economy adjusts exclusively through firm entry, but the intensive margins of firm growth and export participation are kept constant. In contrast, a higher contact rate from employment speeds up worker transitions to more productive firms and exporters, leading to a speeding up of investment and firm growth.

To further characterize the model properties, I rely on a simpler version without innate differences in firm productivity that yields closed-form solutions. Frictions impact the stock effect, and therefore firms' growth and export-entry incentives, through offsetting channels. The stock effect increases with firms' equilibrium likelihoods of meeting employed and unemployed workers, but it falls with stiffer competition in the labor market through either more firms or a higher likelihood of having workers poached away. Under mild parameter restrictions, the encouraging effects dominate and lower frictions end up raising income per worker through faster firm growth and export entry. These forces coexist with other channels through which frictions impact income per employed worker, such as a standard demand externality borne out of monopolistic competition and a response of the returns to exporting through adjustments in the relative size of the domestic market.

\footnotetext{
${ }^{7}$ Figure A.1 in the Online Appendix shows negative correlations across countries between standard indexes that capture different aspects of the labor legislation (the Employment Protection Legislation index from the OECD and the Rigidity of Employment index from by the World Bank) and contact rates of employed and unemployed workers estimated by Hobijn and Şahin (2009), Ridder and van den Berg (2003) and Jolivet et al. (2006).

${ }^{8}$ Haltiwanger et al. (2014) show that more stringent hiring and firing regulations negatively impact job reallocations within industries. Bassanini and Garnero (2013) and chapter 3 of OECD (2010) suggest that employment protection against dismissals reduce the rate of job-to-job transitions within an industry, without a significant effect in job-to-unemployment transitions. Blanchard and Portugal (2001) argue that these policies may also impact unemployment-to-job transitions.
} 
To quantify these effects, I match the model to data from Argentina's economy from 20032007. Being a small open economy with a fairly regulated labor market, Argentina is a natural environment for the quantification. A natural challenge in the parametrization is to discipline the degree of frictions in worker transitions. Conveniently, in addition to summary statistics from the firm size, age, and export distributions, I also observe the rates at which firms with different export statuses hire workers directly from other firms. These observed rates of job-to-job hiring by export status discipline the extent of frictions in job-to-job mobility in the model, allowing me to calibrate the job-finding rates of employed workers. The calibrated model replicates well several key outcomes from the theory, such as the firm-size distribution and the intensity of hiring job-to-job, as well as statistics that are not targeted by the calibration, such as export participation over the firm's life cycle, the average duration of employment relationships, and measures of wage inequality.

Using the calibrated model, I measure the elasticity of income per employed worker with respect to labor market frictions. The elasticity of income per employed worker with respect to the efficiency in job-to-job matching is about 7 times larger than with respect to the efficiency in matching from unemployment. An increase in the contact rate of unemployed workers that would reduce unemployment in Argentina by 3 percentage points would raise income per employed worker by $1 \%$, while an increase in the contact rate of employed workers that would raise the share of job-tojob hires by 3 percentage points would raise income per employed worker by $7 \%$. Lowering frictions from employment also leads to faster growth and export entry of the more productive firms, but to slower growth and export entry of the less productive firms. However, lowering frictions from unemployment does not speed up firm growth nor the timing of investment. Instead, it only raises income per employed worker through the standard demand externality borne out of monopolistic competition.

These results imply that job-to-job transitions are a key channel through which the gains from reductions in labor market frictions materialize. A back-of-the-envelope calculation using the results from the calibration suggests that labor market reforms that would push Argentina from the top third of the World Bank's rigidity of employment index (where it belonged in the years corresponding to my calibration) to the bottom third would lead to a $5.8 \%$ increase in income per worker. Moreover, $80 \%$ of these gains happen through lowering frictions in job-to-job transitions. Using the elasticity of income to labor market rigidities implied by the calibration, a simple development accounting exercise suggests that, through the forces in my model, differences in labor market rigidity may generate about $5 \%$ of the standard deviation in log income per worker observed across countries.

The stronger impact of frictions in job-to-job transitions is a robust finding, as it holds uniformly for small and large reductions in frictions, as well as for a varied range of alternative parametrizations. It also holds in the extension allowing for an arbitrary number of export destinations, in which firms enter sequentially to several export markets as they grow. Unlike in the baseline model, where firms experience a once-and-for-all bump to their revenue per worker, in the multi-market extension they experience a progressive increase in revenue per worker over extended periods of their 
life cycle, consistent with qualitative features of the data. A calibration of this extended model yields similar real-income gains from lowering frictions in job-to-job mobility as in the baseline model with 2 countries.

To conclude, I implement an exercise that speaks to the role of micro features in shaping the macro gains from trade. I find that the real income gains from a given reduction in trade costs are smaller in a calibration that rules out job-to-job transitions and ignores the share of hires that are job-to-job as a calibration target. Therefore, accounting for barriers to worker mobility across firms matters to predict the real income effects of a given reduction in trade costs. The Arkolakis et al. (2012) formula, saying that in gravity models the elasticity of trade flows to trade costs and the change in the domestic expenditure share suffice to measure the gains from changes in trade costs, remains a very good approximation even though my model does not fit in that class of models.

The rest of the paper is structured as follows. Section 2 relates this paper to the existing literature; Section 3 lays out the framework, characterizes the export-entry decision, and establishes the channels through which frictions impact outcomes; Section 4 studies the simpler model; Section 5 presents the calibration; and Section 6 presents the counterfactuals. Section 7 concludes. Additional derivations, proofs, tables, figures, and details on data sources are shown in the appendix.

\section{Literature Background}

Trade, Labor Market Frictions, and Firm Dynamics Helpman and Itskhoki (2010) and Cosar et al. (2016) have studied similar questions to this paper. Helpman and Itskhoki (2010) inspect the impact of labor market frictions on aggregate outcomes and the export decisions of heterogeneous firms. My analysis focuses on how frictions impact outcomes in an economy with slow firm growth and dynamic investments in exporting, while theirs is a static setup. Methodologically, my work is also geared towards a measurement using the calibrated model, whereas theirs is theoretical. Cosar et al. (2016) structurally estimate a small-open economy model with matching frictions and selection into exporting. Their goal is to measure the impact of trade liberalization and firing costs on wage inequality and job turnover in an environment with frequent firm-level productivity shocks and size-dependent vacancy costs. I model firm- and cohort-level growth resulting from sluggish adjustment under convex recruitment costs and linear revenue functions. Relative to both papers, a distinctive feature of my analysis is the presence of job-to-job transitions. This force shapes the general-equilibrium structure of my model, partly through an interaction between export investment and firm growth. ${ }^{9}$ A conclusion of my analysis is that a large part of the income gains from more flexible labor markets operate through this margin.

Many studies have embedded labor market imperfections in heterogeneous-firms models in order to study the impact of trade liberalization on unemployment and the wage distribution. Recent theoretical studies along these lines include Davidson et al. (2008), Felbermayr et al. (2011), and

\footnotetext{
${ }^{9}$ In my model, frictions in unemployment-to-job transitions partly operate through the endogenous value of unemployment, which is exogenously pinned down by the value of working in an outside sector in these setups. The magnitude of this effect turns out to be small in the quantification.
} 
Helpman et al. (2010), while recent empirical papers include Amiti and Davis (2012) and Helpman et al. (2012), among others. The wage distribution is not the focus on my analysis, but I draw some of my model's implications for individual wage trajectories arising from the combination of job-to-job mobility and dynamic investment in exporting, and I contrast some of the calibrated model's implications for wage inequality relative to the data. Kambourov (2009) and Cunat and Melitz (2012) consider how labor market institutions impact labor reallocations across sectors.

Recent models with firm dynamics and exporting include Atkeson and Burstein (2010) and Arkolakis (2016), among others. For a review of this literature see Burstein and Melitz (2011). The driving force underlying firm dynamics here is sluggish adjustment with labor market frictions, while in these papers the dynamics follows from firm-level productivity shocks or innovation. From an empirical standpoint my approach is distinguished by the specific predictions regarding the composition of new hires by export status and by the impact of labor market frictions on export dynamics and aggregate outcomes. I focus on these features throughout the theoretical and quantitative analysis. ${ }^{10}$ Morales et al. (2014) estimate a model with sequential entry into many export markets driven by dynamic fixed costs. While the bulk of my analysis is undertaken assuming a single export destination representing the rest of the world, I also develop and quantitatively implement a version of the model in which firms enter sequentially to many export destinations as they grow.

Search with Multi-Worker Firms In terms of tools, this paper is related to the search literature with job-to-job transitions in the spirit of Burdett and Mortensen (1998). As in Postel-Vinay and Robin (2002), Cahuc et al. (2006), and Dey and Flinn (2005), upon contacting a firm, workers transit from low- to high value jobs, and the surplus is split between worker and firm according to linear sharing rules in which workers use the value of the next-best job as outside option. My model is also related to Lise and Robin (2017), who combine the previous on-the-job search frameworks with a meeting function as in Pissarides (2000). They further introduce aggregate shocks, while I only study steady state outcomes. Moscarini and Postel-Vinay (2017) emphasize the productivity effects of job-to-job transitions over the business cycle, whereas Krusell et al. (2017) show that shocks to job-arrival rates help rationalize gross flows. While I only study steady states, my results suggest an additional channel through which shocks to job-arrival rates may impact productivity over the business cycle.

As in other papers analyzing firm dynamics with job-to-job transitions (Garibaldi et al., 2016; Moscarini and Postel-Vinay, 2013), I assume that firms' revenues are linear in the number of workers. Within a directed-search framework, Schaal (2012) studies uncertainty shocks during the great recession allowing for decreasing returns to scale and job-to-job transitions. Kaas and Kircher (2015) develop a model with firm-level and aggregate productivity shocks, where multiworker firms operate under decreasing returns to scale and may post vacancies besides controlling

\footnotetext{
${ }^{10} \mathrm{My}$ analysis focuses on steady-state comparisons. Some papers studying transitional dynamics arising from labor market frictions in the aftermath of a trade liberalization include Cosar (2010) in a neoclassical trade environment, and Helpman and Itskhoki (2015) in a Melitz (2003) type framework.
} 
the recruiting intensity. The distinctive feature of my model is the introduction of fixed sequential investments and a small open-economy setting into a model with on-the-job search and slow firm growth. In partial equilibrium, given market sizes, the investments can be equivalently interpreted as entering new markets or upgrading technology. However, in general equilibrium, the open economy with monopolistic competition implies that the returns to exporting are endogenous. Because the investments decisions are age-dependent, solving the allocation requires accounting for patterns of job-to-job mobility across firms with two-dimensional heterogeneity, in terms of both firm age and innate productivity. ${ }^{11}$

Labor Market Rigidities and Exports Some papers have identified a negative relationship between labor market rigidities and firm-level export decisions. Seker (2012) uses firm-level survey data across countries to show that firms who report being more size-constrained due to labor market regulations are less likely to export. This evidence suggest that labor regulations may impact the decisions to export through firm size. Other studies show that the effect of export demand shocks on firms' expansion depends on labor market frictions. Almeida and Poole (2017) show that, in response to a currency depreciation in Brazil, plants facing stricter enforcement of labor laws increase employment relatively less than other plants. Wang et al. (2018) show that Chinese firms who receive a positive export shock after China's entry to the World Trade Organization expand their employment by more in regions with more flexible labor markets in terms of the strictness of regulations allowing workers to move across regions. ${ }^{12}$ At the country level, Salas (2018) finds a negative relationship between exports and indexes that capture the rigidity of employment laws in a panel of OECD countries. ${ }^{13}$

\section{The Model}

I develop a small-open economy model where firms expand their workforce slowly by hiring employed or unemployed workers and can pay a sunk cost to sell in foreign markets. This section lays out the environment, develops the partial-equilibrium investment problem of a firm who takes aggregates as given, and establishes properties of the general-equilibrium impact of frictions.

\footnotetext{
${ }^{11}$ Lentz and Mortensen (2012) analyze properties of a model combining labor market frictions with job-to-job transitions and innovation as in Klette and Kortum (2004). Outside the search literature, Hopenhayn and Rogerson (1993) and several others have embedded labor market regulations in perfectly competitive labor markets with firm dynamics to study the role of specific labor market policies.

${ }^{12} \mathrm{~A}$ more indirect type of evidence suggesting that exporters operate in frictional labor markets comes from papers that consider the wage effects of firm-level export shocks. For example, Frias et al. (2018) and Garin et al. (2019) study linked employer-employee datasets in Mexico and Portugal, respectively, and show that positive firm-level export shocks, in the form of a devaluation or higher demand from markets where a firm is likely to export, translate into higher wage premia. Their result suggests that, in order to grow and export, firms cannot seamlessly attract workers at an ongoing market wage.

${ }^{13}$ In Section C of the Online Appendix I provide some additional suggestive evidence of a negative relationship between labor market frictions and exports using different country-level indexes of employment rigidity and standard country-, industry-, and firm-level datasets.
} 


\subsection{Preferences and Labor Market Environment}

I consider a small open economy populated by a mass of identical workers of measure one. Time is continuous. Workers have linear utility for consumption of a final non-tradable good that serves as numeraire, and they discount the future at rate $\rho: \int_{0}^{\infty} e^{-\rho t} c_{t} d t$. The final good is aggregated out of differentiated varieties that may be produced domestically or imported from the rest of the world, as I describe below. I focus on a steady state in which aggregate variables are constant.

Labor markets are subject to standard search frictions whereby workers learn of jobs when unemployed or employed according to a random process. The Poisson rates at which workers contact firms are $\lambda_{u}$ for unemployed workers and $\lambda_{e}$ for employed workers. In addition to the transitions between jobs to be described below, jobs are terminated at an exogenous rate $\gamma$. Taking into account the chance $\mu$ of firm exit, this means that employees move into unemployment at rate $\delta=\gamma+\mu{ }^{14}$ The steady-state rate of unemployment is readily given by:

$$
u=\frac{\delta}{\lambda_{u}+\delta} .
$$

To save notation later, I define the normalized contact rate on the job, $\kappa_{e}=\lambda_{e} / \delta$.

The number of job matches taking place per unit of time depends on the number of effective workers and firms searching through a constant-returns-to-scale matching function. As in Mortensen (2000) unemployed and employed workers are perfect substitutes in the matching process but have different search efficiencies. Letting $\widetilde{\lambda}_{i}$ for $i=e, u$ be the efficiency units in the matching process corresponding to employed and unemployed workers, respectively, then $\widetilde{\lambda}_{u} u+\widetilde{\lambda}_{e}(1-u)$ is the effective measure of workers searching. In addition, I let $\bar{s}$ be the average search effort exerted by firms searching for workers and $M$ be the measure of firms. Then, the rates at which workers in each employment status contact a potential employer are

$$
\lambda_{i}=\widetilde{\lambda}_{i} \chi\left(\frac{\bar{s} M}{\widetilde{\lambda}_{u} u+\widetilde{\lambda}_{e}(1-u)}\right) \text { for } i=e, u,
$$

where $\chi(\cdot)$ is an increasing and concave function. ${ }^{15}$ Given the aggregate search effort of firms, conditions (1) and (2) jointly determine $\lambda_{e}$ and $\lambda_{u}$ as function of the matching efficiencies $\widetilde{\lambda}_{u}$ and $\tilde{\lambda}_{e}$.

Larger values of $\widetilde{\lambda}_{e}$ or $\widetilde{\lambda}_{u}$ imply a higher number of contacts for the same number of bodies and effective measure of firms searching, leading to a lower unemployment rate or to a higher number of workers experiencing job-to-job transitions, respectively. As it was previously mentioned in the introduction, it is possible to interpret these parameters as capturing in reduced-form institutional

\footnotetext{
${ }^{14}$ Firm exit is necessary to induce an invariant distribution of ages. Exogenous separations serve to bound the size of surviving firms.

${ }^{15}$ The total number of matches is the CRS function $m\left(\bar{s} M, \widetilde{\lambda}_{u} u+\widetilde{\lambda}_{e}(1-u)\right)$, and we have defined $\chi(x) \equiv$ $m(x, 1)$. The rates at which each worker meets firms are defined as $\lambda_{i}=\frac{\tilde{\lambda}_{i}}{\lambda_{u} u+\tilde{\lambda}_{e}(1-u)} m$ for $i=e, u$, which yields $(2)$. Unlike in the case with search from unemployment only, labor tightness here is $\bar{s} M /\left(\widetilde{\lambda}_{u} u+\widetilde{\lambda}_{e}(1-u)\right)$.
} 
features of the labor market that hinder the incentives of workers to search for jobs. Hence, a more rigid labor market is represented by lower $\widetilde{\lambda}_{e}$ or lower $\widetilde{\lambda}_{u}{ }^{16}$

\subsection{Firm Revenues and Trade Environment}

The trade environment shares the central features of Krugman (1980). Monopolistically competitive firms produce varieties of a differentiated good using a constant-returns-to-scale technology with labor as the only factor of production. These varieties are internationally traded subject to an iceberg cost, and then aggregated into the final non-tradable good with a constant elasticity of substitution (CES) $\sigma>1$ across varieties.

Firms enter the market with no workers and grow subject to their contacts in the labor market, as I describe below. They suffer a shock that forces them to exit at rate $\mu$, and there is continuous re-entry to replace exiting firms. At birth, firms can only sell domestically, but at any time they can choose to start exporting subject to a sunk cost. In the spirit of Melitz (2003), firms are heterogeneous in terms of labor productivity $\psi$ and cost of exporting $f_{X}$, which are revealed upon entry.

A known feature of the CES demand structure is that product differentiation leads to downward sloping demand and concave revenue functions, because consumers derive a progressively lower marginal utility from a particular variety as firms expand their supply. To incorporate a frictional labor market with job-to-job mobility, it is convenient to operate with linear revenue functions, as in Burdett and Mortensen (1998) and Postel-Vinay and Robin (2002). To resolve this tension, I extend the standard CES structure with a quality choice allowing firms to shift their demand curves outwards as they grow in size. ${ }^{17}$ The key feature of this quality choice is that, because workers can be allocated within the firm to the production of either quality or quantity, the reduction in marginal utility due to increased supply is compensated by the increase in marginal utility due to increased quality as the firm expands.

As a result, as shown in Appendix A.1, exporting entails a revenue premium, but revenue per unit sold is independent from firm size and only depends on firm export status. ${ }^{18}$ Specifically, the real revenue of a firm with labor productivity $\psi$ employing $n$ workers is

$$
y_{j} \psi n
$$

\footnotetext{
${ }^{16}$ Some papers with this this interpretation include Helpman and Itskhoki (2010) in a context close to my analysis and Papageorgiou (2013) in a model of mismatch. An alternative interpretation is that these parameters capture technologies that impact the efficiency of the matching process, as in Martellini and Menzio (2018), or geographic aspects of labor markets, as in Heise and Porzio (2019).

${ }^{17}$ In a trade model, the assumption that firms can choose the quality of their output is appealing because it leads to realistic implications for the pricing of exporters. In my case, it leads to the empirically consistent prediction that exporters set higher prices in larger markets and that exporters to more destinations set higher prices in every market. These facts and the theoretical implications of quality choices for prices in trade models are summarized by Manova and Zhang (2012).

${ }^{18}$ Recent papers have reached a similar linear revenue structure in an open-economy setting through channels other than quality choice. For example, Nocke and Yeaple (2014) and McGrattan and Prescott (2009) derive analogous expressions through diversification of resources across products within a multi-product firm or across investment destinations within a multinational firm, respectively.
} 
where $y_{j}$ for $j=D, X$ denotes the real revenue per unit of output in a domestic producer (i.e., non-exporter) and an exporter, respectively. For domestic producers, this average revenue depends on aggregate real income in the domestic market,

$$
y_{D}=[(1-u) y]^{1 / \sigma}
$$

where $y$ is income per employed worker in the domestic market. For exporters, average revenue is higher due to foreign sales,

$$
y_{X}=[(1-u) y+A]^{1 / \sigma}
$$

where $A>0$ is a constant that increases with foreign market size and decreases with foreign competition and trade costs; the small-open-economy assumption means that $A$ is invariant to conditions at home. ${ }^{19}$ Following the terminology in Redding and Venables (2004) I refer to $A$ as the foreign-market capacity.

This linearization of the revenue function is useful because it preserves a key aspect of monopolistically competitive models of trade, namely the increase in revenue associated with export activity, without compromising tractability once the frictional labor market with job-to-job transitions is introduced. ${ }^{20}$

An important object for the analysis is the revenue premium of exporters, defined as the ratio between a firm's revenue if it exports and if it only sells domestically,

$$
\Gamma \equiv \frac{y_{X}}{y_{D}}=\left(1+\frac{A}{(1-u) y}\right)^{1 / \sigma}>1 .
$$

This expression for the exporter revenue premium follows from the CES structure, and holds regardless of my assumptions about quality upgrading. It reflects that exporting firms sell to consumers with higher willingness to pay. The same revenue advantage holds in Melitz (2003) conditioning on firm size, but in that model it is instantaneously offset by firms' labor choice.

\subsection{Job Values}

The jobs offered by firms differ in value for two reasons. First, job values depend on firm-level productivity, $\psi$. Second, revenue per worker may change throughout the life of firms: domestic

\footnotetext{
${ }^{19}$ Specifically, $A \equiv \tau^{-(\sigma-1)}\left(P^{*}\right)^{\sigma} Y^{*}$ where $P^{*}$ denotes the price index in the rest of the world relative to the domestic price index, $Y^{*}$ is aggregate real income abroad, and $\tau$ is the iceberg trade cost. To undertake counterfactuals, I only need to parametrize $A$ regardless of its decomposition into these variables.

${ }^{20}$ This linear revenue structure is also aligned with a well established tradition of firm-dynamics models outside of the search literature which assumes linear payoffs in the stock of some slowly accumulated factor, such as Klette and Kortum (2004) or Chatterjee and Rossi-Hansberg (2012). Luttmer (2010) surveys that literature and presents a canonical model in that spirit. Besides being tractable, these models lead to realistic predictions for the firm-size distribution. A consequence of the linearization is that the "love for variety" component of welfare is neutralized. This component could be reintroduced as in Benassy (1998) and Acemoglu et al. (2007). See Appendix A.1 for details.
} 
firms with revenue per unit sold $y_{D}$ may intend to upgrade to $y_{X}$ at some point. As a result, conditioning on $\psi$, the value of a match depends on the time a firm plans to wait before starting to export, or whether it has begun to do so. Let $x$ indicate this "time until exporting" for a given firm. Across the economy, each firm may be in one of three possible export states: $x=0$ denotes firms that have already started to export; $x \in(0, \infty)$ denotes firms that will start exporting in $x$ periods from now if they survive for that long; and $x=\infty$ denotes firms that will never export no matter how long they survive.

Let $v(x ; \psi)$ represent the value of a job held by a firm with labor productivity $\psi$ whose time until exporting -if it does not suffer an exit-inducing shock before then- is $x$. This value includes the present discounted sum of future expected revenue generated by the job, as well as future expected value appropriated by the worker in the event of a job-to-job transition. I assume that $v(x ; \psi)$ is shared between workers and firms according to the game posited by Cahuc et al. (2006), who include wage bargaining on top of Bertrand competition among current and prospective employers as in Postel-Vinay and Robin (2002). ${ }^{21}$ An attractive feature of this specification is that, having introduced a matching function in (2), it is similar to the standard Mortensen-Pissarides model when job-to-job transitions are shut down $\left(\lambda_{e}=0\right)$. I will refer to this special case when inspecting the role of frictions in general equilibrium.

When an unemployed worker meets a firm offering jobs of value $v$, the surplus is divided according to the standard Nash-bargaining solution. The fallback position for the worker is the value of unemployment, $U$. On top of that, the worker receives a share $\beta$ of the match rents, $v-U$. As a consequence, the value received by a firm matching with an unemployed worker is

$$
J_{u}(v)=(1-\beta)(v-U)
$$

Let $z$ be the income flow of unemployed workers. Then, the flow-equivalent value of unemployment is

$$
\rho U=z+\lambda_{u} \beta \int_{v_{\min }}^{v_{\max }}(v-U) d P_{v}(v),
$$

where I have defined $P_{v}(v)$ as the probability that, upon a contact, a worker samples a firm offering a job of value of $v$ or less. This sampling distribution is determined endogenously in general equilibrium. Our assumptions will guarantee that it lies in the bounded support $\left[v_{\min }, v_{\max }\right]$.

When an employed worker meets a prospective employer, the firm offering higher value jobs keeps the worker. Following Cahuc et al. (2006), and letting $v_{1}$ and $v_{0}$ be respectively the higherand lower-value jobs offered by the competing firms, the worker receives a share $\beta$ of the match rents, $v_{1}-v_{0}$, in addition to the maximum that could be granted by the alternative employer, $v_{0}$.

\footnotetext{
${ }^{21}$ In Postel-Vinay and Robin (2002), firms observe the current status of the worker, tender take-it-or-leave-it wage offers, and commit to the value promised to the worker. The outcome is similar to Bertrand competition: the firm offering the job of greater total value obtains the worker, offering in exchange a value equal to what the worker could obtain in the alternative employment. In Cahuc et al. (2006), the worker additionally splits the surplus with the higher-value firm according to the conventional Nash solution rule, using the total value in the lower-value job as fallback position. In either case, a worker is hired under a flat wage profile until leaving or triggering a renegotiation.
} 
Therefore, the value received by the firm offering the job with higher value is

$$
J_{e}\left(v_{0}, v_{1}\right)=(1-\beta)\left(v_{1}-v_{0}\right)
$$

Both $J_{u}(v)$ and $J_{e}\left(v_{0}, v_{1}\right)$ denote present discounted sums of expected profits captured by a firm at the time the worker enters the firm or contacts a potential employer. After that time, the worker might leave due to an exogenous shock or contact another firm, triggering a renegotiation or a quit. As detailed in Appendix A.2, these events are included in the computation of $J_{u}(v)$ and $J_{e}\left(v_{0}, v_{1}\right)$.

The sharing rules described so far suffice to characterize the investment decision of firms, income per employed worker, and the general-equilibrium impact of frictions without ever specifying the wage stream received by the worker. Hence, my analysis of these objects is consistent with other frameworks that posit the linear sharing rules (7) to (9). ${ }^{22}$ Besides offering a specific microfoundation for these sharing rules, Cahuc et al. (2006) provide a basis to construct the wage function by assuming flat-wage contracts. I adopt that assumption when contrasting some of the model's implications for wages against the data.

Having imposed the sharing rules, I can return to the value of a job held by a firm with labor productivity $\psi$ whose time until exporting is $x \in(0, \infty)$. As shown in Appendix A.2, it is given by the following differential equation,

$$
\rho v(x ; \psi)=\psi y_{D}+\delta(U-v(x ; \psi))+\lambda_{e} \int_{v(x ; \psi)}^{v_{\max }} \beta\left(v_{0}-v(x ; \psi)\right) d P_{v}\left(v_{0}\right)-v^{\prime}(x ; \psi) \text { for } x>0,
$$

with initial condition equal to the value of jobs offered by the firm once it has invested in exporting:

$$
\rho v(0 ; \psi)=\psi y_{X}+\delta(U-v(0 ; \psi))+\lambda_{e} \int_{v(0 ; \psi)}^{v_{\max }} \beta\left(v_{0}-v(0 ; \psi)\right) d P_{v}\left(v_{0}\right)
$$

For a firm that will never export $(x=\infty)$, the job value is similar to (11), except that revenue per worker equals $\psi y_{D}$ instead of $\psi y_{X} \cdot{ }^{23}$

To understand these expressions, consider first the value of a job in a firm that already sunk the cost of exporting, (11). The flow value of the job, $\rho v(0 ; \psi)$, includes the revenue flow of the match and the probability of match dissolution, in which case the worker obtains the value of being unemployed. In addition, the last term captures worker bargaining power and job-to-job transitions. At Poisson rate $\lambda_{e}$, the worker contacts another firm. If the contacted firm offers jobs of higher value than the current employer, the current job is dissolved and the worker obtains a fraction $\beta$ of the rents. The flow value of a job in a firm that has not yet invested, (10), shares a similar structure but also includes a dynamic component for the change in firm value, $v^{\prime}(x ; \psi)<0$. As the firm ages, the time until investment $x$ shrinks and the value of the firm increases by $\left[-v^{\prime}(x)\right]$

\footnotetext{
${ }^{22}$ E.g., see Dey and Flinn (2005). Lentz (2014) discusses possible sharing arrangements arising from the optimal contract design in the presence of hidden search and relates them to Postel-Vinay and Robin (2002).

${ }^{23}$ Expression (10) corresponds to a firm offering jobs whose value is greater than the minimum of the support of the equilibrium value distribution, $v(x ; \psi) \geq v_{\min }$. Equation (49) in the appendix shows the complete definition of the value function including the region of the state space where $v(x ; \psi)<v_{\min }$.
} 
until it reaches $v(0)$.

When $\beta=0$ or $\lambda_{e}=0$, the equilibrium distribution of jobs from which workers sample, $P_{v}$, does not impact the value of a job. We will focus on the simpler case $\lambda_{e} \beta=0$ below to characterize theoretically the impact of frictions. More generally, $v(x ; \psi)$ is implicitly defined as a functional equation that depends on $P_{v}$, itself an equilibrium object.

\subsection{Value of New Hires}

The export decision is made on the basis of the flow of workers obtained in each period and the valuations attached to each. The total number of matches in the economy is $\lambda_{u} u+\lambda_{e}(1-u)$, out of which the number arriving at a firm exerting search effort $s$ is

$$
\left(\lambda_{u} u+\lambda_{e}(1-u)\right)\left(\frac{s}{\bar{s} M}\right)
$$

where $s / \bar{s}$ is the search effort exerted by the firm relative to average search activity in the economy $\bar{s}$, and $M$ is the measure of firms. I assume that, by virtue of having incurred the cost to enter the market, firms are endowed with a common and arbitrarily small level of $s$, ensuring that all firms are equally likely to be sampled if no additional effort is exerted by any firm. Any additional search effort entails the cost $s^{\zeta}$ with $\zeta>1$, a formulation similar to Bertola and Caballero (1994), among others. ${ }^{24}$

For the subsequent analysis, it is useful to define $q_{u}$ as the rate at which firms contact workers from unemployment:

$$
q_{u} \equiv \frac{\lambda_{u} u}{M \bar{s}}
$$

This notation allows us to express the number of workers arriving at a firm in (12) as

$$
q_{u}\left(1+\kappa_{e}\right) s
$$

where $q_{u}\left(1+\kappa_{e}\right)$ is the probability of a contact per unit of search effort. This expression includes the $q_{u} s$ workers contacted from the pool of unemployment and the $q_{u} \kappa_{e} s$ workers contacted from other firms. ${ }^{25}$ It is worth noting that $q_{u}$ is the standard definition of the vacancy-filling rate in the Mortensen-Pissarides model (Pissarides, 2000). Without search on the job, $q_{u}$ would be the rate at which firms contact workers. As in standard models in the style of Burdett and Mortensen (1998), allowing for on-the-job search expands the total rate of contacts experienced by firms by a factor of $\left(1+\kappa_{e}\right)$ per unit of search.

\footnotetext{
${ }^{24}$ This formulation implies that firms may speed up growth by increasing recruitment effort, but not via vacancy posting. Davis et al. (2013) argue that firms use other instruments in addition to vacancies as they vary the rate of new hires. While adding vacancies would not qualitatively impact the mechanics of the model, the current assumptions allow me to tractably represent the investment problem as in (16), so that the export entry decision is separable with other choices of the firm. Kaas and Kircher (2015) show that including both recruiting effort and vacancy posting helps to match additional moments of the cross section of growth rates.

${ }^{25}$ Specifically, $\left(\frac{s}{\bar{s} M}\right) \lambda_{u} u=q_{u} s$ and $\left(\frac{s}{\bar{s} M}\right) \lambda_{e}(1-u)=\kappa_{e} q_{u} s$. This last expression is attained using the definition of $u$ from (1) and the definition of $\kappa_{e}$.
} 
Of all the workers arriving to a firm in (14), only a subset results in new hires. As long as there are positive match rents $(v>U)$, which will be the case for active firms in equilibrium, all the $q_{u} s$ workers arriving from the pool of unemployment are hired. Each of these workers yields a value to the firm of $J_{u}(v)$. Out of the $s q_{u} \kappa_{e}$ employed workers who contact the firm, only the fraction $G_{v}(v)$ currently employed in firms offering jobs with value $v_{0}<v$ is hired, each yielding a value to the firm of $J_{e}\left(v_{0}, v\right)$. As a result, net of search costs, the present discounted value of profits generated by all workers who are hired by a firm offering jobs of value $v$ is

$$
\pi(v)=\max _{s \geq 0}\left[J_{u}(v)+\kappa_{e} \int_{v_{\min }}^{v} J_{e}\left(v_{0}, v\right) d G_{v}\left(v_{0}\right)\right] q_{u} s-s^{\zeta},
$$

where the term in square brackets is proportional to the expected value of a contact.

\subsection{Stock Effect and Timing of Export Entry}

As anticipated, firms can choose between the alternative export status $y_{D}$ and $y_{X}$. Firms enter the market with no workers and grow subject to their contacts in the labor market while facing the exit risk. At birth, they are endowed with revenue per unit sold of $y_{D}$, but they can choose at any time to make a once-and-for-all investment to start exporting and upgrade revenues to $y_{X}=\Gamma y_{D}$. This investment entails a sunk cost with flow-equivalent value of $f_{X}$ in units of the final good.

Firms have perfect foresight about the evolution of its stock of employees, facing no uncertainty beyond the exit probability. ${ }^{26}$ As a result, each firm chooses an age $h$ to start their export activity. Each firm commits to the timing of exporting when it is born, after having observed its labor productivity $\psi$ and entry cost $f_{X}$. Letting $\varepsilon=\left(\psi, f_{X}\right)$ summarize the firm type, the value at entry of a firm who will start exporting at some generic age $h$ is

$$
\Pi(h ; \varepsilon)=\int_{0}^{h} e^{-(\rho+\mu) a} \pi(v(h-a ; \psi)) d a+e^{-(\rho+\mu) h}\left[\frac{\pi(v(0 ; \psi))-f_{X}}{\rho+\mu}\right] .
$$

The value of a firm at entry captures the following life cycle: a new firm starts with no workers; at age $a=h-x$, the value of jobs held by this firm is $v(h-a ; \psi)$ and incoming workers generate average expected profits with present discounted value of $\pi(v(h-a ; \psi))$; and after age $h$ the firm obtains $\pi(v(0 ; \psi))$ from new workers for the rest of its expected life, but must pay the sunk cost with flow-equivalent value $f_{X}$. The effective rate of time discount, $\rho+\mu$, takes into account the probability of firm exit. ${ }^{27}$

Each firm of type $\varepsilon$ chooses the age $h$ to start exporting to maximize $\Pi(h ; \varepsilon)$. To understand this decision, consider a firm that starts to export at age $h$. If that firm delays export entry, it gives up revenues by delaying the increase in sales per worker. In addition, it gives up growth by

\footnotetext{
${ }^{26}$ Since I treat the stock of workers in the firm as a continuous set, the individual worker contact and exit rates equal the fraction of workers in the firm who experience these shocks.

${ }^{27}$ Note that $\pi(v(h-a ; \psi))$ is the present discounted value of the profits generated by the flow of hires at age $a$ measured at the time of hiring. These values need to be discounted back to age 0 to determine the value of the firm at entry.
} 
reducing the inflow of workers at each age below $h$. As a result, $\pi(v(h-a ; \psi))$ in (16) shifts down for all $a$. At the same time, by delaying the time of exporting, the firm saves the cost $f_{X}$. Formally, this decision is similar to a stopping time in which firms with constant-returns-to-scale technologies decide the optimal time to switch into a superior technology with high fixed cost and low marginal cost. Here, the timing of this switch also impacts growth rates before switching through the rate of job-to-job hiring. ${ }^{28}$

In a strictly positive solution, adopting the convention that $h=\infty$ denotes that the optimal choice is to never invest, the first-order condition for $h$ that maximizes $\Pi(h ; \varepsilon)$ can be characterized as follows:

$$
\begin{aligned}
& S(h ; \psi)=f_{X} \text { if } h<\infty, \\
& S(h ; \psi) \leq f_{X} \text { if } h=\infty,
\end{aligned}
$$

where

$$
S(h ; \psi)=\int_{0}^{h} e^{(\rho+\mu) x} \pi^{\prime}(v(x ; \psi))\left[-v^{\prime}(x ; \psi)\right] d x .
$$

I refer to $S(h)$ as the stock effect of a delay in $h$. It captures the opportunity costs of delaying the age of entry into exporting in terms of foregone revenues and firm growth. The firm chooses the $h$ where these opportunity costs equal the savings from delaying export entry, in terms of the flow-equivalent value of the sunk cost. Since the firm grows over time, the longer it waits, the larger is the opportunity cost of not exercising the investment in exporting. Furthermore, $S(0 ; \psi)=0$, i.e., there is no stock effect at entry because there is no initial labor force. Therefore, it must be that $h>0$ unless the sunk cost is zero, in which case exporting occurs at birth.

To assess the impact of labor market frictions it will be necessary to move on to general equilibrium, where competition, captured by the measure of firms $M$ and the distribution of job values $P_{v}(v)$ from which workers sample offers upon contact, is determined endogenously. For that, it is useful to characterize the value of firms at entry. As shown in Appendix A.3, using an envelope condition and letting $h(\varepsilon) \equiv \arg \max _{h} \Pi(h ; \varepsilon)$ be the optimal export timing of a firm of type $\varepsilon$, the value of such a firm at entry is

$$
\Pi^{e}(\varepsilon)=\frac{\pi(v(h(\varepsilon) ; \psi))}{\rho+\mu} .
$$

As further shown in Section 6.4, the characterization of the optimal timing and value at entry in conditions (17) to (20) generalizes to the case with multiple sequential investments.

\subsection{General Equilibrium}

The development so far pertains to an individual firm given the sampling and employment functions $P_{v}(v)$ and $G_{v}(v)$, the number of firms $M$, the average search intensity of other firms $\bar{s}$,

\footnotetext{
${ }^{28}$ Formally, the problem is related to the structure in Burdett and Menzio (2017), who characterize the optimal stopping time of a firm that must decide when to change its price in the presence of fixed menu costs and search frictions in product markets.
} 
and income per employed worker, $y$. Each firm of type $\varepsilon=\left(\psi, f_{X}\right)$ solves the problem discussed in Section 3.5, optimizing over the investment time $h$ and the search effort $s$ taking these objects as given.

In general equilibrium, the measure of firms is determined through free entry. Firms face an entry cost with flow-equivalent value of $f_{D}$ units of the final good, and learn their type $\varepsilon$ after incurring this cost. The free-entry condition implies that a potential entrant must be indifferent about entering,

$$
\mathbb{E}_{\varepsilon}\left[\max \left\{\Pi^{e}(\varepsilon), 0\right\}\right]=\frac{f_{D}}{\rho+\mu},
$$

where $\mathbb{E}_{\varepsilon}$ denotes the expectation with respect to the distribution of firm types, $\varepsilon$. The max operator inside the expectation denotes that, upon observing its type, firms may choose to exit immediately without hiring. This defines a region in the space of $\varepsilon$ for firms that decide to continue after having entered. While there is no additional overhead cost after entry, the value of unemployment entering in (7) implies that some types may exit if the surplus from the jobs they create is too low relative to the value of unemployment.

In addition, the sampling distribution $P_{v}(v)$ must be consistent with the optimal search effort exerted by firms along the age and firm-type distributions, and $G_{v}(v)$ must be consistent with the transition patterns induced by $P_{v}(v)$. I define each of these objects in Appendix A.4. After imposing the free-entry and consistency of the sampling and employment distributions, it is possible to compute the key outcome of interest, real income per employed worker $y$ (see (22) below). The steady-state consumption level is obtained residually from market clearing in the final good.

Now it is possible to define the equilibrium.

Definition 1. The general equilibrium consists of contact and unemployment rates $\left\{\lambda_{e}, \lambda_{u}, u\right\}$, revenues per unit of exporters and domestic producers $\left\{y_{D}, y_{X}\right\}$, unemployment value $U$, value functions $v(x ; \psi)$, investment times $h(\varepsilon)$, a measure of firms $M$, employment and sampling distributions $\left\{G_{v}(v), P_{v}(v)\right\}$, income per employed worker $y$, and consumption $c$ such that

a) contact and unemployment rates are given by (1) and (2);

b) revenues per unit sold are given by (4) and (5).

c) the value of unemployment is given by (8);

d) the value functions solve (10)-(11);

e) the investment times are given by the first-order conditions from the firm problem, (17)-(18);

f) the number of firms $M$ adjusts to satisfy free entry, i.e. (21) holds;

g) the sampling and employment distributions are consistent with firms decisions; i.e., they are given by (56) and (58);

h) output per employed worker is given by (22); and

i) the goods market clears.

\subsection{General-Equilibrium Channels}

I discuss here the channels through which frictions impact income per employed worker in the full model, and the next section relies on a simpler environment to characterize the direction of the comparative statics. Letting $I_{a \geq h(\varepsilon)}$ be an indicator for whether a type- $\varepsilon$ firm is old enough to be 
an exporter, income per employed worker is

$$
y=(1-u)^{\frac{1}{\sigma-1}} \mathbb{E}_{\varepsilon, a}\left[\psi\left(1+(\Gamma-1) I_{a \geq h(\varepsilon)}\right) n(a ; \varepsilon)\right]^{\frac{\sigma}{\sigma-1}}
$$

where $n(a, \varepsilon)$ is the density of workers employed by a type- $\varepsilon$ firm at age $a$, resulting from the firm-level growth process specified in (59) to (61) in Appendix A.4.

A cursory inspection of (22) points to the determinants of income per employed worker. The first term, including the unemployment rate, is a standard demand externality borne out of monopolistic competition. This term holds regardless of the presence of firm growth or fixed investments, and is therefore orthogonal to the misallocation forces I focus on. ${ }^{29}$ Instead, the margins I focus on manifest themselves through the distribution of employment by firm type and age, $n(a ; \varepsilon)$, and the timing of investments, $h(\varepsilon)$. The following result establishes the role of frictions in shaping these outcomes.

Proposition 1. Given $\lambda_{e}$, changes in the contact rate from unemployment $\lambda_{u}$ impact the employment allocation and the timing of investments $\{n(a ; \varepsilon), h(\varepsilon)\}$ only through general-equilibrium adjustments in revenue per unit sold $\left\{y_{D}, y_{X}\right\}$ or in the value of unemployment, $U$. Given $\lambda_{u}$, changes in the contact rate from employment $\lambda_{e}$ generically impact these outcomes regardless of whether $\left\{y_{D}, y_{X}, U\right\}$ may adjust.

The focus on $\left\{\lambda_{e}, \lambda_{u}\right\}$ is without loss of generality, since any equilibrium change in $\left\{\lambda_{e}, \lambda_{u}\right\}$ can be implemented by a set of changes in the matching efficiencies $\left\{\tilde{\lambda_{e}}, \tilde{\lambda_{u}}\right\}$. Therefore, the proposition applies to changes in the fundamental matching efficiencies as well. ${ }^{30}$

The proposition implies that, if $\left\{U, y_{X}, y_{D}\right\}$ are exogenously given, then $\lambda_{u}$ has no impact on firm growth or the timing of investments, while $\lambda_{e}$ does. The value of unemployment $U$ is not an active margin if it is pinned down by an outside sector instead of being determined by (8), as in Helpman and Itskhoki (2010), or if workers have no bargaining power $(\beta=0)$, as in PostelVinay and Robin (2002). In turn, $\left\{y_{D}, y_{X}\right\}$ are exogenously given in the absence of monopolistic competition $(\sigma \rightarrow \infty)$ if we reinterpret the investment decision as productivity upgrading instead of exporting. While these cases may be extreme, they highlight that the extent of the response of firm growth and investments to $\lambda_{u}$ is bounded by how elastic $\left\{U, y_{X}, y_{D}\right\}$ are, while the same is not generically true for $\lambda_{e}$.

The fact that $\lambda_{u}$ does not directly impact the employment density $n(a ; \varepsilon)$ while $\lambda_{e}$ does is intuitive. Because workers transit to high-value jobs, a higher rate of contact on the job speeds

\footnotetext{
${ }^{29}$ The same term appears in theories combining unemployment with monopolistic competition in the MortensenPissarides model; e.g., see Schaal and Taschereau-Dumouchel (2016) for a recent example. Blanchard and Kiyotaki (1987) is an early analysis of the role of monopolistic competition in leading to demand externalities.

${ }^{30}$ This is trivially the case if the contact rates $\lambda_{e}$ and $\lambda_{u}$ are exogenous, as in Postel-Vinay and Robin (2002). Under endogenous contact rates, note that, from (2), any set of counterfactual $\left(\lambda_{e}^{\prime}, \lambda_{u}^{\prime}\right)$ with $\lambda_{u}^{\prime} \neq 0$ can be implemented with the counterfactual fundamentals $\left(\tilde{\lambda_{e}{ }^{\prime}}, \tilde{\lambda_{u}}{ }^{\prime}\right)$ such that $\tilde{\lambda_{e}{ }^{\prime}} /{\tilde{\lambda_{u}}}^{\prime}=\lambda_{e}^{\prime} / \lambda_{u}^{\prime}$ and $\tilde{\lambda_{u}{ }^{\prime}=}$ $\lambda_{u}^{\prime} \chi\left((\bar{s} M)^{\prime} /\left(\widetilde{\lambda}_{u}^{\prime} u^{\prime}+\widetilde{\lambda}_{e}^{\prime}\left(1-u^{\prime}\right)\right)\right)^{-1}$, where $u^{\prime}$ and $(\bar{s} M)^{\prime}$ are the outcomes corresponding to $\left(\lambda_{e}^{\prime}, \lambda_{u}^{\prime}\right)$. In the quantitative section I perform the counterfactuals with respect to the fundamentals $\left(\tilde{\lambda_{e}}, \tilde{\lambda_{u}}\right)$ and endogenously solve for $\left(\lambda_{e}, \lambda_{u}\right)$.
} 
up transitions, skewing the employment distribution towards more productive or older firms; in contrast, $\lambda_{u}$ scales the size of the employment pool, but it does not alter its composition.

Conditioning on $\left\{U, y_{D}, y_{X}\right\}, \lambda_{u}$ does not directly impact $h(\varepsilon)$ because it scales up both the stock effect and firm value at entry in the same proportion, by making it easier to hire both from employment (through a larger employment pool) and from unemployment (through a higher jobfinding rate of the unemployed) for every productivity and age. ${ }^{31}$ Because firm entry (higher $M$ ) scales down the stock effect and the expected value of firms at entry in the same proportion, higher $\lambda_{u}$ leads to more firms but leaves the equilibrium meeting rate $q_{u}$ and the stock effect unchanged, unless other general-equilibrium variables adjust.

In short, the model inherits a well-known property from the Mortensen-Pissarides model: given the value of unemployment $U$, the rate at which firms meet unemployed workers, $q_{u}$, is pinned down by free entry, so that changes in the matching efficiency do not affect $q_{u}$. This comparison with the Mortensen-Pissarides model is more explicit in the simpler model of the next section. This role of $\lambda_{u}$ also echoes features of the static monopolistic competition trade models. In the symmetric Melitz (2003) model, an increase in the size of the labor force leads to a proportional adjustment in the measure of firms without affecting export thresholds. ${ }^{32}$

In contrast, the impact of $\lambda_{e}$ on firm growth is back-loaded: $\lambda_{e}$ slows down net worker flows in young potential exporters (whose employees are more likely to be poached away) and speeds them up in older potential exporters (offering higher-value jobs). As a result, the effects of $\lambda_{e}$ on the stock effect are unevenly distributed over the life cycle of potential exporters, instead of raising the stock effect proportionally for all ages. In equilibrium, firm's meeting rate with employed workers, $q_{u} \kappa_{e}$, is not offset by firm entry, therefore impacting the investment time $h(\varepsilon)$ regardless of whether $\left\{U, y_{X}, y_{D}\right\}$ adjusts.

\section{Impact of Frictions in a Simpler Model}

I will use the model developed so far to quantify the impact of labor-market frictions on income per employed worker. The goal of this section is to establish the comparative statics with respect to frictions. To sharpen the role of key forces, in Section 4.1 I sequentially impose simplifying assumptions on the full model which yield closed-form solutions for most outcomes. After imposing each assumption, I describe the key part of the model that it simplifies, allowing me to characterize

\footnotetext{
${ }^{31}$ This property follows from the fact that $q_{u}$ enters proportionally in the number of workers contacting a firm in (14), which in turn results from the definition of the measure of contacts in (12) and the steady-state rate of unemployment, (1). These ingredients are all in keeping with standard equilibrium search models with random search and job-to-job transitions.

${ }^{32}$ This property follows from the CES demand structure with constant markups, whereby changes in the size of the labor force are associated with changes in the extensive margin (number firms) but not the intensive margin (firm size). As shown by Zhelobodko et al. (2012), both the extensive and intensive margins respond to market size under deviations from CES. The fact that frictions in hiring from unemployment impact export participation through market sizes is also consistent with features of Helpman and Itskhoki (2010). In a model combining a Melitz framework with symmetric countries and frictions in hiring from unemployment, Felbermayr et al. (2011) show that labor market tightness does not impact export participation.
} 
equilibrium properties. The simplified model is the basis upon which I discuss comparative statics in Section 4.2.

\subsection{Closed-Form Solutions}

I start by imposing that $\lambda_{e} \beta=0$. This means that the economy features either no job-to-job transitions $\left(\lambda_{e}=0\right)$ or no worker bargaining power $(\beta=0)$. Thanks to this assumption, the value of a new job in a firm who is $x \geq 0$ periods away from investing presented in (10) admits a simple closed-form expression. Imposing $\lambda_{e} \beta=0$ in (10) and solving for the value function gives

$$
v(x ; \psi)=\frac{\left[y_{D}+\left(y_{X}-y_{D}\right) e^{-(\rho+\delta) x}\right] \psi+\delta U}{\rho+\delta} .
$$

This expression holds regardless of other general-equilibrium objects; it simply states that the value of a job consists of the expected revenues generated by the worker throughout the duration of the match, plus the value of unemployment obtained by the worker when the match is dissolved.

Second, I assume that the search effort $s$ is common to all firms and normalized to one. As a result, a worker who hears of an opening has the same probability of being matched with any firm, and differences in the rate at which firms hire workers arise solely from the ability to attract workers away from other firms (formally, this is attained by assuming that exerting search effort is infinitely costly, $\zeta \rightarrow \infty$ ). Using the expression for the value of a new job in (23), I can explicitly compute the integrand of stock effect defined in (19) and introduce it into the first-order condition (17) determining the optimal timing of investment:

$$
S(h(\varepsilon) ; \psi)=\int_{0}^{h(\varepsilon)} \underbrace{q_{u}(1-\beta)\left[1+\kappa_{e} G_{v}(v(x ; \psi))\right]}_{\text {New Hires }} \underbrace{(\Gamma-1) y_{D} \psi e^{-\gamma x}}_{\text {Revenue }} d x=f_{X} .
$$

This condition shows the channels that determine the timing of investment in partial equilibrium. The larger the number of new hires and the expected discounted revenue that each generates, the larger the opportunity cost of delaying export entry. A higher probability of contacting unemployed workers, $q_{u}$, or employed workers, $q_{u} \kappa_{e}$, speeds up the number of new hires and accelerates the investment, whereas a first-order shift in the employment distribution $G_{v}$ towards high-value jobs reduces the share of meetings that translate into new hires, slowing down growth and delaying the investment. Naturally, a larger return to exporting $\Gamma$ speeds up investment, higher worker bargaining power $\beta$ slows it down, and firms with higher productivity to cost ratio $\psi / f_{X}$ invest earlier.

Third, as in Krugman (1980), I impose that firms have no innate differences productivity or in fixed costs across firms. However, as in Melitz (2003) exporting still entails the fixed cost $f_{X}$. As a result, firms are now heterogeneous in only one dimension, their age, and there is a common timing for the investment across firms, $H$. This common timing determines the fraction of employment in 
exporters and, through it, income per employed worker. The free entry condition (21) becomes:

$$
\pi(v(H ; \psi))=q_{u}(1-\beta) \frac{\left[y_{D}+e^{-(\rho+\delta) H}\left(y_{X}-y_{D}\right)\right] \psi-\rho U}{\rho+\delta}=f_{D} .
$$

Given $\left\{U, y_{D}, y_{X}\right\}$, conditions (24) and (25) jointly determine firms' probability of contacting unemployed workers and the investment time, $\left\{q_{u}, H\right\}$.

It is now possible to grasp some of the mechanics of Proposition 1 by drawing an explicit comparison with the canonical equilibrium matching model of unemployment without heterogeneous match productivities (Pissarides, 1985, 2000). When $h \rightarrow \infty$ or $y_{X}=y_{D}$, so that my model does not feature upgrading over the firm life cycle, condition (25) pins down firm's meeting rates $q_{u}$ in the same way as the standard equilibrium unemployment model, regardless of the presence of job-to-job transitions. ${ }^{33}$ Because the stock effect $S(H ; \psi)$ in $(17)$ is also proportional to $q_{u}$, changes in $\lambda_{u}$ are compensated by entry or exit through $M$, leaving $\left\{q_{u}, H\right\}$ unchanged given $\left\{y_{D}, y_{X}, U\right\}$. In contrast, conditioning on $\left\{y_{D}, y_{X}, U\right\}, \lambda_{e}$ impacts income per worker both directly, by speeding up transitions to exporters (the component $\kappa_{e}$ in the stock effect), and indirectly, through the endogenous timing of investment $H$.

\subsection{Comparative Statics}

I now inspect comparative statics with respect to the equilibrium contact rates $\left\{\lambda_{u}, \lambda_{e}\right\}$; as mentioned above, any change in $\left\{\lambda_{e}, \lambda_{u}\right\}$ can always be implemented by a set of changes in the matching efficiencies $\left\{\tilde{\lambda_{e}}, \tilde{\lambda_{u}}\right\}$. The following result establishes the impact of each type of friction on the timing of entry into exporting, the exporter employment share, and income per employed worker.

Proposition 2. Assume $\lambda_{e} \beta=0$, constant search effort s across firms and ex-ante homogeneous firms. Then, given $\left(\lambda_{e}, \lambda_{u}\right)$, there is a unique general equilibrium. Firms never invest at entry unless $f_{X}=0$, but eventually invest if and only if $f_{X}$ is below a finite threshold. Given $\Gamma$ :

i) if $\beta>0$ and $\lambda_{e}=0$ then lower matching frictions from unemployment (higher $\lambda_{u}$ ) lead to faster export entry, a higher employment share in exporters, and higher income per employed worker if $z<\psi y_{D}$; and

ii) if $\beta=0$ and $\lambda_{e}>0$ then lower matching frictions from employment (higher $\lambda_{e}$ ) also lead to these outcomes if $\sigma$ is sufficiently large or if $z=$ by for some positive constant $b<\psi \frac{y_{D}}{y}$.

The proof first establishes uniqueness based on whether each firm's incentive to export increases when other firms delay export entry. A larger $H$ shifts the distribution of employment $G_{v}(v(x))$ towards firms that are further away from exporting. From our preceding discussion, this shift

\footnotetext{
${ }^{33}$ More precisely, in the notation of Chapter 2 of Pissarides (2000), the free-entry condition stating that the value of a new vacancy equals the cost of creating it is $J=(1-\beta) \frac{p-r U}{r+\lambda}=\frac{p c}{q}$, where $p c$ is the cost of a vacancy per unit of time, $r$ is the discount rate, $\lambda$ is the job-termination rate, $q$ is the job-filling rate, $\beta$ is the worker bargaining power, and $U$ is the value of unemployment. When $y_{X}=y_{D}$ or $h \rightarrow \infty$, this condition is the same as (25) properly adjusting notation (i.e., relabeling $q$ as $q_{u}, p c$ as $f_{D}, p$ as $y_{D}, r$ as $\rho$, and $\lambda$ as $\delta$ ).
} 
strengthens the stock effect and speeds up investment. At the same time, the longer it takes firms to invest, the smaller their value at entry, reducing entry and also strengthening the stock effect. As a result, there is a unique interior solution for the common timing of investment, $H .{ }^{34}$ As for whether the unique equilibrium features export entry, immediate exporting cannot be an outcome if $f_{X}>0$ because there is no stock effect at firm birth. An alternative candidate for an equilibrium is that firms never export. Since the stock effect is bounded, firms invest if and only if the cost of investing $f_{X} / f_{D}$ is below the threshold $\overline{f_{X} / f_{D}}$ defined in (83) in the appendix.

For simplicity, the comparative statics assume a constant exporter revenue premium $\Gamma$, which is consistent with the simplifying assumption in Melitz (2003) that the world economy consists of symmetric countries. ${ }^{35}$ Consider first the case in which job-to-job transitions are not allowed, $\lambda_{e}=0$ and $\beta>0$. Proposition 1 implies that the contact rate from unemployment $\lambda_{u}$ impacts the timing of investment through the value of unemployment $U$ and the domestic market size. A higher $\lambda_{u}$ leads to a higher value of unemployment, reducing the value of the firm at entry. As a result, to maintain zero profits, the extent to which the measure of firms grows must be less than in the case with $U$ constant. But $q_{u}$ is invariant to frictions in that case, so that $q_{u}$ must now increase with $\lambda_{u}$, as it would in the Mortensen-Pissarides model. Using the first order condition (24), we conclude that the higher contact rate $q_{u}$ speeds up the investment.

As for the role of $\lambda_{e}$, it also impacts outcomes through a higher value of unemployment. In addition, it changes the stock effect in different proportions for different types of firms. Specifically, a lower $\lambda_{e}$ benefits older and larger firms relatively more. It only strengthens the growth margin in (17) through the higher entry rate of workers from other jobs, so that variation in the number of firms cannot absorb this effect as with $\lambda_{u}$. Therefore, conditioning on $U$, the adjustment to lower $\lambda_{e}$ occurs partly through the number of firms and partly through the common age of switching. Both when $\lambda_{u}$ and when $\lambda_{e}$ increase, a determinant of the comparative statics is whether the value of unemployment $U$ increases relative to market size. In the case of higher $\lambda_{u}$, this is necessarily the case if $z<\psi y_{D}$. For $\lambda_{e}$, this is the case under the additional restrictions in the proposition.

With the quantitative application in mind, it is worth discussing two qualifications of these results. First, I have taken $\Gamma$ as given. In general equilibrium, when $\Gamma$ adjusts, shocks increasing domestic market size lower the exporter revenue premium $\Gamma$. As a result, the potential gains from lower frictions are partially offset by the reduction in the exporter premium. Second, I have conditioned the discussion on the case with no innate productivity differences across firms. In the quantitative model, which allows for these differences, it is not necessarily the case that every firm speeds up investment when frictions are reduced. To the contrary, it is possible that low-

\footnotetext{
${ }^{34}$ There is one offsetting effect: as long as workers have bargaining power $(\beta>0)$ a larger value of $H$ also lowers the value of unemployment, increasing the value of firms and leading to firm entry, weakening the stock effect. This effect is dominated by the other forces.

${ }^{35}$ In the current case, $\Gamma$ is readily given by parameters. With $K+1$ symmetric countries, interpreting $f_{X}$ as the cost of starting to export to all countries simultaneously, then $\Gamma=\left(1+K \tau^{-(\sigma-1)}\right)^{1 / \sigma}$. In Section 6.4 I implement an extension with $K$ countries where firms enter export destinations sequentially. A constant $\Gamma$ is also consistent with the assumption that foreign market size $A$ adjusts to compensate the domestic market size or with a closed-economy environment, where the investment is interpreted as a productivity upgrade.
} 
productivity firms delay investment due to higher chances of having workers poached away. In fact, the calibrated model implies that low-productivity firms slow down growth and investment relative to high-productivity firms due to faster labor reallocation towards higher-productivity firms.

The model also has implications for how international trade frictions, captured by the iceberg trade costs in the definition of foreign-market capacity $A$, interact with labor market frictions. Foreign market capacity has a direct effect on real income, via $\Gamma$, as well as an indirect effect via reallocations to exporters. In Krugman (1980), where all firms are identical, an increase in the size of an economy is met with an increase in every firm's exports to that country. Here, in addition, it leads to an extensive export-entry margin through $H$. As in Melitz (2003), this margin involves firms switching export status. However, unlike in that paper, export participation increases with lower trade frictions across firms with different age and size but identical productivity. The magnitude of the indirect effect through reallocations is mediated by labor market frictions, as $\lambda_{e}$ and $\lambda_{u}$ impact the response of the exporter employment share to lower trade frictions. ${ }^{36}$ Section 6.5 illustrates this interaction using the calibrated model.

\section{Calibration}

\subsection{Preliminaries}

To proceed, I must specify the distribution of innate differences in productivity $\psi$ and export fixed costs $f_{X}$ across firms. In quantifications of trade models with heterogeneous firms such as Melitz (2003) it is common to assume a Pareto distribution of productivities because it leads to empirically consistent predictions for the right tail of the firm-size distribution. In my context, for the derivation of the theoretical results it has been convenient to assume a bounded productivity distribution. This assumption also facilitates the numerical implementation. Therefore, I assume that productivity is distributed according to a bounded Pareto distribution. ${ }^{37}$ The probability that a firm draws a productivity level below $x$ upon entry is parametrized as follows:

$$
\operatorname{Pr}(\psi<x)=\frac{1}{p}\left[1-\left(\frac{x}{\psi_{\min }}\right)^{-\eta}\right],
$$

\footnotetext{
${ }^{36}$ Atkeson and Burstein (2010) show that, to a first order approximation, allowing for process innovation or for selection into exporting as in Melitz (2003) does not impact the size of the indirect component of the welfare gains from a reductions in trade costs, because the gains from process innovation or selection into exporting are offset in general equilibrium by changes in product variety. They analyze a world general equilibrium with 2 symmetric countries. In my case, because of the small-open economy nature of the model (implying a fixed number of imported varieties) and the linearization of the revenue function (implying a neutralization of gains from product variety, as I explain in Appendix A.1), the indirect component of the gains from trade only includes the reallocation into exporters and is not offset by product innovation.

${ }^{37}$ In the multi-country extension of my model from Section 6.4, the upper bound rationalizes that not every potential export market is accessed. Helpman et al. (2008) quantifies a multi-country version of the Melitz model assuming truncated Pareto distributions to help rationalize zeros in bilateral trade flows. For a recent international trade model inspecting the gains from trade assuming the bounded Pareto distribution see Feenstra (2014).
} 
with support $\psi \in\left[\psi_{\min }, \psi_{\max }\right]$, where $\psi_{\max } \equiv \psi_{\min }(1-p)^{-1 / \eta}$. As $p \rightarrow 1$, this distribution converges to the unbounded Pareto, whereas $p<1$ corresponds to a truncated Pareto with upper bound equal to the $p^{\text {th }}$ percentile of the unbounded distribution. For the benchmark calibration I use $p=0.99$. By choosing units I normalize the mean of the productivity distribution to 1 through $\psi_{\text {min }}$. The ensuing distribution is indexed by a single parameter, $\eta$, which controls the dispersion of the productivity distribution without affecting its mean.

I assume that the fixed cost of exporting $f_{X}$ is independent from $\psi$. I allow for two levels of fixed costs: potential exporters (with finite $f_{X}$ ) and never exporters (with arbitrarily large $f_{X}$ ). This binomial distribution gives the model additional flexibility to approximate key targets of the theory, such as the fraction of non-exporters and the average age of exporters and non-exporters.

I must also take a stand on the matching function in (2). Following Cosar et al. (2016), I assume that the job-finding rate for workers depends on the CES matching function,

$$
\chi(x)=\left(1+x^{-\theta}\right)^{-1 / \theta}
$$

and in robustness checks I also allow for a Cobb-Douglas matching function.

\subsection{Data}

I match the model to summary statistics from official tax records of the manufacturing sector of Argentina from 2003 to 2007. I use data on the number of firms in the manufacturing sector by cells of employment size, age, and export status. Importantly, the data also includes information about worker transitions between firms. In particular, it includes the share of new hires who enter directly from other jobs rather than from non-employment in firms with different export statuses. The data also includes additional statistics, such as average wages, which are used to check some of the model's predictions. These statistics were extracted from confidential micro data from Argentina's Ministry of Labor, including the universe of formal employment in manufacturing in Argentina for the period 2003 to 2007. Appendix C.1 describes in more detail the underlying dataset.

The years 2003 to 2007 chosen for the calibration feature rapid economic growth after a recession. During these years, Argentina featured a fairly regulated labor market by international standards. ${ }^{38}$ Despite the contrast in the macro outlook between this phase and the preceding years, Table 6 in Appendix C.1 shows that the summary statistics matched in the calibration are quite stable over the 5 -year period $2003-2007$ relative to $1998-2002 .{ }^{39}$

I must determine the value of the following 15 parameters: preferences $\{\rho, \sigma\}$, firm and job exit

\footnotetext{
${ }^{38}$ In 2001 and 2004, Argentina enacted new employment laws that partially offset labor market policies from the 1990's. These laws included an strengthening of employment protection through higher costs of layoffs and severance pay. According to the rigidity of employment index from the World Bank, in 2005 Argentina had stricter laws regulating the flexibility of hours, hiring, and firing than $74 \%, 67 \%$ and $67 \%$ of the 153 countries for which the index is available. Overall, the summary index of rigidity of employment placed Argentina in the top third of countries with more heavily regulated labor markets in the world.

${ }^{39}$ One difference between the two 5 -year periods is the somewhat lower average share of job-to-job hires in total hires among exporters from 1998-2002. This feature is consistent with evidence on the fall in job-to-job hiring by larger firms during the recessions; e.g., see Moscarini and Postel-Vinay (2016).
} 
rates $\{\mu, \gamma\}$, flow income to unemployed workers $z$, worker bargaining power $\beta$, convexity in the search effort $\zeta$, the shape of the productivity distribution $\eta$, the fraction of never-exporters, the elasticity of the matching function $\theta$, entry and export costs $\left\{f_{D}, f_{X}\right\}$, foreign market size $A$, and efficiency of matching from unemployment and employment, $\left\{\widetilde{\lambda}_{u}, \widetilde{\lambda}_{e}\right\}$.

The cross-sectional predictions depend on the matching efficiencies $\left\{\widetilde{\lambda}_{u}, \widetilde{\lambda}_{e}\right\}$ only through $\left\{\lambda_{e}, \lambda_{u}\right\}$, and on the exogenous market capacity $A$ only through the exporter revenue premium $\Gamma$. In the calibration I treat $\lambda_{e}, \lambda_{u}$ and $\Gamma$ as parameters. Having calibrated their equilibrium values, I then back out the fundamentals $\left\{\widetilde{\lambda}_{u}, \tilde{\lambda}_{e}, A\right\}$. In the counterfactuals these fundamental parameters are kept constant, while $\left\{\lambda_{e}, \lambda_{u}, \Gamma\right\}$ are allowed to change.

\subsection{Parameters Set Without Solving the Model}

Table 1 lists 10 parameters set without solving the model. The first 5 rows list parameters whose values are set following the literature, and the last 5 rows list parameters that are set to match empirical counterparts from my data.

Within the first group, the elasticity of the matching function is set to $\theta=1.83$ following Cosar et al. (2016), and the elasticity of demand $\sigma$ is set equal to 2.98 following Eaton et al. (2011). I assume that the adjustment cost is quadratic, $\zeta=2 .{ }^{40}$ In robustness checks, I verify the sensitivity of the results with respect to these parameters.

I allow for different values of worker bargaining power $\beta$. Within French manufacturing, Cahuc et al. (2006) estimate values of $\beta$ between 0 and 0.35 , whereas within Colombian manufacturing Cosar et al. (2016) estimate $\beta=0.44$. Therefore I undertake the benchmark analysis for $\beta=$ $\{0,0.44\}$, which spans the estimates in these two papers.

There is no direct empirical counterpart to the flow value of unemployment $z$, as it includes both transfers to the unemployed and unobserved non-monetary components. I choose $z$ such that, in the calibrated model, $\frac{z}{y}$ matches the estimate of Cosar et al. (2016); in my case this implies $z=0.3 y .{ }^{41} \mathrm{I}$ undertake robustness checks with respect to the value of this coefficient.

Within the group of parameters matching empirical counterparts, $\mu=0.075$ fits the density of the firm age distribution; $\gamma=0.15$ matches the probability in the data that workers employed in non-exiting firms move into the unemployment pool; and $\rho$ matches the reference average monthly rate on deposits in domestic currency from the Argentine Central Bank. From (1), $\lambda_{u}=\frac{1-u}{u}(\mu+\gamma)$, where the unemployment rate $u$ equals $10 \%$ on average as reported by the Argentine institute of statistics.

The remaining parameter matching a moment from the data is the exporter revenue premium,

\footnotetext{
${ }^{40}$ Cooper et al. (2007) assume either quadratic or linear costs of posting vacancies in an estimation of a labor search model to match employment changes at the establishment level in U.S. data. Since my revenue function has constant returns to scale, I need curvature in the cost of searching to bound firm size. If the cost function included a scale parameter such that the cost of exerting search effort $s$ was $\zeta_{0} s^{\zeta}$, the constant $\zeta_{0}$ would not be separately identified from the domestic entry cost $f_{D}$; therefore, I normalize $\zeta_{0}=1$.

${ }^{41}$ These authors measure $z$ to be $40 \%$ of the labor income in the service sector in Colombia. According to data from the Argentine Ministry of Labor, income per worker in the service sector in Argentina is $75 \%$ of manufacturing. Hence, $z=0.4 * 0.75 * y$ in my model.
} 


\begin{tabular}{lccc} 
Parameter & Notation & Value & Source/Target \\
\hline \hline Elasticity of substitution & $\sigma$ & 2.98 & Eaton et al. (2011) \\
Elasticity of the matching function & $\theta$ & 1.83 & Cosar et al. (2016) \\
Convexity in hiring cost & $\zeta$ & 2 & Quadratic Adjustment \\
Worker bargaining power & $\beta$ & $\in\{0,0.44\}$ & See text \\
Income flow of the unemployed & $\frac{z}{y}$ & 0.3 & Cosar et al. (2016) \\
\hline Firm exit rate & $\mu$ & 0.075 & Firm age distribution \\
Job separation rate & $\gamma$ & 0.15 & Probability of E-U transition \\
Time discount & $\rho$ & 0.0058 & Interest Rate \\
Contact rate from unemployment & $\lambda_{u}$ & 2.025 & Unemployment rate \\
Exporter Revenue Premium & $\Gamma$ & 1.12 & Export share of exporters \\
\hline
\end{tabular}

Table 1: Parameters Set Without Solving the Model

Г. As implied by (38) in Appendix A.1, the CES structure I have imposed yields an export share of revenues within any exporting firm equal to $1-\Gamma^{-\sigma}$. I choose $\Gamma$ such that the model matches the average export revenue share of $28 \%$ across manufacturing firms that I computed from the World Bank's 2007 Enterprise Survey for Argentina. Given the value assumed for $\sigma$, this implies $\Gamma=(1-0.28)^{-1 / \sigma}=1.12$. This calibrated value is close to Cosar et al. (2016), who estimate an exporter revenue premium of 1.09 in Colombian data using firm-level revenue data and a controlfunction approach. ${ }^{42}$

\subsection{Parameters Set Solving the Model}

The remaining 5 parameters, listed in Table 2, are chosen to minimize the sum of square residuals between the model prediction and the empirical values of 6 targets: 2 statistics that reflect export participation and relative size of exporters (share of exporting firms and share of employment in exporting firms), 3 from the firm-size distribution (average firm size, share of firms with 14 workers or less, and share of firms with more than 14 workers and less then 99), and the simple average across firms of the share of job-to-job transitions in the total number of hires.

To gain some intuition for how the parameters are determined, it is possible to see that some parameters have a more direct impact on specific moments. The export cost relative to the domestic cost $f_{X} / f_{D}$ and the fraction of never exporters affect the share of exporters and their relative size, whereas a common increase in both $f_{D}$ and $f_{X}$ raises average firm size through the freeentry condition without impacting export participation. Naturally, the shape of the productivity distribution $\eta$ has a direct impact on dispersion in firm sizes. The share of job-to-job transitions in new hires is key to determining the job-finding rate of employed workers, $\lambda_{e}$.

Table 2 shows the 5 calibrated parameters for each value of $\beta$. To facilitate the interpretation,

\footnotetext{
${ }^{42}$ In their notation, the term defined here as $\Gamma$ is $\exp \left(d_{F}\right)$ and their Table 1 reports $d_{F}=0.09$. An alternative approach would be to recover $\Gamma$ from a regression of unit values on an export dummy; specifically, the model implies that the price at which an exporter sells domestically relative to the price at which a non-exporter sells domestically is exactly $\Gamma$. Through this lens, in the Colombian data, the exporter dummy in Table 2 of Kugler and Verhoogen (2012) would imply a revenue premium of 1.1 that is also close to my calibration.
} 


\begin{tabular}{ll|lc}
\multirow{2}{*}{ Parameter } & \multirow{2}{*}{ Notation } & \multicolumn{2}{|c}{ Calibrated Value } \\
& & $\beta=0$ & $\beta=0.44$ \\
\hline \hline Domestic Cost (relative to pc. income) & $\frac{f_{D}}{(1-u) y}$ & 7.28 & 4.81 \\
Export Cost (relative to pc. income) & $\frac{f_{X}}{(1-u) y}$ & 5.04 & 1.83 \\
Relative Contact Rate from Employment & $\frac{\lambda_{e}}{\lambda_{u}}$ & 0.16 & 0.11 \\
Fraction of Never Exporters & - & 0.15 & 0.00 \\
Coeff. of variation of productivity distribution & - & 0.35 & 0.60
\end{tabular}

Table 2: Calibrated Parameters

I report the costs $f_{D}$ and $f_{X}$ relative to income per capita. From 2003-2007, income per worker in Argentina was on average $\$ 8,542$ constant 2010 US dollars. ${ }^{43}$ Hence, the calibration implies, approximately, flow-values for the domestic entry costs of between $\$ 41,000$ and $\$ 62,000$ and export fixed costs of between $\$ 16,000$ and $\$ 43,000$, depending on worker bargaining power. Higher worker bargaining power leads to lower profit margins, implying smaller calibrated fixed costs in order to match the observed average firm size. The order of magnitude of these costs is similar to results from structural estimations based on firm-level data in other Latin-American countries, such as Cosar et al. (2016) for Colombia and Dickstein and Morales (2018) for Chile, with the export costs closer to the lower bound of these estimates. ${ }^{44}$

Importantly, the calibration yields a reasonable job-finding rate of employed workers. Relative to the job-finding rate of unemployed workers, it implies $\lambda_{e} / \lambda_{u}$ between $11 \%$ and $16 \%$. This ratio is comparable to results from structural estimations that use micro data such as Bontemps et al. (2000) and Jolivet et al. (2006). The latter estimate values of $\lambda_{e} / \lambda_{u}$ between $6 \%$ and $19 \%$ across a group of OECD countries.

The last two rows report the fraction of firms that are never exporters and the coefficient of variation of the bounded-Pareto distribution implied by the calibrated $\eta$. The ex-ante dispersion in productivities implied by the calibration is larger under $\beta=0.44$, in which case the calibrated parameter $\eta=2.06$ implies a coefficient of variation of the productivity distribution equal to 0.6 , with productivity range $\left[\psi_{\min }, \psi_{\max }\right]=[0.57,5.13]$. The fraction of never exporters is relatively small, equal to $15 \%$ when $\beta=0$ and close to zero for positive $\beta$.

Table 3 shows the empirical value and the model prediction for the 6 targeted moments and for additional statistics that are not targeted by the calibration but relate closely to the variables from the theory. The targeted moments, marked with a $\checkmark$ in the table, are well approximated.

\footnotetext{
${ }^{43}$ Average income per capita is computed from data.worldbank.org. Normalizing relative to income per worker in manufacturing rather than income per capita in the economy would yield similar results.

${ }^{44}$ These structural estimations fit a broad set of moments from micro data, and they include additional forces such as high-frequency productivity shocks and uncertainty that are not present in my analysis. Cosar et al. (2016) find domestic fixed cost of $\$ 27,000$, entry costs of $\$ 54,000$, and export fixed costs of $\$ 390,000$ for Colombia, whereas Dickstein and Morales (2016) estimates export fixed costs in Chile of between $\$ 60,000$ and $\$ 100,000$.
} 


\subsection{Statistics not Targeted by the Calibration}

I discuss the implications for key outcomes discussed in the theory, export entry times and firm growth. I do not observe these outcomes in the data, but they underlie the computation of the observed non-targeted statistics I discuss below. Panel (a) of Figure A.3 in the Online Appendix shows the time of export entry over the firm productivity distribution. I report figures corresponding to the calibrated model with $\beta=0$ in Table 2 , but results are similar in the calibration with $\beta=$ 0.44. Among potential exporters, only firms above a threshold of productivity eventually export. The highest-productivity firm invests quickly, whereas lower-productivity firms take considerably longer; e.g., firms in the 90th percentile of the productivity distribution take almost 4 years to start exporting, whereas the average-productivity firm never reaches the size at which exporting is profitable. These export entry times have a correlate in the fraction of exporters within productivity type shown in Panel (b). Consistent with well-known empirical evidence (Eaton et al., 2011), exporters and non-exporters coexist over the productivity distribution.

Panel (c) shows growth for different firms within a cohort. Each dashed-dotted line corresponds to a productivity level $\psi$. The figure includes both potential and never exporters. The red segments correspond to productivity-export cost-age combinations that currently export, whereas the black ones are non-exporters. As firms age, higher-productivity firms grow faster both because of higher search effort $s$ and higher job-to-job hiring. As a result, consistent with evidence in Arkolakis (2016) and others, dispersion in firm sizes grows within a cohort over time. Panel (d) shows the average firm size by export status for potential and never exporters. Being able to export leads to a size premium for identical firms.

I do not observe the firm-level outcomes in Figure A.3, but I can verify the predictions for statistics that aggregate these outcomes. These statistics are reported in Table 3. As noted, the model matches the export revenue share within exporting firms observed in the World Bank's Enterprise Survey. Economy-wide, it leads to a somewhat larger export revenue share $(22.4 \%$ in the model versus $15.6 \%$ in that survey). ${ }^{45}$ It also does a reasonable job in terms of the fraction of firms in different bins of firm size. For non-exporters, the model predicts an average fraction of job-to-job hiring and an average age that are close to the data, although in the model exporters are somewhat younger and hire too often from other jobs relative to the data.

The last two sets of statistics assess the model implications for job duration and wages. To compute wages, I follow Cahuc et al. (2006) and assume that firms offer flat-wage contracts. Unlike in Cahuc et al. (2006), the model does not yield closed form expressions for the wage or job duration distributions due to the dynamic component and the multi-dimensional state of the value function (age, productivity, and fixed cost). Therefore, I obtain the distributions of wages and of job duration by simulating labor trajectories in the calibrated model. ${ }^{46}$

\footnotetext{
${ }^{45}$ The World Bank Survey is focused on a subset of manufacturing sectors. From 2003-2007, the average export share of GDP in the Argentine economy was $22 \%$, according to data.worldbank.org.

${ }^{46} \mathrm{I}$ compute the transition function $\chi\left(a_{0}, \varepsilon_{0}, a_{1}, \varepsilon_{1}\right) \in\{0,1\}$ indicating whether the value of a job is larger in firm $\varepsilon_{1}$ at age $a_{1}$ than in firm $\left(\varepsilon_{0}, a_{0}\right)$, and the wage function $w\left(a_{0}, \varepsilon_{0}, a_{1}, \varepsilon_{1}\right)$ for workers employed in $\left(\varepsilon_{1}, a_{1}\right)$ whose next-best alternative in the last wage renegotiation was $\left(\varepsilon_{0}, a_{0}\right)$, for all combinations of $\left(\varepsilon_{0}, a_{0}\right)$ and $\left(\varepsilon_{1}, a_{1}\right)$, as well
} 


\begin{tabular}{|c|c|c|c|c|}
\hline Statistic & Target & Data & $\begin{array}{c}\text { Model } \\
\beta=0\end{array}$ & $\begin{array}{c}\text { Prediction } \\
\beta=0.44\end{array}$ \\
\hline Aggregate Export Shares & & & & \\
\hline Fraction of exporting firms & $\checkmark$ & $10.9 \%$ & $10.5 \%$ & $10.9 \%$ \\
\hline Employment share of exporters & $\checkmark$ & $52.8 \%$ & $57.2 \%$ & $51.2 \%$ \\
\hline Revenue share of exports & & $15.6 \%$ & $20.7 \%$ & $22.4 \%$ \\
\hline Firm Size Distribution & & & & \\
\hline Average Firm Size & $\checkmark$ & 21.7 & 21.8 & 19.5 \\
\hline Share of firms with $0-14$ workers & $\checkmark$ & $75.5 \%$ & $73.8 \%$ & $72.6 \%$ \\
\hline Share of firms with 15-99 workers & $\checkmark$ & $21.0 \%$ & $21.9 \%$ & $24.5 \%$ \\
\hline Share of firms 100-199 workers & & $2.0 \%$ & $2.7 \%$ & $2.1 \%$ \\
\hline Share of firms 200-399 workers & & $0.9 \%$ & $1.3 \%$ & $0.8 \%$ \\
\hline Job-to-job Hiring & & & & \\
\hline Average share of job-to-job hires, all firms & $\checkmark$ & $17.3 \%$ & $17.6 \%$ & $16.7 \%$ \\
\hline Average share of job-to-job hires, non-exporters & & $15.7 \%$ & $14.5 \%$ & $13.9 \%$ \\
\hline Average share of job-to-job hires, exporters & & $30.3 \%$ & $45.0 \%$ & $40.1 \%$ \\
\hline Average Firm Age (years) & & & & \\
\hline Non-exporters & & 11.7 & 13.0 & 13.0 \\
\hline Exporters & & 20.8 & 16.4 & 15.9 \\
\hline Unemployment and Employment Spells (months) & & & & \\
\hline Average duration of employment spells & & 40.7 & 33.7 & 36.7 \\
\hline Average duration of unemployment spells & & 14.4 & 5.9 & 5.9 \\
\hline Wages & & & & \\
\hline Gini coefficient & & 0.44 & 0.43 & 0.41 \\
\hline Export wage premium* & & 1.71 & 1.54 & 3.21 \\
\hline Slope of log firm wage on log firm size** & & 0.18 & 0.11 & 0.51 \\
\hline
\end{tabular}

Table 3: Model Implications for Targeted and Non-Targeted Statistics

Note: The table shows statistics that are targeted $(\checkmark)$ and not targeted by the calibration.

*: Average wage in exporters over average wage in importers. In the model, this corresponds to $\mathbb{E}_{\varepsilon, a}[\bar{w}(\varepsilon ; a) \mid a \geq h(\varepsilon)] / \mathbb{E}_{\varepsilon, a}[\bar{w}(\varepsilon ; a) \mid a<h(\varepsilon)]$, where $\bar{w}(\varepsilon ; a)$ is the average wage in a type- $\varepsilon$ firm at age $a$. **: $\beta$ from $\log \left(\right.$ wage $\left._{q}\right)=\alpha+\beta \log \left(\right.$ size $\left._{q}\right)$ where wage $_{q}$ and size $_{q}$ are average firm wage and average firm size of quantile $q$ of the firm-size distribution, respectively.

The model yields a reasonable prediction for average job duration, 34-37 months versus 41

as the wage function $w_{U}\left(a_{1}, \varepsilon_{1}\right)$ for workers hired directly from unemployment. Constructing the wage function requires first constructing the worker value function $W(w, a, \varepsilon)$ for being employed in firm $(a, \varepsilon)$ at wage $w$ defined in (43), and then implicitly finding $w\left(a_{0}, \varepsilon_{0}, a_{1}, \varepsilon_{1}\right)$ and $w_{U}\left(a_{1}, \varepsilon_{1}\right)$ as the solutions to $W\left(w\left(a_{0}, \varepsilon_{0}, a_{1}, \varepsilon_{1}\right), a_{1}, \varepsilon_{1}\right)=$ $(1-\beta) V\left(a_{0}, \varepsilon_{0}\right)+\beta V\left(a_{1}, \varepsilon_{1}\right)$ for all $\chi\left(a_{0}, \varepsilon_{0}, a_{1}, \varepsilon_{1}\right)=1$ and $W\left(w_{U}\left(a_{1}, \varepsilon_{1}\right), a_{1}, \varepsilon_{1}\right)=(1-\beta) U+\beta V\left(a_{1}, \varepsilon_{1}\right)$, respectively. The wage, value and duration distributions are then computed by simulating five-hundred thousand employment spells, each potentially spanning multiple jobs, using these transition rules and wage and value functions, the equilibrium contact rates $\left(\lambda_{u}, \lambda_{e}\right)$, and the job termination probability $\delta$. 
months in the data. ${ }^{47}$ In the model, jobs are terminated either exogenously at rate $\delta$ or endogenously due to job-to-job transitions. Without job-to-job transitions, the average job duration would be $1 / \delta=53$ months. The lower average job duration implied by the calibrated model is closer to the data, reflecting endogenous job termination due to job-to-job mobility. In turn, the duration of unemployment spells is $1 / \lambda_{u}$. Since $\lambda_{u}$ was chosen to exactly match the steady-state unemployment rate, the model yields unemployment spells of about 6 months, which are shorter than in the data.

In terms of the wage distribution, the model yields a Gini coefficient of around 0.4. Inequality is considerable due to a large mass of low-wage workers entering directly from unemployment and to the backloading of wages inherent to the job-ladder model. ${ }^{48}$ Similarly to Helpman et al. (2012) and Cosar (2010), among others, an exporter wage premium arises because of rent sharing, selection of high-productivity firms into exporting, and the fact that exporting increases revenue per unit sold. Thanks to the linearity of the revenue function, the model also yields a positive relationship between wages and average size. ${ }^{49}$ In the absence of worker bargaining power, the model underpredicts the exporter wage premium and the elasticity of wages to firm size, whereas with high worker bargaining power it over-predicts both measures.

I now discuss some of the implications for wage dynamics. Panel (a) of Figure A.4 in the Online Appendix shows the relationship between the individual wage and months spent in employment over simulated labor trajectories. The dashed red line limits the model-generated data to trajectories spent in potential exporters (with finite export costs) and the solid blue line limits the data to trajectories spent entirely in never exporters (with infinite export costs). Panel (b) restricts the model-generated data to "lucky" trajectories, corresponding to spells entirely spent in the top $1 \%$ of the productivity distribution. Wages increase over a spell thanks to on-the-job renegotiations upon a contact. The relationship is steeper for workers employed in potential exporters, and even more so in high-productivity ones. Hence, the model suggests a potential explanation for fast wage growth within exporters which is complementary to explanations based on human capital accumulation. ${ }^{50}$ Panels (c) and (d) plot the worker value instead. Like wages, values increase during the duration of a match. The increase in value over time is not as steep as the increase in wages, reflecting the

\footnotetext{
${ }^{47}$ The average duration of employment and unemployment spells as well as the wage distribution statistics reported in Table 3 were computed by the Argentine Ministry of Labor using the same micro data from which the summary statistics that I use were extracted.

${ }^{48}$ Excluding workers whose wage was determined after being hired from unemployment, the Gini falls to 0.28 . Hornstein et al. (2011) discuss the limitations of models with frictional labor markets to generate sizable wage inequality across ex-ante homogeneous workers, and suggests that job-ladder models in the spirit of Dey and Flinn (2005) and Cahuc et al. (2006) may lead to plausible wage dispersion. Papp (2013) demonstrates that calibrated versions of these models generate empirically plausible wage dispersion.

${ }^{49}$ Under decreasing returns to scale in production and convex search costs, a positive correlation between wages and firm sizes is not guaranteed. See Kaas and Kircher (2015) for a discussion of conditions leading to positive wage-size relationship in a frictional labor market with these characteristics.

${ }^{50}$ Dix-Carneiro (2014) estimates the impact of trade liberalization on wages taking into account human capital accumulation in export-oriented and import-competing sectors in Brazil, whereas Molina and Muendler (2013) document selection of high-human capital workers, with past experience in exporting firms, into potential exporters. Quantifying the magnitude of this effect is outside the scope of this paper, as doing so would require a different data and incorporating human capital accumulation in my model. Due to the lack of human capital accumulation, some of the model's implications do not fit empirical patterns; e.g., worker's wages here are fully reset upon fall into unemployment regardless of experience.
} 
value option of future wage increases upon labor market entry.

To conclude this discussion, Figure A.5 in the Online Appendix contrasts additional modelimplied outcomes against the data. Panel (a) shows the firm-size distribution implied by the model under each assumed value of $\beta$ (the broken red lines) as well as the empirical one (the black solid line). The model provides a good fit, although it does not predict as many extremely large firms as in the data. Although firm-level growth leads to dispersion in firm sizes, including ex-ante firm heterogeneity is key to obtain sufficient dispersion in sizes. Panel (b) shows the growth of export participation over a representative cohort's age. The model captures well the slope for relatively younger firms, although it predicts that export participation plateaus at around $15 \%$ after a few decades. Panels (c) and (d) show the pattern of employment growth by age for all firms and for current exporters in the model and in the data. These outcomes correspond to averaging the firmlevel trajectories from panel (c) of the online appendix Figure A.3. For all firms, the model captures the average growth taking place until around age 30, whereas for exporters it does so until about age 40. Firms grow relatively faster in the model than in the data when they are young, and then slow down. The limitation of the model to predict long-run growth within a cohort should not be surprising, as it lacks other sources of firm growth such as knowledge or capital accumulation.

\section{Counterfactuals}

\subsection{Impact of Labor Market Frictions}

The main goal of the counterfactuals is to obtain the elasticity of income per employed worker $y$ to labor market rigidities. For that, I simulate reductions in frictions from unemployment only, from employment only, and from both. In the model, this corresponds to increasing the efficiency in the matching functions (only $\tilde{\lambda_{u}}$, only $\tilde{\lambda_{e}}$, or both).

Panels (a) and (b) of Figure 1 show the change in income per employed worker when these parameters are increased from their calibrated values to $50 \%$ above these values starting from the benchmark calibration with $\beta=0$ (left panel) and $\beta=0.44$ (right panel). Income per employed worker increases due to lower frictions from both unemployment and employment. The increase is faster when frictions from employment are reduced. The combined effect of the two frictions is slightly more than additive, suggesting a small complementarity from reducing both frictions simultaneously.

Table 4 reports the average elasticity of $y$ with respect to frictions across the range of counterfactuals reported in panels (a) and (b) of Figure 1. The elasticity of income per employed worker with respect to the efficiency of job-to-job matching is about 7 times higher than with respect to matching from unemployment. 


\begin{tabular}{l|cc} 
Reduction in Frictions & $\beta=0$ & $\beta=0.44$ \\
\hline \hline From Unemployment Only $\left(\tilde{\lambda_{u}}\right)$ & 0.019 & 0.021 \\
Job-to-job Only $\left(\tilde{\lambda_{e}}\right)$ & 0.131 & 0.145 \\
Both & 0.156 & 0.173
\end{tabular}

Table 4: Elasticity of Income Per Employed Worker $(y)$ with respect to Frictions

Note: This table reports the average elasticity of $y$ with respect to $\tilde{\lambda_{e}}, \tilde{\lambda_{u}}$, and a shift in both across the range of counterfactuals displayed in panels (a) and (b) of Figure 1.

To better grasp these magnitudes and to relate the counterfactuals to cross-country differences, we can inspect labor-market outcomes commonly associated with the rigidity of labor market institutions, such as unemployment or job finding rates. Consider first a 50\% increase in the matching efficiency from unemployment. Panels (c)-(d) imply that, according to the model, labor market policies that would reduce the unemployment rate in Argentina by 3.2 percentage points, would also raise income per employed worker by about $1 \%$. Cross-country differences in unemployment are often within the $3 \%-10 \%$ range, but only a fraction of these differences may be attributed to differences in labor market policies (Nickell, 1997).

In the same spirit, consider a $50 \%$ increase in the matching efficiency from employment. Panels (e)-(f) imply that, according to the model, labor market policies that would raise the average fraction of job-to-job hires by between 2 and 3 percentage points, would raise income per employed worker by about 7\%. By comparison, in the U.S. the fraction of all new hires entering firms directly from other jobs near the period of my study is 12 percentage points larger than in Argentina. ${ }^{51}$ In terms of job-finding probabilities, this counterfactual corresponds to moving from the average value of $\frac{\lambda_{e}}{\lambda_{u}}$ estimated across 11 countries in Jolivet et al. (2006) to close to the maximum estimate across the 11 countries in their sample.

Panels (c)-(d) imply that the unemployment rate increases under lower frictions in job-to-job mobility, an implication of employed workers crowding out unemployed workers in the matching function as matching from employment becomes more efficient. However, as implied by panels (g) and (h), the income per capita gains from higher $\lambda_{e}$ are only partially offset by the higher unemployment rate.

Next, I inspect the implications for firm growth and for the timing of export entry. Consider the $50 \%$ reduction in frictions from employment only or from unemployment only. Panels (a) and (b) of Figure 2 show firm size by age for seven potential exporters uniformly distributed over the productivity distribution, ranging from the lowest productivity firm (the lightest-blue lines) to the highest-productivity firm (the darkest-red line). Solid lines correspond to the benchmark calibration, and dashed lines correspond to lower frictions from employment only (panel (a)) or from unemployment only (panel (b)). Panel (c) shows the percentage change in average firm size

\footnotetext{
${ }^{51}$ The rate of new hires entering firms directly from other jobs in the U.S. since 1994 is $36 \%$ (Fallick and Fleischman, 2004). In the U.S. I do not observe the simple average of the fraction of new hires across firms. Instead, this fraction is the average ratio between aggregate employment-to-employment flows and the sum of aggregate unemployment-to-employment and non-employment-to-employment flows in the U.S. using data from from http://www.federalreserve.gov/econresdata/researchdata/feds200434.html.
} 


\section{Figure 1: Impact of Lowering Frictions}

(a) Income Per Employed Worker $(\beta=0)$

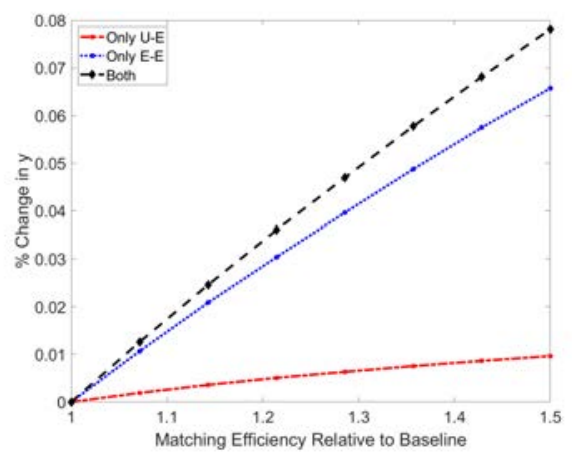

(c) Unemployment Rate $(\beta=0)$

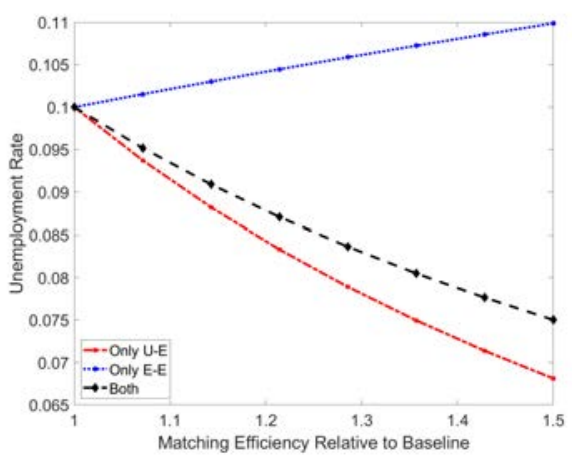

(e) Share of Job-to-job hires $(\beta=0)$

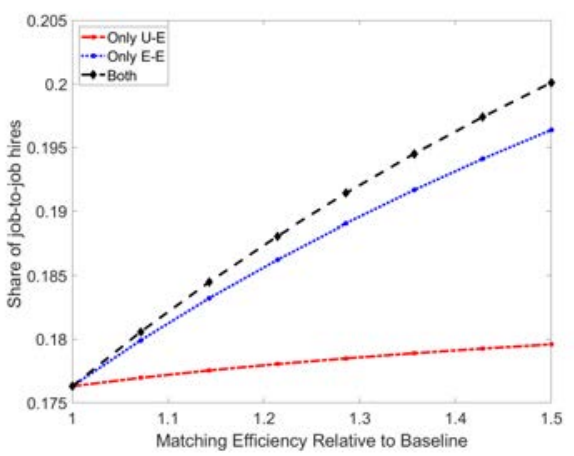

(g) Income Per Capita $(\beta=0)$

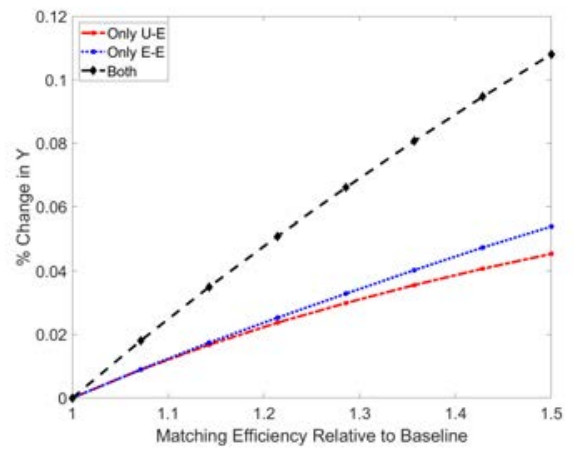

(b) Income Per Employed Worker $(\beta=0.44)$

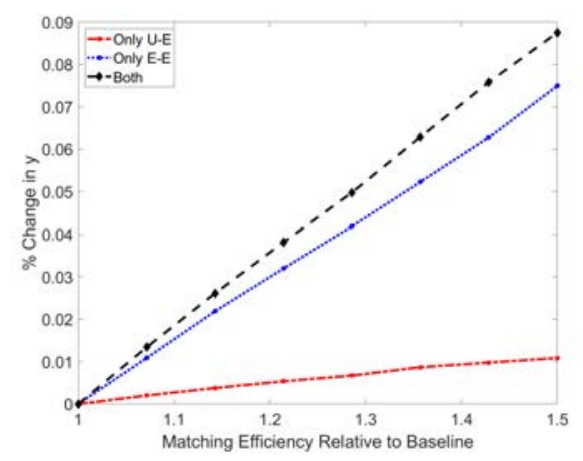

(d) Unemployment Rate $(\beta=0.44)$

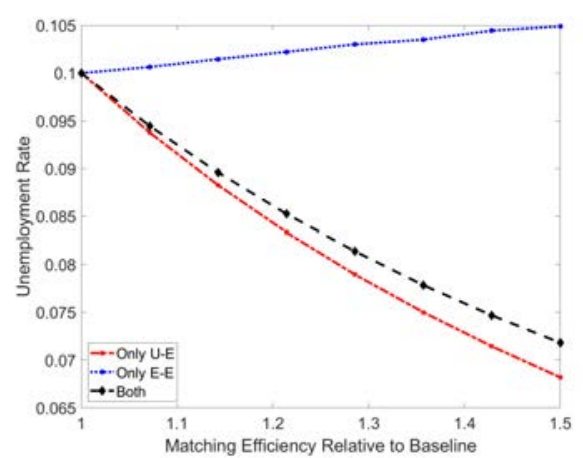

(f) Share of Job-to-job hires $(\beta=0.44)$

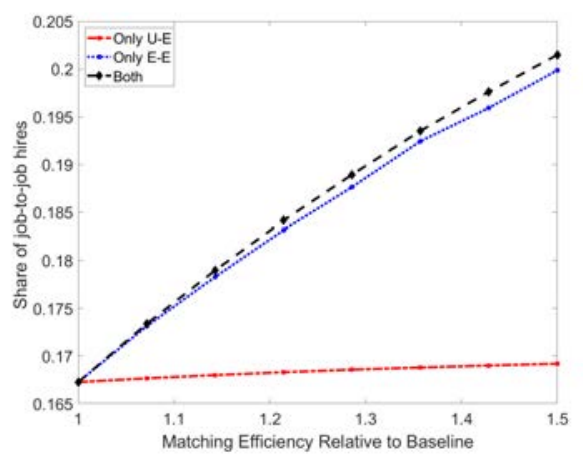

(h) Income Per Capita $(\beta=0.44)$

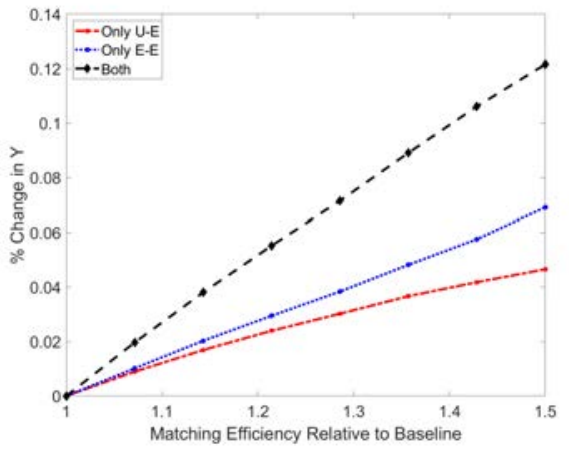

Note: the figures show interpolated values using the counterfactual results over an equally spaced grid with 10 values of the matching rates. 
across the full productivity distribution when each type of frictions is reduced, and panel (d) shows the percentage change in the entry time into exporting.

Figure 2: Impact of 50\% Reduction in Frictions on Firm Growth and Timing of Entry

(a) Firm Size by Age (Only E-E)

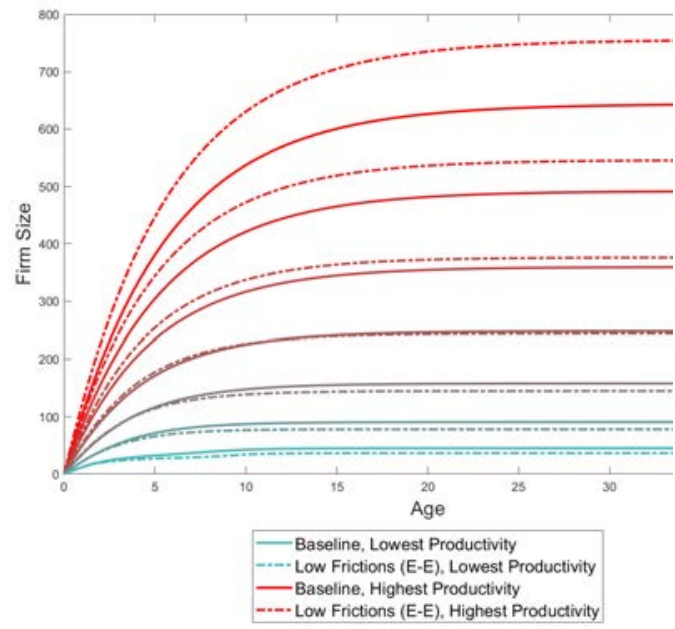

(c) $\%$ Change in Firm Size

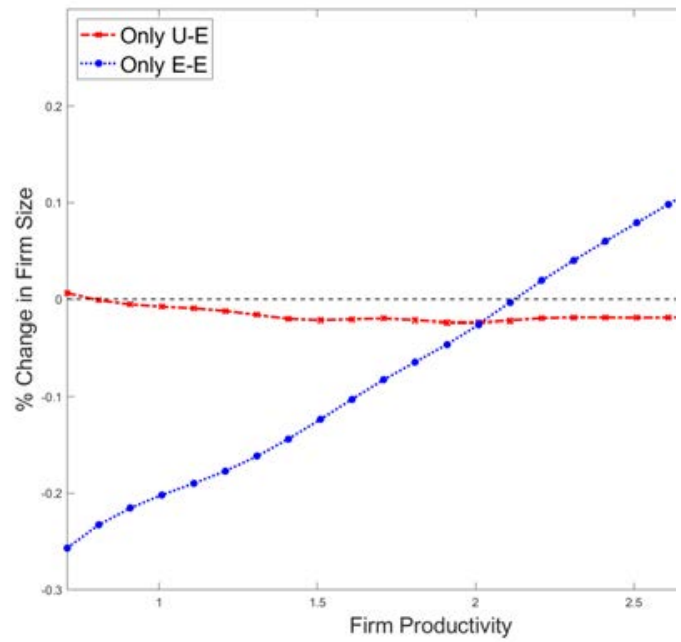

(b) Firm Size by Age (Only U-E)

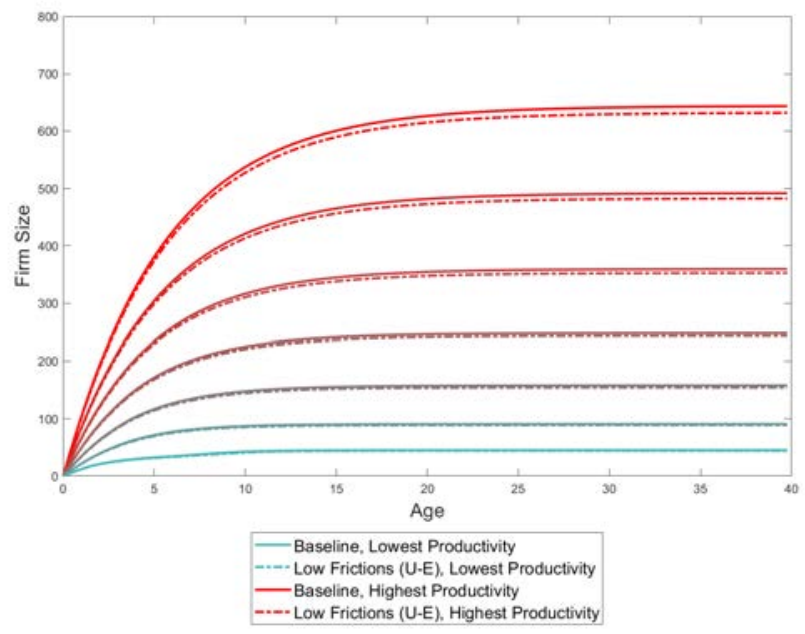

(d) \% Change in Age of Export Entry

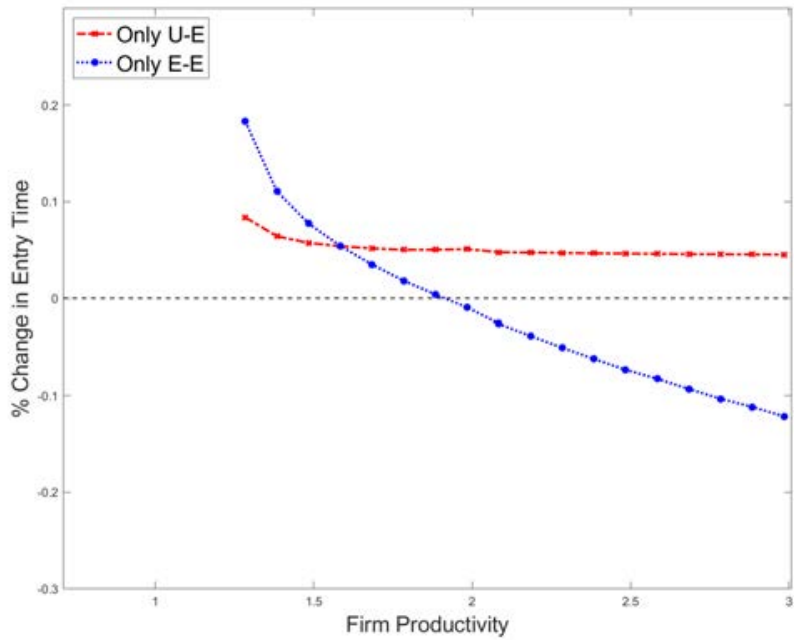

Note: the figures show the changes in outcomes under a $50 \%$ increase in matching efficiency from employment only (E-E), or unemployment only (U-E) relative to the baseline calibration with $\beta=0$.

Under easier job-to-job hiring, more productive firms grow faster and start to export earlier, while less productive firms grow more slowly and delay export entry. ${ }^{52}$ As a result, labor shares

\footnotetext{
${ }^{52}$ Appendix C shows a negative correlation between the export share of exporting firms and country-level employment rigidity using the World Bank Enterprise Survey and the World Bank Doing Business index of labor market rigidity, controlling for industry, time, and country fixed effects. The interaction term between rigidity and firm size is negative, suggesting that the positive relationship between flexibility and exports is weaker among small exporters.
} 
are reallocated to high-productivity firms. In contrast, under lower frictions in transitions out of unemployment, firm growth and average firm size slightly fall, while the timing of export entry slows down across the productivity distribution. Therefore, frictions in job-to-job mobility are a quantitatively relevant driver of firm growth and the timing of investment. In addition, the fact that neither reallocation to the most productive firms nor faster export entry take place under lower frictions from unemployment implies that the gains in income per employed worker in that case result from the standard demand externality discussed in Section 3.7.

To see why there is a slow down in the timing of export entry under lower frictions from unemployment, Panels (a) and (b) in Figure A.6 in the Online Appendix show that the export revenue premium $\Gamma$ falls in response to lower frictions. As we have discussed, this follows from the definition of $\Gamma$ in (6). This force dominates the impact on the timing of export entry across the entire firm-productivity distribution in the case of lower frictions from unemployment. As shown in panels (c) and (d) of Figure A.6, under higher $\tilde{\lambda_{e}}$ the faster growth and export entry of highproductivity firms leads to an increase in the exporter employment share, whereas under higher $\tilde{\lambda_{u}}$ the exporter employment share falls. Finally, panels (e) and (f) show that the fraction of exporting firms falls with reductions in frictions. In the case of higher $\tilde{\lambda_{e}}$, this simply results from the fact that, on average, there are fewer high-productivity firms speeding up investment than there are low-productivity firms slowing it down.

\subsection{Implications for Country Income Differences}

It is possible to give some approximate sense of how labor market reforms would map to changes in income per worker through the forces included in the analysis. While admittedly "back-of-the envelope" and relying on strong assumptions, the calculations in this section help to give a sense of the importance of the mechanisms in my model for cross-country income differences.

First, a simple calculation can be done to translate the counterfactual changes in contact rates into counterfactual changes in labor market institutions. The bottom right panel of Figure A.1 in the Online Appendix plots estimates of $\lambda_{u}$ and $\lambda_{e}$ from Jolivet et al. (2006) against the rigidity of employment index from the Doing Business report by the World Bank. ${ }^{53}$ Within the years of my data, a labor market reform equivalent to a one standard deviation decline of the rigidity index distribution across countries would have pushed Argentina from the position 58 to the position 111 of the rigidity ranking (out of 153 countries), or a $41 \%$ reduction in the rigidity index. ${ }^{54}$ Using

\footnotetext{
${ }^{53}$ The index, first introduced by Botero et al. (2004), assigns a number from 0 to 100 to policies that regulate the rigidity of hiring, firing, and hours and then averages these values. The top panels of the figure show contact rates estimated by Hobijn and Şahin (2009) and Ridder and van den Berg (2003), and the bottom left panel shows the estimates of Jolivet et al. (2006) against an alternative rigidity measure, the employment protection legislation (EPL) index by the OECD. The elasticities of contact rates with respect to the World Bank and OECD employment protection indexes are different due to the different policies captured by each index and the set of countries included. Argentina does not appear in these figures because none of these papers include it in the computation of the contact rates. The analysis in this section uses the World Bank index because the EPL from OECD is not available for Argentina.

${ }^{54}$ Given how the index is constructed, this decline in rigidity would be equivalent to the following policy package: an increase in the maximum duration of fixed term contracts from 3 years to 5 years or more; a $20 \%$ reduction in the
} 
the elasticities of $\lambda_{u}$ and $\lambda_{e}$ with respect to rigidity in the bottom right panel of Figure A.1 in the Online Appendix, and under the (strong) assumption that labor market rigidities are uncorrelated with other drivers of contact rates, this fall in rigidity would be equivalent to a $25 \%$ increase in $\lambda_{u}$ and a $30 \%$ increase in $\lambda_{e}{ }^{55}$

Simulating these simultaneous changes in matching efficiencies yields a $5.8 \%$ increase in income per worker; however, the increase is only $0.9 \%$ if only $\lambda_{u}$ is increased by $25 \%$, and $4.7 \%$ if only $\lambda_{e}$ is increased by $30 \%$. Hence, about $80 \%$ of the real income gains from relaxing all frictions materialize through relaxing job-to-job transitions. This labor-market reform also implies a $9 \%$ increase in exports, and a $7 \%$ increase if only frictions in job-to-job transitions are relaxed. ${ }^{56}$ In addition, it leads to a shift in the firm-size distribution, raising by $17 \%$ the fraction of very large firms (with at least 400 workers). As pointed out by Hsieh and Klenow (2014) and Bento and Restuccia (2018), higher-income countries are characterized by a higher prevalence of relatively larger firms.

Next, we can also ask how far labor market institutions may go, through the specific channels in the model, in generating differences in income across countries. The previous calculations yield an elasticity of income per worker to the rigidity index of $5.8 \% / 40 \%=0.145$. Assuming that this elasticity would apply to other countries besides Argentina, a simple developing accounting exercise in the spirit of Caselli (2005) would suggest that, through the forces in the model, differences in labor market rigidity may generate a standard deviation in log income per worker across countries equivalent to $5.2 \%$ of what is observed. ${ }^{57}$

A final simple calculation can be done to gauge how much of the observed relationship between labor market frictions and income may be captured by the model. As shown in Figure A.2 in the Online Appendix, in 2005 the unconditional elasticity of real income per worker to the rigidity of employment index across countries was -0.736 (standard error of 0.197). Of course, this correlation may be driven by many spurious forces and reverse causality. Under the strong assumption that other determinants of income are uncorrelated with labor rigidities, the forces in the model can be said to generate about $0.145 / 0.736 \approx 1 / 5$ of this unconditional correlation.

ratio of minimum wage to the average value added per worker; a $10 \%$ increase in the length of the workweek from 5 days to 5.5 or more; a $50 \%$ increase in the length of the workday (going from 8 to 12 hours); and a $25 \%$ reduction in the cost of dismissal induced by redundancy as fair ground for dismissal.

${ }^{55}$ Specifically, a one standard deviation change in the index implies a $41 \%$ reduction in the rigidity index for Argentina, and the estimates from Jolivet et al. (2006) imply an elasticity of the contact rates with respect to the rigidity index of 0.60 for $\lambda_{u}$ and 0.74 for $\lambda_{e}$. I use the indexes from Jolivet et al. (2006) because they have the advantage of being simultaneously available for contact rates on the job and from unemployment. Using these estimates yields the most conservative magnitudes for the shock, as using the estimates from Hobijn and Şahin (2009) would imply a $70 \%$ increase in $\lambda_{u}$, and using the estimates from Ridder and van den Berg (2003) would imply a $110 \%$ increase in $\lambda_{e}$. However, the latter would only be based on a cross-section of only 5 countries.

${ }^{56}$ Using a panel of countries in Appendix Section $\mathrm{C}$, the elasticity of real exports to the rigidity index after controlling for country and time fixed effects is $4.2 \%$.

${ }^{57}$ In 2005 , the standard deviation of $\log$ real income per capita $y_{i}$ from the World Development Indicators was $s d\left(\ln y_{i}\right)=1.53$, while the standard deviation implied by our calculations is $s d\left(0.145^{*} \ln R E_{i}\right)=0.08$, where $R E_{i}$ stands for the employment rigidity index. 


\subsection{Robustness}

Columns (1) to (6) of Table A.1 in the Online Appendix report additional calibrations used for robustness checks. I re-calibrate the model under alternative values of the parameters $\sigma, \zeta$, and $z$ which in the benchmark calibration were set to existing values from the literature. I allow for for $\sigma=\{4.5,6.7\}$, corresponding to the average estimate of the elasticity of substitution in the gravity literature reported by Head et al. (2013) and to the estimate in Cosar (2010), respectively. I also allow for $\zeta=\{1.75,1.5\}$, broadly accounting for the fact that my model does not include scale effects like other parametrizations of recruitment costs such as Merz and Yashiv (2007), which tend to reduce the marginal cost of posting vacancies for larger firms.

I also perform two alternative calibrations with different income flows in unemployment, $z$. First, I assume that $z$ only includes observable monetary transfers to the unemployed, and set $z$ to match the share of unemployment benefits in GDP of $0.56 \%$ according to data from the Argentine Ministry of Labor, leading to a flow value of unemployment relative to income per employee of $\frac{z}{y}=5 \% .58$ Second, I set $z$ such that $\frac{z}{y}=0.7$, which corresponds to the mid-range of values estimated by Karabarbounis et al. (2015) accounting both for unemployment transfers and the value of home production or leisure.

Table A.2 in the Online Appendix reports, for the benchmark as well as each of these parametrizations, the change in income per employed worker, unemployment rate and rate of job-to-job hiring corresponding to a $25 \%$ increase in the matching efficiencies from unemployment only, job to job, or both. This shock lies at the middle range of the counterfactuals reported in Figure 1. In addition, I also undertake the counterfactuals assuming that $\frac{z}{y}$ is fixed at its calibrated value, instead of fixing $z$ as in all the other counterfactuals, and imposing a Cobb-Douglas matching function with equal weights on firms and workers instead of the CES matching function in (27).

The result from the benchmark calibration goes through in all of these cases. The magnitude of the gains in income per worker is stable across specifications. Reductions in both types of frictions increase income per employed worker, but the effect is stronger for frictions in matching from employment.

\subsection{Multiple Investments}

I extend the model to allow for multiple export destinations. I assume that firms may access a sequence of export markets $j=1, . ., K$. Analyzing this extension is feasible under the assumption that $\lambda_{e} \beta=0$ because, in this case, the value of the firm in (10) is independent from the sampling distribution. The value of a new job held by a firm with productivity $\psi$ and times until entry into

\footnotetext{
${ }^{58}$ This is the average spending in unemployment insurance and re-employment programs as share of GDP over 20032007. In the model, the share of unemployment transfers in GDP is $\frac{u z}{(1-u) y}$, which implies $\frac{z}{y}=0.0056 * \frac{1-u}{u}=5.04 \%$. The analogue coefficient computed by Karabarbounis et al. (2015) for the U.S. is 6\%.
} 
each market $\boldsymbol{x} \equiv\left\{x_{1}, x_{2}, . ., x_{K}\right\}$ retains the same structure as (23) in the simplified model:

$$
v(\boldsymbol{x} ; \psi)=\frac{\psi y_{0}+\delta U}{\rho+\delta}+\sum_{k=1}^{K} \frac{e^{-(\rho+\delta) x_{k}}\left(\psi y_{k}-\psi y_{k-1}\right)}{\rho+\delta},
$$

where, from (35), $y_{k}=\left(\sum_{j=0}^{k} A_{j}\right)^{1 / \sigma}$ is the revenue per unit sold for a firm that exports to markets 1 to $j$ and $A_{j}$ is market $j$ 's capacity. As before, the export entry decision can be characterized by the stock effect. Letting $h_{j}$ be the time elapsed between a firm's entry to markets $j$ and $j+1$, Appendix A.5 shows that the entry times $h_{1}, h_{2}, . ., h_{K}$ satisfy

$$
\begin{aligned}
S_{1}\left(h_{1}, h_{2}, . ., h_{K}\right) & \leq f_{1},=\text { if } h_{1}<\infty \\
S_{j}\left(h_{j}, h_{j+1}, . ., h_{K}\right) & \leq f_{j}-e^{-\gamma h_{j}} \frac{y_{j}-y_{j-1}}{y_{j-1}-y_{j-2}} f_{j-1},=\text { if } h_{j}<\infty \text { for } j=2, . ., K,
\end{aligned}
$$

where $f_{j}$ is the fixed entry cost to market $j$ conditional on having entered the previous markets and $S_{j}(\cdot)$ is the stock effect of delaying the entry to market $j$ after having entered the previous markets, defined in (63). These conditions characterize the timing and ordering of multiple investments. Firms enter faster in market $j$ the lower its cost $f_{j} / f_{j-1}$ or the higher its revenue gain $\left(y_{j}-y_{j-1}\right) /\left(y_{j-1}-y_{j-2}\right)$ relative to the previous market. ${ }^{59}$ The general equilibrium variables $\left\{P_{v}(v), G_{v}(v), \lambda_{e}, \lambda_{u}, u,\left\{y_{k}\right\}\right\}$ can be solved following similar steps as in the benchmark model.

I calibrate this extended model to the same targets of the baseline calibration under the assumption that $\beta=0$. The model allows for an arbitrary number of asymmetric markets. Since I do not observe exports by destination, I simply assume that foreign markets are symmetric: $A_{j}=\left(\frac{j}{K}\right) A$ and $f_{j}=\left(\frac{j}{K}\right) f_{X}$, so that higher- $j$ markets are larger but also harder to enter. Given $K$, this model includes the same number of parameters as the benchmark, and exactly nests it when $K=1$. I set $K=10$, and choose the remaining parameters to simultaneously target the same statistics as in the baseline calibration. Column (7) of Table A.1 in the Online Appendix shows the calibrated parameters. This parametrized extended model gives an average number of export destinations across exporters equal to 6.7 , whereas in the data the same number is 5.2.

An appealing feature of this extended model is that it yields growth in income per employed worker throughout the lifetime of firms as firms enter to more export markets. In contrast, in the baseline model, firms grow in revenue per worker only once at the moment of export entry. This property is illustrated in Figure A.7 in the Online Appendix, which shows the increase in revenue per worker for 25 firms with different productivity evenly split over the productivity distribution. Higher productivity firms enter to more markets, and more rapidly so. Hence, by adding more

\footnotetext{
${ }^{59}$ This structure also allows for a simple numerical solution algorithm for the partial-equilibrium problem. Because the first-order condition to enter market $j$ only depends on the times $h_{j}, . ., h_{K}$, these conditions define a triangular system which can be solved starting with the solution for $h_{K}$ and iterating backwards. This solution also gives a necessary condition such that the ordering $1, . ., K$ is chosen: because an interior solution requires a positive stock effect $S_{j}$ at $h_{j}=0$, the sequence $1, \ldots, K$ cannot be an outcome if $f_{j} / f_{j-1}<\left(y_{j}-y_{j-1}\right) /\left(y_{j-1}-y_{j-2}\right)$ for some $j$. If that were the case, market $j$ would be more attractive than market $j-1$ and the firm would revert their ordering.
} 
markets, revenue per worker can grow more frequently for extended periods of time over the firm life cycle for some firms.

\begin{tabular}{|c|c|c|}
\hline \multirow{2}{*}{ Reduction in Frictions } & \multicolumn{2}{|c|}{ Impact on } \\
\hline & Income per Employee & Export Destinations \\
\hline "From Unemployment Only $\left(\lambda_{u}\right)$ & $0.2 \%$ & $0.9 \%$ \\
\hline Job-to-job Only $\left(\lambda_{e}\right)$ & $3.6 \%$ & $2.9 \%$ \\
\hline
\end{tabular}

Table 5: Impact of a $25 \%$ reduction in Frictions, Multiple Investments

Table 5 shows the impact of a $25 \%$ increase in the matching efficiencies from employment and unemployment on income per employed worker $y$ and on the average number of export destinations across exporters. This impact is similar to the benchmark case with a single export destination. Hence, this extra margin of adjustment does not change the elasticity of income with respect to frictions. The average number of export destinations among exporters grows by a similar order of magnitude as the increase in income per employed worker.

\subsection{Labor Market Frictions and Gains from Trade Liberalization}

To conclude, I examine the interaction between trade and labor market frictions. Specifically, I ask if frictions in job-to-job mobility matter for the model-implied effects of lower trade costs. I simulate increases in the market capacity $A$, both in the benchmark calibration and in a restricted calibration assuming $\lambda_{e}=0$ and dropping the average share of job-to-job hires as a target. The parameters resulting from this restricted calibration are reported in column (8) of Table A.1 in the Online Appendix.

Figure 3 shows the impact on income per employed worker resulting from increasing $A$ from its calibrated value to $50 \%$ above that value, in both the benchmark calibration (dashed red line) and in the calibration assuming away job-to-job transitions (dotted blue line). Since trade costs enter in the definition of $A$ (see (6) and Footnote 19), these counterfactuals are equivalent to trade liberalizations of varying magnitudes. In both cases, there is an increase in real income per employed worker, but the elasticity of income with respect to trade costs is larger in the benchmark calibration. Excluding job-to-job transitions from the calibration leads to an under-estimation of the gains from reducing trade frictions.

The previous result suggests that matching the share of job-to-job transitions matters to predict the real income gains of a given trade liberalization. It is still worth asking whether the Arkolakis et al. (2012) formula, according to which the elasticity of trade flows to trade costs and the change in the domestic expenditure share suffice to measure the gains from changes in trade costs, remains a good approximation. My model falls outside of the class of models in that paper because it assumes frictional labor markets, but it also shares the key feature of a constant-elasticity aggregator of varieties. Section B of the Online Appendix shows that the Arkolakis et al. (2012) formula indeed remains a very good approximation in data generated by my model. I conclude that accounting for job-to-job transitions matters for the change in the domestic expenditure share of a given reduction 
in trade costs, but this change and the trade elasticity provide a very good approximation to the real income gains when combined with the Arkolakis et al. (2012) formula.

Figure 3: Impact of Increasing Foreign Market Capacity

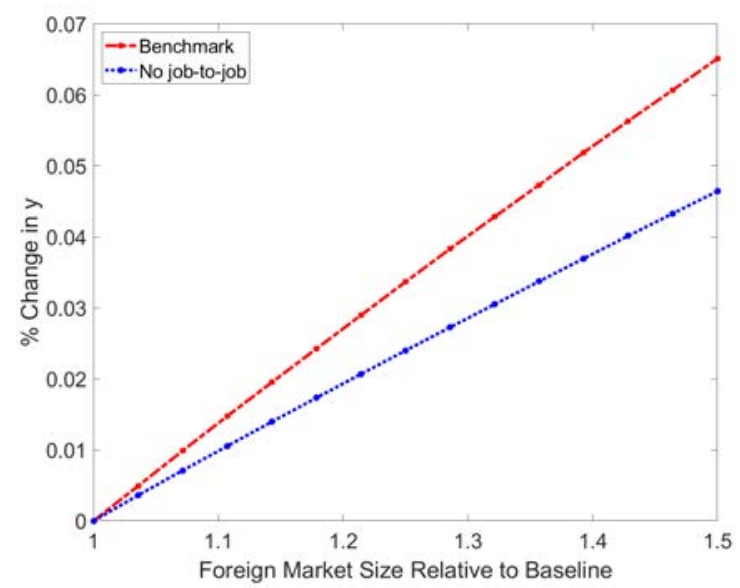

\section{Conclusion}

This paper developed a model to study the aggregate effects of labor market frictions in a small open economy where firms grow slowly and make fixed export investments. The novel feature of the model is the interaction between firms' dynamic fixed investments in exporting and search frictions with job-to-job mobility. Through this channel, the degree of firm heterogeneity in the economy is partly endogenous and depends on export investments undertaken during the firm's life cycle.

Using the model I demonstrated the channels through which frictions in hiring from unemployment and from other jobs impact firm growth and the timing of export entry. I calibrated the model to Argentina's economy, where I can observe both firm export dynamics and the rates at which firms with different export statuses hire workers directly from other employers. The calibrated model replicates various aggregate statistics pertaining to export participation and labor market outcomes, as well as cross-sectional features of the data such as the firm size distribution.

The theoretical and quantitative results suggest that frictions in job-to-job transitions have a stronger impact on income per worker, firm investments and growth than frictions in hiring from unemployment. Through the mechanisms in the model, I find that labor market reforms that would push Argentina from the top to the bottom third of the distribution labor market rigidities would lead to a $5 \%$ increase in income per worker, of which $80 \%$ would be due to lower frictions in job-to-job mobility. I also find that accounting for barriers to worker mobility across firms matters to predict the real income effects of a given reduction in trade costs

While I focused the analysis on investments in export capacity, the framework naturally lends itself to the interaction between labor market frictions and other fixed investments in either closed or open economy, such as technology choice, foreign direct investment, or number of products. I 
have also studied the implications of changes in contact rates, but abstracted from including specific labor market policies or additional forces such as firm-level productivity shocks that may interact with labor market frictions.

\section{References}

Acemoglu, D., P. Antràs, and E. Helpman (2007). Contracts and technology adoption. The American economic review 97(3), 916-943.

Acemoglu, D. and R. Shimer (2000). Wage and technology dispersion. The Review of Economic Studies 67(4), 585-607.

Almeida, R. K. and J. P. Poole (2017). Trade and labor reallocation with heterogeneous enforcement of labor regulations. Journal of Development Economics 126, 154-166.

Amiti, M. and D. R. Davis (2012). Trade, firms, and wages: Theory and evidence. The Review of economic studies $79(1), 1-36$.

Arkolakis, C. (2016). A unified theory of firm selection and growth. The Quarterly Journal of Economics 131(1), 89-155.

Arkolakis, C., A. Costinot, and A. Rodríguez-Clare (2012). New trade models, same old gains? The American Economic Review 102(1), 94-130.

Atkeson, A. and A. Burstein (2010). Innovation, firm dynamics, and international trade. Journal of political economy 118(3), 433-484.

Atkin, D., A. K. Khandelwal, and A. Osman (2017). Exporting and firm performance: Evidence from a randomized experiment. The Quarterly Journal of Economics 132(2), 551-615.

Bagger, J. and R. Lentz (2014). An empirical model of wage dispersion with sorting. Technical report, National Bureau of Economic Research.

Bassanini, A. and A. Garnero (2013). Dismissal protection and worker flows in oecd countries: Evidence from cross-country/cross-industry data. Labour Economics 21, 25-41.

Benassy, J.-P. (1998). Is there always too little research in endogenous growth with expanding product variety? European Economic Review 42(1), 61-69.

Bento, P. and D. Restuccia (2018). On average establishment size across sectors and countries. Technical report, National Bureau of Economic Research.

Bernard, A. B., J. B. Jensen, S. J. Redding, and P. K. Schott (2007). Firms in international trade. The Journal of Economic Perspectives 21(3), 105-130.

Bertola, G. and R. J. Caballero (1994). Cross-sectional efficiency and labour hoarding in a matching model of unemployment. The Review of Economic Studies 61(3), 435-456.

Blanchard, O. and P. Portugal (2001). What hides behind an unemployment rate: comparing portuguese and us labor markets. American Economic Review 91(1), 187-207.

Blanchard, O. J. and N. Kiyotaki (1987). Monopolistic competition and the effects of aggregate demand. The American Economic Review, 647-666.

Bontemps, C., J.-M. Robin, and G. J. Van den Berg (2000). Equilibrium search with continuous productivity dispersion: Theory and nonparametric estimation. International Economic Review 41(2), 305-358.

Botero, J. C., S. Djankov, R. La Porta, F. Lopez-de Silanes, A. Shleifer, et al. (2004). The regulation of labor. The Quarterly Journal of Economics 119(4), 1339-1382.

Burdett, K. and G. Menzio (2017). The (q, s, s) pricing rule. The Review of Economic Studies 85(2), 892-928. 
Burdett, K. and D. T. Mortensen (1998). Wage differentials, employer size, and unemployment. International Economic Review, 257-273.

Burstein, A. and M. J. Melitz (2011). Trade liberalization and firm dynamics. Technical report, National Bureau of Economic Research.

Cahuc, P., F. Postel-Vinay, and J.-M. Robin (2006). Wage bargaining with on-the-job search: Theory and evidence. Econometrica 74(2), 323-364.

Caliendo, L., M. Dvorkin, and F. Parro (2019). Trade and labor market dynamics: General equilibrium analysis of the china trade shock. Econometrica 87(3), 741-835.

Caselli, F. (2005). Accounting for cross-country income differences. Handbook of economic growth 1, 679-741.

Chatterjee, S. and E. Rossi-Hansberg (2012). Spinoffs and the market for ideas. International Economic Review 53(1), 53-93.

Cooper, R., J. Haltiwanger, and J. L. Willis (2007). Search frictions: Matching aggregate and establishment observations. Journal of Monetary Economics 54, 56-78.

Cosar, A. K., N. Guner, and J. Tybout (2016). Firm dynamics, job turnover, and wage distributions in an open economy. The American Economic Review 106(3), 625-663.

Cosar, K. (2010). Adjusting to trade liberalization: Reallocation and labor market policies. University of Chicago Booth School of Business, unpublished manuscript.

Cuñat, A. and M. J. Melitz (2012). Volatility, labor market flexibility, and the pattern of comparative advantage. Journal of the European Economic Association 10(2), 225-254.

Das, S., M. J. Roberts, and J. R. Tybout (2007). Market entry costs, producer heterogeneity, and export dynamics. Econometrica 75(3), 837-873.

Davidson, C., S. J. Matusz, and A. Shevchenko (2008). Globalization and firm level adjustment with imperfect labor markets. Journal of International Economics 75(2), 295-309.

Davis, S. J., R. J. Faberman, and J. C. Haltiwanger (2013). The establishment-level behavior of vacancies and hiring. The Quarterly Journal of Economics 128(2), 581-622.

Davis, S. J. and J. Haltiwanger (2014). Labor market fluidity and economic performance. Technical report, National Bureau of Economic Research.

Dey, M. S. and C. J. Flinn (2005). An equilibrium model of health insurance provision and wage determination. Econometrica 73(2), 571-627.

Dickstein, M. J. and E. Morales (2016). What do exporters know? Technical report.

Dickstein, M. J. and E. Morales (2018). What do exporters know? The Quarterly Journal of Economics 133(4), 1753-1801.

Dix-Carneiro, R. (2014). Trade liberalization and labor market dynamics. Econometrica 82(3), 825-885.

Djankov, S. and R. Ramalho (2009). Employment laws in developing countries. Journal of Comparative Economics 37(1), 3-13.

Eaton, J., S. Kortum, and F. Kramarz (2011). An anatomy of international trade: Evidence from french firms. Econometrica 79(5), 1453-1498.

Fallick, B. and C. A. Fleischman (2004). Employer-to-employer flows in the us labor market: The complete picture of gross worker flows.

Feenstra, R. C. (2014). Restoring the product variety and pro-competitive gains from trade with heterogeneous firms and bounded productivity. Technical report, National Bureau of Economic Research.

Felbermayr, G., J. Prat, and H.-J. Schmerer (2011). Globalization and labor market outcomes: Wage bargaining, search frictions, and firm heterogeneity. Journal of Economic theory 146(1), 39-73. 
Frıas, J. A., D. S. Kaplan, E. Verhoogen, and D. Alfaro-Serrano (2018). Exports and wage premia: Evidence from mexican employer-employee data.

Garibaldi, P., E. R. Moen, and D. E. Sommervoll (2016). Competitive on-the-job search. Review of Economic Dynamics 19, 88-107.

Garin, A., F. Silvério, et al. (2019). How responsive are wages to demand within the firm? evidence from idiosyncratic export demand shocks. Technical report.

Haltiwanger, J., S. Scarpetta, and H. Schweiger (2014). Cross country differences in job reallocation: the role of industry, firm size and regulations. Labour Economics 26, 11-25.

Head, K., T. Mayer, et al. (2013). Gravity equations: Toolkit, cookbook, workhorse. Handbook of international economics 4, 131-195.

Heckman, J. and C. Pages-Serra (2000). Gross worker flows over the business cycle. Economia 1(1), 109-154.

Heise, S. and T. Porzio (2019). Workers home bias and spatial wage gaps. Technical report, Working Paper, UCSD.

Helpman, E. and O. Itskhoki (2010). Labour market rigidities, trade and unemployment. The Review of Economic Studies 77(3), 1100-1137.

Helpman, E. and O. Itskhoki (2015). Firms, trade, and labor market dynamics. Manuscript, Princeton University.

Helpman, E., O. Itskhoki, M.-A. Muendler, and S. J. Redding (2012). Trade and inequality: From theory to estimation. Technical report, National Bureau of Economic Research.

Helpman, E., O. Itskhoki, and S. Redding (2010). Inequality and unemployment in a global economy. Econometrica 78(4), 1239-1283.

Helpman, E., M. Melitz, and Y. Rubinstein (2008). Estimating trade flows: Trading partners and trading volumes. The Quarterly Journal of Economics 123(2), 441-487.

Hobijn, B. and A. Şahin (2009). Job-finding and separation rates in the oecd. Economics Letters 104(3), $107-111$.

Hopenhayn, H. and R. Rogerson (1993). Job turnover and policy evaluation: A general equilibrium analysis. Journal of political Economy, 915-938.

Hornstein, A., P. Krusell, and G. L. Violante (2011). Frictional wage dispersion in search models: A quantitative assessment. The American Economic Review 101(7), 2873-2898.

Hsieh, C.-T. and P. J. Klenow (2014). The life cycle of plants in india and mexico. The Quarterly Journal of Economics 129(3), 1035-1084.

Jolivet, G., F. Postel-Vinay, and J.-M. Robin (2006). The empirical content of the job search model: Labor mobility and wage distributions in europe and the us. European Economic Review 50(4), 877-907.

Kaas, L. and P. Kircher (2015). Efficient firm dynamics in a frictional labor market. The American Economic Review 105(10), 3030-3060.

Kambourov, G. (2009). Labour market regulations and the sectoral reallocation of workers: The case of trade reforms. The Review of Economic Studies 76(4), 1321-1358.

Karabarbounis, L., G. Chodorow-Reich, et al. (2015). The cyclicality of the opportunity cost of employment. Technical report, Federal Reserve Bank of Minneapolis.

Klette, T. J. and S. Kortum (2004). Innovating firms and aggregate innovation. Journal of Political Economy 112(5).

Krugman, P. (1980). Scale economies, product differentiation, and the pattern of trade. The American Economic Review 70(5), 950-959. 
Krusell, P., T. Mukoyama, R. Rogerson, and A. Şahin (2017). Gross worker flows over the business cycle. American Economic Review 107(11), 3447-76.

Kugler, A. D. (2007). The effects of employment protection in europe and the us. Opuscle, CREI.

Kugler, M. and E. Verhoogen (2012). Prices, plant size, and product quality. The Review of Economic Studies 79(1), 307-339.

Lagos, R. (2006). A model of tfp. The Review of Economic Studies 73(4), 983-1007.

Lentz, R. (2014). Optimal employment contracts with hidden search. Technical report, National Bureau of Economic Research.

Lentz, R. and D. T. Mortensen (2012). Labor market friction, firm heterogeneity, and aggregate employment and productivity. University of Wisconsin Discussion Paper.

Lise, J. and J.-M. Robin (2017). The macrodynamics of sorting between workers and firms. American Economic Review 107(4), 1104-35.

Luttmer, E. G. (2010). Models of growth and firm heterogeneity. Annu. Rev. Econ. 2(1), 547-576.

Manova, K. and Z. Zhang (2012). Export prices across firms and destinations. The Quarterly Journal of Economics 127, 379-436.

Martellini, P. and G. Menzio (2018). Declining search frictions, unemployment and growth. Technical report, National Bureau of Economic Research.

Matsuyama, K. (1992). A simple model of sectoral adjustment. The Review of Economic Studies 59(2), $375-387$.

McGrattan, E. R. and E. C. Prescott (2009). Openness, technology capital, and development. Journal of Economic Theory $144(6), 2454-2476$.

Melitz, M. J. (2003). The impact of trade on intra-industry reallocations and aggregate industry productivity. Econometrica 71(6), 1695-1725.

Merz, M. and E. Yashiv (2007). Labor and the market value of the firm. The American Economic Review 97(4), 1419-1431.

Molina, D. and M.-A. Muendler (2013). Preparing to export. Technical report, National Bureau of Economic Research.

Morales, E., G. Sheu, and A. Zahler (2014). Extended gravity. Technical report, mimeo, Princeton University.

Mortensen, D. T. (2000). Equilibrium unemployment with wage posting: Burdett-mortensen meet pissarides. Contributions to Economic Analysis 243, 281-292.

Moscarini, G. and F. Postel-Vinay (2013). Stochastic search equilibrium. The Review of Economic Studies, rdt012.

Moscarini, G. and F. Postel-Vinay (2016). Did the job ladder fail after the great recession? Journal of Labor Economics 34(S1), S55-S93.

Moscarini, G. and F. Postel-Vinay (2017). The job ladder: Inflation vs. reallocation. Draft, Yale University.

Nickell, S. (1997). Unemployment and labor market rigidities: Europe versus north america. The Journal of Economic Perspectives 11(3), 55-74.

Nickell, S. and R. Layard (1999). Labor market institutions and economic performance. Handbook of labor economics 3, 3029-3084.

Nocke, V. and S. Yeaple (2014). Globalization and multiproduct firms. International Economic Review 55(4), 993-1018.

OECD (2010). OECD Employment Outlook 2010: Moving Beyond the Jobs Crisis. Organisation for Economic Co-operation and Development. 
Papageorgiou, T. (2013). Learning your comparative advantages. The Review of Economic Studies, rdt048.

Papp, T. K. (2013). Frictional wage dispersion with bertrand competition: an assessment. Review of Economic Dynamics 16(3), 540-552.

Pissarides, C. A. (1985). Short-run equilibrium dynamics of unemployment, vacancies, and real wages. The American Economic Review 75(4), 676-690.

Pissarides, C. A. (2000). Equilibrium unemployment theory. MIT press.

Postel-Vinay, F. and J.-M. Robin (2002). The distribution of earnings in an equilibrium search model with state-dependent offers and counteroffers. International Economic Review 43(4), 989-1016.

Redding, S. and A. J. Venables (2004). Economic geography and international inequality. Journal of international Economics 62(1), 53-82.

Ridder, G. and G. J. van den Berg (2003). Measuring labor market frictions: a cross-country comparison. Journal of the European Economic Association 1(1), 224-244.

Salas, J. (2018). Drivers of spain export performance and the role of the labor market reforms. IMF Working Paper 18/283.

Schaal, E. (2012). Uncertainty, productivity and unemployment in the great recession. Federal Reserve Bank of Minneapolis, mimeo.

Schaal, E. and M. Taschereau-Dumouchel (2016). Aggregate demand and the dynamics of unemployment. Technical report, unpublished manuscript.

Seker, M. (2012). Rigidities in employment protection and exporting. World Development 2(40), 238-250.

Shimer, R. (2005). The assignment of workers to jobs in an economy with coordination frictions. Journal of Political Economy 113(5), 996-1025.

Shimer, R. and L. Smith (2000). Assortative matching and search. Econometrica 68(2), 343-369.

Wang, F., C. Milner, and J. Scheffel (2018). Labour market reform, firm-level employment adjustment and trade liberalisation. Technical report.

Zhelobodko, E., S. Kokovin, M. Parenti, and J.-F. Thisse (2012). Monopolistic competition: Beyond the constant elasticity of substitution. Econometrica 80(6), 2765-2784.

\section{A Additional Expressions and Derivations}

\section{A.1 Appendix to Section 3.2 (Firm Revenues)}

Exporter Revenue Premium I characterize the revenue premium in an environment with $K+1$ countries indexed by $j=0, . ., K$, where $j=0$ denotes the home country. This environment can be specialized to the benchmark model and to the extension with multiple destinations. The derivations in this section follow from CES demand and monopolistic competition; i.e., they do not rely on either the quality choice discussed in the next section or features of the labor market environment. In each country $j$, aggregate output of the final good results from combining imported varieties $i$,

$$
Y_{j}=\left(\int_{i \in I_{j}} z_{j}(i)^{1 / \sigma} q_{j}(i)^{(\sigma-1) / \sigma} d i\right)^{\sigma /(\sigma-1)},
$$

where $I_{j}$ is the set of varieties from any origin available in country $j$. Each differentiated variety is produced by a different firm. $z_{j}(i)$ and $q_{j}(i)$ respectively denote the quality and the quantity at which firm $i$ sells its variety in 
country $j$. Using (31), we obtain the inverse demand for each variety. From that inverse demand, the price in country $j$ of a variety with quality $z_{j}(i)=z$ sold in quantity $q_{j}(i)=q_{j}$ is

$$
\left(\frac{z}{q_{j}}\right)^{1 / \sigma} P_{j} Y_{j}^{1 / \sigma}
$$

where $P_{j}$ is the price index in market $j$. Consider the problem of a firm located in the home country that produces $q$ units of output with quality $z$ which are then shipped to markets 1 to $k \leq K$ in addition to the home market. The decision to export is characterized in the text, and here it is taken as given. Given the set of export destinations $j=1,2, . ., k$, the choice variables for the firm are the fractions $s_{j}^{k}$ of total output $q$ allocated to each markets. Because of iceberg trade $\operatorname{costs} \tau_{j}>1$ to market $j$, only $\left(1 / \tau_{j}\right) s_{j}^{k} q$ units are exported to market $j$, the quantity $\left(1-1 / \tau_{j}\right) s_{j}^{k} q$ being used shipping the good. Using (32), gross revenues of a firm selling to $k$ markets are

$$
\begin{aligned}
r_{k}(z, q) & =\max _{\left\{s_{j}^{k}\right\}_{j=0}^{k}}\left\{z^{1 / \sigma} q^{1-1 / \sigma} \sum_{j=0}^{k} P_{j} Y_{j}^{1 / \sigma}\left(\frac{s_{j}^{k}}{\tau_{j}}\right)^{1-1 / \sigma} \text { s.t. } \sum_{j=0}^{k} s_{j}^{k}=1\right\} \\
& =y_{k} z^{1 / \sigma} q^{1-1 / \sigma} .
\end{aligned}
$$

In the last expression, $y_{k}$ is the revenue per quality-adjusted unit of output for a firm that exports to markets 0 to $k$,

$$
y_{k}=\left(\sum_{j=0}^{k} A_{j}\right)^{1 / \sigma}
$$

where

$$
A_{j} \equiv \tau_{j}^{-(\sigma-1)} P_{j}^{\sigma} Y_{j}
$$

From the aggregate budget constraint, aggregate expenditures equal aggregate income, $P_{j} Y_{j}=\left(1-u_{j}\right) y_{j}$, where $y_{j}$ is income per employed worker in $j$. Conditions (4) and (5) follow from assuming only one export market $(K=1)$, letting $A_{1}=A$, using $\tau_{0}=1$, and letting the final good be the numeraire. The revenue premium relative to a firm that only sells domestically is:

$$
\Gamma_{k} \equiv \frac{y_{k}}{y_{0}}=\left(1+\sum_{j=1}^{k} \frac{A_{j}}{Y_{0}}\right)^{1 / \sigma}
$$

Equation (34) follows from evaluating the revenue function at the optimal output shares allocated to each destination that solves the maximization problem in (33),

$$
s_{j}^{k}=\frac{P_{j}^{\sigma} Y_{j} \tau_{j}^{1-\sigma}}{\sum_{j^{\prime}=0}^{k} P_{j^{\prime}}^{\sigma} Y_{j^{\prime}} \tau_{j^{\prime}}^{1-\sigma}} .
$$

Note that $s_{j}^{k}$ is also the share of market $j$ in firm revenues. ${ }^{60}$ Combining (38) and (37) implies

$$
s_{j}^{k}=\left(\frac{P_{j} Y_{j}^{1 / \sigma}}{Y_{0}^{1 / \sigma}}\right)^{\sigma} \tau_{j}^{-(\sigma-1)} \Gamma_{k}^{-\sigma},
$$

so that the domestic revenue share of an exporter to $k$ markets is $s_{0}^{k}=\Gamma_{k}^{-\sigma}$.

Quality Choice I assume that workers are perfect substitutes within the firm between production of quality $z$ and quantity $q$. The number of workers in the firm, $n$, is determined over time through the process of labor search characterized in the text. A firm with $n$ workers and productivity $\psi$ that sells to markets $j=0, . ., k$ solves

$$
\max _{z, q} r_{k}(z, q) \text { s.t. }(1 / \sigma) z+(1-1 / \sigma) q=\psi n
$$

${ }^{60}$ I.e., it can be verified that $s_{j}^{k}=\frac{p_{j}\left(s_{j}^{k} / \tau_{j}\right)^{1-1 / \sigma} z^{1 / \sigma} q^{1-1 / \sigma}}{\sum_{j^{\prime}=0}^{k} p_{j^{\prime}}\left(s_{j^{\prime}}^{k} / \tau_{j^{\prime}}\right)^{1-1 / \sigma} z^{1 / \sigma} q^{1-1 / \sigma}}$. 
where $r_{k}(z, q)$ is given in (34). The introduction of the parameter $\sigma$ in the constraint of this firm problem only serves the purpose of saving notation. The optimal allocation of workers between producing quantity $q$ and quality $z$ resulting from (40) implies that quantity and quality increase linearly with the stock of workers, regardless of the firm's export status:

$$
z=q=\psi n .
$$

Using (41) into the revenue function (34), the total real revenues of a firm located in market $j=0$ with $n$ workers exporting to markets $j=1, . ., k$ is

$$
y_{k} \psi n,
$$

which corresponds to (3) when $K=1$, the home market is denoted by $D$, and the foreign market is denoted by $X$. Note that the linearization of the revenue function implies that the "love for variety" component of welfare is neutralized. To see why, consider aggregate real income in a closed economy where all firms have productivity $\psi$. Letting $z$ and $q$ be the quality and productivity of every firm, from $(31)$ we have $Y=(M q)^{\sigma /(\sigma-1)}=((1-u) \psi)^{\sigma /(\sigma-1)}$ where the first equality follows from (41) and the second from the fact that, with symmetric firms, $q M=\psi(1-u)$. Hence, the measure of firms does not impact aggregate real income directly. However, love for variety could be easily reintroduced as in Benassy (1998) and Acemoglu et al. (2007), among others, by including the measure of firms elevated to some power as an additional term in front of the definition of aggregate real income.

\section{A.2 Appendix to Section 3.3 (Job Values)}

I present the solution for the value of a new job in an economy where the CDF of the sampling distribution (i.e., of the probability that a worker samples a firm offering jobs with value lower than $v)$ is $P_{v}(v)$ with bounded support $\left[v_{\min }, v_{\max }\right]$. Firms are heterogeneous in terms of age $a$ and of an age-invariant firm type $\varepsilon=\left(\psi, f_{X}\right)$ where $\psi$ is firm productivity and $f_{X}$ is the cost of investing, $f_{X}$. At age $a$, firm $\varepsilon$ makes revenue per worker of $r(a, \varepsilon)$.

Let $V(a, \varepsilon)$ be the value of a match in firm $(a, \varepsilon), W(w, a ; \varepsilon)$ be the value received by a worker who is employed in a firm of type $\varepsilon$ and age $a$ who has committed to pay wage $w$, and $\beta$ be the worker bargaining power. When an employed worker contacts a potential employer then the worker and the competing employers start a bargaining process as in Cahuc et al. (2006). If a worker employed in firm $(a, \varepsilon)$ at wage $w$ contacts a prospective employer $\left(a_{0}, \varepsilon_{0}\right)$ such that $V\left(a_{0}, \varepsilon_{0}\right)<V(a, \varepsilon)$ (so that the prospective employer offers a job of lower value than the current employer) then, if it is to the worker's advantage, a wage renegotiation starts in which the worker uses the value in the competing employer as fallback position and remains with the current employer $(a, \varepsilon)$ at the wage $w\left(a_{0}, \varepsilon_{0}, a, \varepsilon\right)$ that guarantees a value for the worker of $W\left(w\left(a_{0}, \varepsilon_{0}, a, \varepsilon\right), a ; \varepsilon\right)=V\left(a_{0}, \varepsilon_{0}\right)+\beta\left(V(a, \varepsilon)-V\left(a_{0}, \varepsilon_{0}\right)\right)$. When the worker contacts a prospective employer $\left(a_{1}, \varepsilon_{1}\right)$ such that $V(a, \varepsilon)<V\left(a_{1}, \varepsilon_{1}\right)$, a re-negotiation is triggered ending up with the worker transitioning to firm $\left(a_{1}, \varepsilon_{1}\right)$ who commits to pay the wage $w\left(a, \varepsilon, a_{1}, \varepsilon_{1}\right)$ such that the value for the worker is $W\left(w\left(a, \varepsilon, a_{1}, \varepsilon_{1}\right), a_{1} ; \varepsilon_{1}\right)=V(a, \varepsilon)+\beta\left(V\left(a_{1}, \varepsilon_{1}\right)-V(a, \varepsilon)\right)$. The value for the new employer is $V\left(a_{1}, \varepsilon_{1}\right)-\left[V(a, \varepsilon)+\beta\left(V\left(a_{1}, \varepsilon_{1}\right)-V(a, \varepsilon)\right)\right]=(1-\beta)\left(V\left(a_{1}, \varepsilon_{1}\right)-V(a, \varepsilon)\right)$.

Hence, a worker employed in firm $(a, \varepsilon)$ at wage $w$ experiences a wage renegotiation (and potentially a transition to another job) whenever the worker contacts a firm offering jobs whose value $v>\frac{W(w, a, \varepsilon)-\beta V(a, \varepsilon)}{1-\beta}$. The flow-value of a job for a worker employed in firm $(a, \varepsilon)$ at wage $w$ is:

$$
\begin{aligned}
(\rho+\delta) W(w, a, \varepsilon) & =w+\delta U+\lambda_{e}\left(\int_{\frac{W(w, a, \varepsilon)-\beta V(a, \varepsilon)}{1-\beta}}^{V(a, \varepsilon)}[(1-\beta) v+\beta V(a, \varepsilon)-W(w, a, \varepsilon)] d P_{v}(v)\right) \\
& +\lambda_{e} \int_{\min \left[V(a, \varepsilon), v_{\max }\right]}^{v_{\max }}[(1-\beta) V(a, \varepsilon)+\beta v-W(w, a, \varepsilon)] d P_{v}(v)+\frac{d W}{d a}
\end{aligned}
$$

which, integrating by parts, can be re-written as follows:

$(\rho+\delta) W(w, a, \varepsilon)=w+\delta U+\lambda_{e}\left[(1-\beta) \int_{\frac{W(w, a, \varepsilon)-\beta V(a, \varepsilon)}{1-\beta}}^{V(a, \varepsilon)}\left[1-P_{v}(v)\right] d v+\beta \int_{\min \left[V(a, \varepsilon), v_{\max }\right]}^{v_{\max }}\left[1-P_{v}(v)\right] d v\right]+\frac{d W}{d a}$ 
Similarly, because when a match ends there is no value for the firm, the value for the firm $(a, \varepsilon)$ of employing a worker at wage $w$ is

$$
\begin{aligned}
(\rho+\delta) J(w, a, \varepsilon) & =r(a, \varepsilon)-w+\lambda_{e} \int_{\frac{W(w, a, \varepsilon)-\beta V(a, \varepsilon)}{1-\beta}}^{V(a, \varepsilon)}[(1-\beta)(V(a, \varepsilon)-v)-J(w, a, \varepsilon)] d P_{V}(v) \\
& +\lambda_{e} \int_{\min \left[V(a, \varepsilon), v_{\max }\right]}^{v_{\max }}[-J(w, a, \varepsilon)] d P_{V}(v)+\frac{d J}{d a}
\end{aligned}
$$

Adding up (42) and (44), the value of the job is:

$$
\begin{aligned}
(\rho+\delta) V(a, \varepsilon) & =r(a, \varepsilon)+\delta U+\lambda_{e} \int_{\frac{W(w, a, \varepsilon)-\beta V(a, \varepsilon)}{1-\beta}}^{V(a, \varepsilon)}[(1-\beta) v+\beta V(a, \varepsilon)+(1-\beta)(V(a, \varepsilon)-v)-V(a, \varepsilon)] d P_{v}(v) \\
& +\lambda_{e} \int_{\min \left[V(a, \varepsilon), v_{\max }\right]}^{v_{\max }}[(1-\beta) V(a, \varepsilon)+\beta v-V(a, \varepsilon)] d P_{v}(v)+\frac{d V}{d a}
\end{aligned}
$$

According to this expression, as long as the worker gets an offer above $\frac{W(w, a, \varepsilon)-\beta V(a, \varepsilon)}{1-\beta}$ but below $V(a, \varepsilon)$ there is no change in value; instead, only redistribution from the firm to the worker takes place. However, when the worker draws an offer above $V(a, \varepsilon)$, the total surplus increases by the fraction that the worker is able to extract from the new firm. We can re-write the last expression as

$$
\rho V(a, \varepsilon)=r(a, \varepsilon)+\delta(U-V(a, \varepsilon))+\lambda_{e} \beta \int_{\min \left[V(a, \varepsilon), v_{\max }\right]}^{v_{\max }}(v-V(a, \varepsilon)) d P_{v}(v)+\frac{d V}{d a} .
$$

Integrating by parts, expression (45) for the value of a job held by firm $\varepsilon$ at age $a$ can be written as

$$
\rho V(a, \varepsilon)=r(a, \varepsilon)+\delta(U-V(a, \varepsilon))+\lambda_{e} \beta\left[Z(V(a, \varepsilon))+\max \left(v_{\min }-V(a, \varepsilon), 0\right)\right]+\frac{d V}{d a}
$$

where

$$
Z(v) \equiv \int_{\min \left[\max \left(v, v_{\min }\right), v_{\max }\right]}^{v_{\max }}\left[1-P_{v}\left(v_{0}\right)\right] d v_{0}
$$

Consider now the case with one investment option from the benchmark model. The investment age, $h$, is a deterministic function of the firm type, $\varepsilon=\left(\psi, f_{X}\right)$. A firm $\varepsilon$ who invests at age $h$ has revenue per worker $r(a, \varepsilon)=\psi y_{D}$ for $a<h$ and $r(a, \varepsilon)=\psi y_{X}$ for $a \geq h$. The flow equivalent value of a job held by this firm at age $a$ therefore is given by

$$
(\rho+\delta) V(a, \varepsilon)= \begin{cases}\psi y_{D}+\delta U+\lambda_{e} \beta\left[Z(V(a, \varepsilon))+\max \left(v_{\min }-V(a, \varepsilon), 0\right)\right]+\frac{\partial V(a, \varepsilon)}{\partial a} & \text { for } a \leq h(\varepsilon) \\ \psi y_{X}+\delta U+\lambda_{e} \beta\left[Z(V(h(\varepsilon), \varepsilon))+\max \left(v_{\min }-V(h(\varepsilon), \varepsilon), 0\right)\right] & \text { for } a>h(\varepsilon) .\end{cases}
$$

The fixed cost $f_{X}$ only impacts the value of a job through the age of investing. Hence the value of a job in firm of type $\varepsilon=\left(\psi, f_{X}\right)$ who will invest after the next $h-a$ periods can be defined as $v(h(\varepsilon)-a, \psi) \equiv V(a, \varepsilon)$. Using the change of variables $x=\max (h-a, 0)$, the value of the job (48) can be re-written as shown in (10) and (11) in the text.

Using the definition of $Z(v)$ in (47) and integrating (10) forward, the value of the job in a firm that has not yet invested is:

$$
v(x ; \psi)=\left\{\begin{array}{ll}
v_{\min } e^{\left(\rho+\delta+\lambda_{e} \beta\right)\left(h_{\min }(\psi)-x\right)}+\frac{\psi y_{D}+\delta U+\lambda_{e} \beta\left[Z\left(v_{\min }\right)+v_{\min }\right]}{\rho+\delta+\lambda_{e} \beta}\left(1-e^{\left(\rho+\delta+\lambda_{e} \beta\right)\left(h_{\min }(\psi)-x\right)}\right) & x>h_{\min }(\psi) \\
\frac{\psi y_{D}+\delta U}{\rho+\delta}+e^{-(\rho+\delta) x}\left(v(0 ; \psi)-\frac{\psi y_{D}+\delta U}{\rho+\delta}\right)+\lambda_{e} \beta \int_{0}^{x} e^{-(\rho+\delta)\left(x-x^{\prime}\right)} Z\left(v\left(x^{\prime} ; \psi\right)\right) d x^{\prime} & x \in\left[0, h_{\min }(\psi)\right]
\end{array},\right.
$$

where we have defined $h_{\min }(\psi)$ such that $v\left(h_{\min }(\psi) ; \psi\right)=v_{\min }$, if it exists (otherwise, $\left.h_{\min }(\psi)=\infty\right)$. The initial condition $v(0 ; \psi)$ corresponds to the value of a job in a firm with productivity $\psi$ who has already invested. Using 
the definition of $Z(v)$ in (47) and (11), it is implicitly determined as the solution to:

$$
v(0 ; \psi)=\frac{\psi y_{X}+\delta U+\lambda_{e} \beta Z(v(0 ; \psi))}{\rho+\delta} .
$$

Since $Z^{\prime}(v)=-\left[1-P_{V}(v)\right] \leq 0$, there is a a unique solution for $v(0 ; \psi)$.

\section{A.3 Appendix to Section 3.5 (Stock Effect and Timing of Export Entry)}

I derive expression 20 for the value of a firm at entry. First, take the derivative of $\Pi(h ; \varepsilon)$ in $(16)$ to reach

$$
\begin{aligned}
\Pi^{\prime}(h ; \varepsilon) & =\int_{0}^{h} e^{-(\rho+\mu) a} \pi^{\prime}(v(h-a) ; \psi) v^{\prime}(h-a ; \psi) d a+e^{-(\rho+\mu) h} f_{X} \\
& =\pi(v(h ; \psi))-e^{-(\rho+\mu) h} \pi(v(0 ; \psi))-(\rho+\mu) \int_{0}^{h} e^{-(\rho+\mu) a} \pi(v(h-a ; \psi)) d a+e^{-(\rho+\mu) h} f_{X}
\end{aligned}
$$

where the second line follows from integrating by parts. Rearranging terms and using (16) implies that the value at entry of a type $\varepsilon$ firm in (16) can be written

$$
\Pi(h ; \varepsilon) \equiv \frac{\pi(v(h ; \varepsilon))-\Pi^{\prime}(h ; \varepsilon)}{\rho+\mu} .
$$

This expression holds generically for any $h$. However, in an interior solution to the firm's maximization problem, a firm of type $\varepsilon$ chooses $h$ such that $\Pi^{\prime}(h ; \varepsilon)=0$. Applying this condition gives 20 .

\section{A.4 Appendix to Section 3.6 (Definition of the General Equilibrium)}

Optimal Search Effort Using (7) and (9), (15) can be written:

$$
\pi(v)=\max _{s \geq 0}(1-\beta) \pi_{0}(v) q_{u} s-s^{\zeta},
$$

where

$$
\pi_{0}(v) \equiv(v-U)+\kappa_{e} \int_{v_{\min }}^{v} G_{v}\left(v_{0}\right) d v_{0} .
$$

Therefore the optimal search effort satisfies the first order condition

$$
s(v)=\left((1-\beta) q_{u} \frac{\pi_{0}(v)}{\zeta}\right)^{1 /(\zeta-1)},
$$

Replacing the solution for the optimal search effort $s(v)$ from (53) into (51), the maximized present discounted value for the firm from all the new hires, is:

$$
\begin{aligned}
\pi(v) & \equiv(1-\beta) \pi_{0}(v) q_{u} s(v)-s(v)^{\zeta} \\
& =(\zeta-1) s(v)^{\zeta}
\end{aligned}
$$

Sampling Distribution Let

$$
s^{*}(a ; \varepsilon) \equiv s(v(h(\varepsilon)-a ; \psi))
$$

be the search effort exerted by a firm of type $\varepsilon$ at age $a$. The probability that a worker samples a firm offering jobs with value lower than $v$ is

$$
P_{v}(v)=\mathbb{E}_{\varepsilon}\left[\int_{0}^{a(v ; \varepsilon)} \frac{s^{*}(a ; \varepsilon)}{\bar{s}} \mu e^{-\mu a} d a\right],
$$

where the limit of integration $a\left(v_{0} ; \varepsilon\right)=\sup \left\{a: v(h(\varepsilon)-a ; \varepsilon) \leq v_{0}\right\}$ is the age at which firm type $\varepsilon$ attains the value 
$v_{0}$ and where $\mathbb{E}_{\varepsilon}$ denotes the expectation over the distribution of firm types, $\varepsilon .{ }^{61}$ Using (53), we can further write

$$
P_{v}(v)=\frac{\mathbb{E}_{\varepsilon}\left[\int_{0}^{a(v ; \varepsilon)} \pi_{0}(v(h(\varepsilon)-a ; \varepsilon))^{1 /(\zeta-1)} e^{-\mu a} d a\right]}{\mathbb{E}_{\varepsilon}\left[\int_{0}^{\infty} \pi_{0}(v(h(\varepsilon)-a ; \varepsilon))^{1 /(\zeta-1)} e^{-\mu a} d a\right]} .
$$

Using (52), this functional equation gives $P_{v}(v)$ given the equilibrium objects $\left\{\lambda_{e}, U, a(v ; \varepsilon)\right\}$. This function yields the share of employment in firms with value of jobs below $v,{ }^{62}$

$$
G_{v}(v)=\frac{P_{v}(v)}{1+\kappa_{e}\left[1-P_{v}(v)\right]}
$$

Firm Size Let $N(a ; \varepsilon)$ be the number of workers employed by a firm of age $a$ and type $\varepsilon$. Conditional on firm type $\varepsilon$ not exiting the market, firm size evolves according to

$$
N^{\prime}(a ; \varepsilon)=q_{u} s^{*}(a ; \varepsilon)\left[1+\kappa_{e} G_{v}(V(a, \varepsilon))\right]-\left[\gamma+\lambda_{e}\left(1-P_{v}(V(a, \varepsilon))\right)\right] N(a ; \varepsilon)
$$

where $V(a, \varepsilon) \equiv v(h(\varepsilon)-a ; \psi)$ is the value of jobs offered by firm of age $a$ and type $\varepsilon=\left(\psi, f_{X}\right)$. Integrating we get

$$
N(a, \varepsilon)=q_{u} \int_{0}^{a} s^{*}(a ; \varepsilon)\left[1+\kappa_{e} G_{v}\left(V\left(a^{\prime} ; \varepsilon\right)\right)\right] e^{\gamma\left(a^{\prime}-a\right)-\lambda_{e} \int_{a^{\prime}}^{a}\left(1-P_{v}\left(V\left(a^{\prime \prime} ; \varepsilon\right)\right)\right) d a^{\prime \prime}} d a^{\prime} .
$$

Therefore, normalizing by the average firm size we have

$$
n(a ; \varepsilon)= \begin{cases}\frac{N(a, \varepsilon)}{\mathbb{E}_{\varepsilon, a}[N(a, \varepsilon)]} & \text { if } \Pi^{e}(\varepsilon) \geq 0 \\ 0 & \text { otherwise }\end{cases}
$$

For the proof of Proposition (1) below, it is useful to write this expression explicitly. Using (53) and $(60)$, if $\Pi^{e}(\varepsilon) \geq 0$ then:

$$
n(a ; \varepsilon)=\frac{\int_{0}^{a} \pi_{0}\left(V\left(a^{\prime}, \varepsilon\right)\right)^{1 /(\zeta-1)}\left[1+\kappa_{e} G_{v}\left(V\left(a^{\prime} ; \varepsilon\right)\right)\right] e^{\gamma\left(a^{\prime}-a\right)-\lambda_{e} \int_{a^{\prime}}^{a}\left(1-P_{v}\left(V\left(a^{\prime \prime} ; \varepsilon\right)\right)\right) d a^{\prime \prime}} d a^{\prime}}{\mathbb{E}_{\varepsilon, a_{0}}\left[\int_{0}^{a_{0}} \pi_{0}\left(V\left(a^{\prime}, \varepsilon\right)\right)^{1 /(\zeta-1)}\left[1+\kappa_{e} G_{v}\left(V\left(a^{\prime} ; \varepsilon\right)\right)\right] e^{\gamma\left(a^{\prime}-a\right)-\lambda_{e} \int_{a^{\prime}}^{a}\left(1-P_{v}\left(V\left(a^{\prime \prime} ; \varepsilon\right)\right)\right) d a^{\prime \prime}} d a^{\prime}\right]}
$$

\section{A.5 Appendix to Section 6.4 (Multiple Export Destinations)}

This section shows that the solution to the firm investment problem under multiple markets is given by (29) and (30), where the stock effect is defined as:

$$
S_{j}\left(h_{j}, h_{j+1}, . ., h_{K} ; \psi\right) \equiv \int_{0}^{h_{j}} e^{(\rho+\mu) x_{j}}\left[-\pi_{j}\left(\mathbf{x}_{j} ; \psi\right)\right] d x_{j} \text { for } j>1,
$$

where $\pi_{j}\left(\mathbf{x}_{j} ; \psi\right)$ denotes the partial derivative of $\pi(v(\boldsymbol{x} ; \psi))$ with respect to $x_{j}$ evaluated at $\mathbf{x}_{j}$, where each element of $\mathbf{x}_{j}$ is the time until entry to each market for a firm that has entered market $j-1$ but is still $x_{j}$ periods away from entering market $j$, i.e.:

$$
\mathbf{x}_{j}=\{\underbrace{0, \ldots, 0}_{j-1 \text { times }}, x_{j}, x_{j}+h_{j+1}, . ., x_{j}+h_{j+1}+\ldots+h_{K}\}
$$

To prove the result, note first that we can follow similar arguments to the model with a single investment option to characterize the value of all new hires as in $\pi(v)$ in (15). Using (28), following similar steps to solve for the optimal

\footnotetext{
${ }^{61}$ By definition the average search intensity is $\bar{s}=\mathbb{E}_{\varepsilon}\left[\int_{0}^{\infty} s^{*}(a ; \varepsilon) \mu e^{-\mu a} d a\right]$, so that $P_{v}\left(v_{\max }\right)=1$.

${ }^{62}$ This is obtained by setting $d G_{v}(v)=0$ in the equation describing the evolution of $G_{v}(v):(1-u) d G_{v}(v)=$ $u \lambda_{u} P_{v}(v)-\left(\delta+\lambda_{e}\left(1-P_{v}(v)\right)\right)(1-u) G_{v}(v)$.
} 
search intensity as in Appendix A.4, and imposing $\lambda_{e} \beta=0$, we obtain:

$$
\begin{aligned}
\pi_{k}(\boldsymbol{x} ; \psi) & \equiv \frac{\partial \pi_{v}(v(\boldsymbol{x} ; \psi))}{\partial x_{k}} \\
& =-\left((1-\beta) q_{u}\right)^{\zeta /(\zeta-1)}\left(\frac{\pi_{0}(v(\boldsymbol{x} ; \psi))}{\zeta}\right)^{1 /(\zeta-1)} \frac{1+\kappa_{e}}{1+\kappa_{e}\left[1-P_{v}(v(\boldsymbol{x} ; \psi))\right]} \psi\left(y_{k}-y_{k-1}\right) e^{-(\rho+\delta) x_{k}}
\end{aligned}
$$

In parallel to $(16)$, let $\Pi\left(h_{1}, h_{2}, . ., h_{K}\right)$ be the value at entry of a firm that enters export markets $k=1,2, . ., K$ at ages $H_{k}=\sum_{j=1}^{k} h_{j}$. Defining this value at entry involves more than in the simpler case with one investment option. It is convenient to define $\mathbf{1}_{i}$ as the length- $K$ vector

$$
\mathbf{1}_{i}=\{\underbrace{0, \ldots, 0}_{i-1 \text { times }}, 1, . ., 1\}
$$

and $\mathbf{h}_{i+1}$ as

$$
\mathbf{h}_{i+1}=\{\underbrace{0, \ldots, 0}_{i \text { times }}, h_{i+1}, h_{i+1}+h_{i+2}, h_{i+1}+h_{i+2}+h_{i+3}, . ., h_{i+1}+h_{i+2}+\ldots+h_{K}\} .
$$

Using this notation, we can recursively define $\Pi_{i}\left(\mathbf{h}_{i+1} ; \varepsilon\right)$ as the value of a type- $\varepsilon$ firm at the moment of entry to market $i$,

$$
\begin{aligned}
\Pi_{i}\left(\mathbf{h}_{i+1} ; \varepsilon\right) & =\int_{0}^{h_{i+1}} e^{-(\rho+\mu)\left(h_{i+1}-x_{i+1}\right)} \pi_{v}\left(v\left(x_{i+1} \mathbf{1}_{i+1}+\mathbf{h}_{i+2} ; \psi\right)\right) d x_{i+1} \\
& +e^{-(\rho+\mu) h_{i+1}}\left(\Pi_{i+1}\left(\mathbf{h}_{i+2} ; \varepsilon\right)-\frac{f_{i+1}}{\rho+\mu}\right) \text { for } i<K
\end{aligned}
$$

where, at the next-to-last market,

$$
\Pi_{K-1}\left(h_{K} ; \varepsilon\right)=\int_{0}^{h_{K}} e^{-(\rho+\mu)\left(h_{K}-x_{K}\right)} \pi_{v}\left(v\left(x_{K} \mathbf{1}_{K} ; \psi\right)\right) d x_{K}+e^{-(\rho+\mu) h_{K}} \frac{\pi_{v}(v(0,0, . ., 0 ; \psi))-f_{K}}{\rho+\mu} .
$$

Therefore, the value at entry is $\Pi\left(\mathbf{h}_{1} ; \varepsilon\right)=\Pi_{0}\left(\mathbf{h}_{1} ; \varepsilon\right)$. The firm's problem is now defined as $\max _{\mathbf{h}_{1}} \Pi\left(\mathbf{h}_{1} ; \varepsilon\right)$. After some manipulations we can express the derivative of the profit function with respect to each entry time as

$$
\frac{\partial \Pi\left(\mathbf{h}_{1} ; \varepsilon\right)}{\partial h_{1}}=\sum_{i=1}^{K} e^{-(\rho+\mu) H_{i}}\left(\int_{0}^{h_{i}} e^{(\rho+\mu) x_{i}} \frac{d \pi\left(x_{i} \mathbf{1}_{i}+\mathbf{h}_{i+1} ; \psi\right)}{d x_{i}} d x_{i}+f_{i}\right),
$$

and

$$
\begin{aligned}
\frac{\partial \Pi\left(\mathbf{h}_{1} ; \varepsilon\right)}{\partial h_{j}} & =\sum_{i=1}^{j-1} \int_{0}^{h_{i}} e^{(\rho+\mu)\left(x_{i}-H_{i}\right)} \frac{d \pi\left(x_{i} \mathbf{1}_{i}+\mathbf{h}_{i+1} ; \psi\right)}{d h_{j}} d x_{i} \\
& +\sum_{i=j}^{K} e^{-(\rho+\mu) H_{i}}\left(\int_{0}^{h_{i}} e^{(\rho+\mu) x_{i}} \frac{d \pi\left(x_{i} \mathbf{1}_{i}+\mathbf{h}_{i+1} ; \psi\right)}{d x_{i}} d x_{i}+f_{i}\right)
\end{aligned}
$$

for $j>1$. Note, in addition, that

$$
\begin{aligned}
& \frac{d \pi\left(x_{i} \mathbf{1}_{i}+\mathbf{h}_{i+1} ; \psi\right)}{d h_{j}}=\sum_{m=j}^{K} \pi_{m}\left(x_{i} \mathbf{1}_{i}+\mathbf{h}_{i+1} ; \psi\right) \text { for } j>i, \\
& \frac{d \pi\left(x_{i} \mathbf{1}_{i}+\mathbf{h}_{i+1} ; \psi\right)}{d x_{i}}=\sum_{m=i}^{K} \pi_{m}\left(x_{i} \mathbf{1}_{i}+\mathbf{h}_{i+1} ; \psi\right),
\end{aligned}
$$

where $\pi_{m}(\cdot ; \psi)$ denotes the partial derivative of $\pi(\cdot ; \psi)$ with respect to its $m^{\text {th }}$ argument. Combining (69) and (70) with (67) and (68), and imposing the first-order conditions $\frac{\partial \Pi\left(\mathbf{h}_{1} ; \varepsilon\right)}{\partial h_{i}}=0$ for all $i=1, . ., K$, we reach the set of 
conditions:

$$
\sum_{i=1}^{j} \int_{0}^{h_{i}} e^{(\rho+\mu)\left(x_{i}+H_{j}-H_{i}\right)} \pi_{j}\left(x_{i} \mathbf{1}_{i}+\mathbf{h}_{i+1} ; \psi\right) d x_{i}+f_{j}=0 \text { for all } j \geq 1 .
$$

Finally, note that (64) implies:

$$
\frac{\pi_{k+1}(\boldsymbol{x} ; \psi)}{\pi_{k}(\boldsymbol{x} ; \psi)}=e^{-(\rho+\delta)\left(x_{k+1}-x_{k}\right)}\left(\frac{y_{k+1}-y_{k}}{y_{k}-y_{k-1}}\right) .
$$

Using (72) we get that, for $j>i$,

$$
\frac{\pi_{j}\left(x_{i} \mathbf{1}_{i}+\mathbf{h}_{i+1} ; \psi\right)}{\pi_{j-1}\left(x_{i} \mathbf{1}_{i}+\mathbf{h}_{i+1} ; \psi\right)}=e^{-(\rho+\delta) h_{j}} \frac{y_{j}-y_{j-1}}{y_{j-1}-y_{j-2}}
$$

Evaluating (71) at $j$ and at $j+1$ together with (73) gives the result.

\section{B Proofs}

Proposition 1. Given $\lambda_{e}$, changes in the contact rate from unemployment $\lambda_{u}$ impact the employment allocation and the timing of investments $\{n(a ; \varepsilon), h(\varepsilon)\}$ only through general-equilibrium adjustments in revenue per unit sold $\left\{y_{D}, y_{X}\right\}$ or in the value of unemployment, $U$. Given $\lambda_{u}$, changes in the contact rate from employment $\lambda_{e}$ generically impact these outcomes regardless of whether $\left\{y_{D}, y_{X}, U\right\}$ may adjust.

Proof. Using (53) and (54), the free-entry condition (21) can be written:

$$
(\zeta-1)\left(q_{u} \frac{1-\beta}{\zeta}\right)^{\zeta /(\zeta-1)} \mathbb{E}_{\varepsilon}\left[\max \left\{\pi_{0}(v(h(\varepsilon) ; \psi))^{\zeta /(\zeta-1)}, 0\right\}\right]=f_{D}
$$

This condition defines the set of active firms in equilibrium, $\left\{\varepsilon: \pi_{0}(v(h(\varepsilon) ; \psi))^{\zeta /(\zeta-1)}>0\right\}$.

Given the value of jobs at entry $v(h(\varepsilon) ; \psi)$, the value of unemployment $U$, the contact rate from employment $\lambda_{e}$, and the sampling distribution, this free-entry condition pins down $q_{u}$. In turn, the integrand of the stock effect defined in (19) is $\pi_{v}^{\prime}(v(x ; \psi))\left[-v^{\prime}(x ; \psi)\right]$. The two components of this product can be written as follows. First, using (53) and (54), we have:

$$
\pi^{\prime}(v)=\left((1-\beta) q_{u}\right)^{\zeta /(\zeta-1)}\left(\frac{\pi_{0}(v)}{\zeta}\right)^{1 /(\zeta-1)} \frac{1+\kappa_{e}}{1+\kappa_{e}\left[1-P_{v}(v)\right]}
$$

Second, from (49), after some manipulations we can express the derivative of the value function with respect to the time until the investment in implicit form as follows:

$$
-e^{(\rho+\delta) x} v^{\prime}(x ; \psi)=\psi\left(y_{X}-y_{D}\right)+\lambda_{e} \beta \int_{0}^{x} e^{(\rho+\delta) x^{\prime}}\left(1-P_{v}\left(v\left(x^{\prime} ; \psi\right)\right)\right) v^{\prime}\left(x^{\prime} ; \psi\right) d x^{\prime} .
$$

Combining the first-order condition for optimal investment timing, (17), with the last two expressions, the timing $h(\varepsilon)$ for the optimal investment of firm type $\varepsilon=\left(\psi, f_{X}\right)$ is determined as the solution to:

$$
\begin{gathered}
\left(\frac{(1-\beta) q_{u}}{\zeta}\right)^{\zeta /(\zeta-1)} \zeta \int_{0}^{h} e^{-\gamma x} \pi_{0}(v(x ; \psi))^{1 /(\zeta-1)} \frac{1+\kappa_{e}}{1+\kappa_{e}\left[1-P_{v}(v(x ; \psi))\right]} * \\
*\left[\psi\left(y_{X}-y_{D}\right)+\lambda_{e} \beta \int_{0}^{x} e^{(\rho+\delta) x^{\prime}}\left(1-P_{v}\left(v\left(x^{\prime}\right)\right)\right) v^{\prime}\left(x^{\prime}\right) d x^{\prime}\right] d x \leq f_{X}
\end{gathered}
$$

with equality if $h(\varepsilon)<\infty$. Solving for the contact rate from unemployment $q_{u}$ from the free entry condition (74), 
the last expression becomes:

$$
\frac{\zeta}{\zeta-1} \frac{\int_{0}^{h(\varepsilon)} e^{-\gamma x} \pi_{0}(v(x ; \psi))^{1 /(\zeta-1)} \frac{1+\kappa_{e}}{1+\kappa_{e}\left[1-P_{v}(v(x ; \psi))\right]}\left[\psi\left(y_{X}-y_{D}\right)+\lambda_{e} \beta \int_{0}^{x} e^{(\rho+\delta) x^{\prime}}\left[1-P_{v}\left(v\left(x^{\prime} ; \psi\right)\right)\right] v^{\prime}\left(x^{\prime} ; \psi\right) d x^{\prime}\right] d x}{\mathbb{E}_{\varepsilon}\left[\max \left\{\pi_{0}(v(h(\varepsilon) ; \psi))^{\zeta /(\zeta-1)}, 0\right\}\right]} \leq \frac{f_{X}}{f_{D}}
$$

We can now partition the general-equilibrium objects from Definition (1) into three blocks:

$$
\begin{aligned}
& G E_{1}=\left\{v(x, ; \psi), P_{v}(v), G_{v}(v), n(a ; \varepsilon), h(\varepsilon)\right\} \\
& G E_{2}=\left\{\lambda_{e}, U, y_{D}, y_{X}\right\} \\
& G E_{3}=\left\{\lambda_{u}, q_{u}, M, u, y\right\} .
\end{aligned}
$$

Given $G E_{2}$, conditions (49), (57), (58), (62) and (77) jointly determine the objects in $G E_{1}$ independently from the objects in $G E_{3}$. Conditions (1), (2) for $i=e, u,(4),(5),(8),(13),(22)$, (74) jointly determine $G E_{2}$ and $G E_{3}$ given $G E_{1}$. We conclude that variables in $G E_{3}$ impact the variables in $G E_{1}$ only through $G E_{2}$. Hence, $\lambda_{u}$ only impacts the employment distribution $n(a ; \varepsilon)$ and the investment times $h(\varepsilon)$ if there are changes in $\left\{\lambda_{e}, U, y_{D}, y_{X}\right\}$. Moreover, in any counterfactual where $\lambda_{e}$ is kept constant but $\lambda_{u}$ changes (which are always feasible to implement -see Footnote 30 ), the variables in $G E_{3}$ are affected only if $G E_{2} \equiv\left\{U, y_{D}, y_{X}\right\}$ are allowed to change.

Proposition 2. Assume $\lambda_{e} \beta=0$, constant search effort s across firms and ex-ante homogeneous firms. Then, given $\left(\lambda_{e}, \lambda_{u}\right)$, there is a unique general equilibrium. Firms never invest at entry unless $f_{X}=0$, but eventually invest if and only if $f_{X}$ is below a finite threshold. Given $\Gamma$ : i) if $\beta>0$ and $\lambda_{e}=0$ then lower matching frictions from unemployment (higher $\lambda_{u}$ ) lead to faster export entry, a higher employment share in exporters, and higher income per employed worker if $z<\psi y_{D}$; and ii) if $\beta=0$ and $\lambda_{e}>0$ then lower matching frictions from employment (higher $\left.\lambda_{e}\right)$ also lead to these outcomes if $\sigma$ is sufficiently large or if $z=b y$ for some positive constant $b<\psi \frac{y_{D}}{y}$.

Proof. This proof proceeds under the following three additional assumptions on the full model from Definition 1: i) $\lambda_{e} \beta=0$; ii) the search effort $s$ is exogenously given, common across firms, and (to ease notation) normalized to one; and iii) there are no innate differences in productivity or in fixed costs across firms. Since all firms are identical, I drop the index $\psi$ from the value $v(x ; \psi)$ of a firm that is $x$ periods away from investing and write instead $v(x)$.

Now I establish the uniqueness of the equilibrium in the home economy given $\Gamma$, and then show that there is a unique $\Gamma$ consistent with the equilibrium. Using the consistency condition g) of the equilibrium Definition (1) and taking the ratio between the optimal timing condition (24) and the free entry condition (25) implies that, in equilibrium:

$$
\Omega(H) \equiv(\rho+\delta)(\Gamma-1)\left(1+\kappa_{e}\right) \frac{\int_{0}^{H} e^{-\gamma x}\left[1+\kappa_{e} e^{-\mu(H-x)}\right]^{-1} d x}{1-\rho \frac{U}{y_{D} \psi}+(\Gamma-1) e^{-(\rho+\delta) H}}=\frac{f_{X}}{f_{D}} .
$$

where we have used the fact that firms exit at constant rate $\mu$, so that $P_{v}(v(x))=1-e^{-\mu(H-x)}$. The value of unemployment defined in (8) is

$$
U=\frac{z+\beta \lambda_{u}\left[\int_{0}^{H} v(x) \mu e^{-\mu(H-x)} d x+e^{-\mu H} v(0)\right]}{\rho+\beta \lambda_{u}} .
$$

Replacing $v(x)$ from (23), and after manipulations, we obtain

$$
\rho U=\frac{\rho+\delta}{\rho+\delta+\lambda_{u} \beta} z+\frac{\beta \lambda_{u}}{\rho+\delta+\lambda_{u} \beta} \psi\left[y_{D}+\left(y_{X}-y_{D}\right) e^{-(\rho+\delta) H}\left(1+(\rho+\delta) \frac{1-e^{-\mu H}}{\mu}\right)\right] .
$$


Replacing this expression into (78), after some manipulations that condition becomes

$$
\Omega(H)=\frac{\left(\rho+\delta+\lambda_{u} \beta\right)(\Gamma-1)\left(1+\kappa_{e}\right) \int_{0}^{H} e^{-\gamma x}\left[1+\kappa_{e} e^{-\mu(H-x)}\right]^{-1} d x}{1-\frac{z}{\psi y_{D}}+\left(1+\frac{\beta \lambda_{u}}{\mu}\left(e^{-\mu H}-1\right)\right)(\Gamma-1) e^{-(\rho+\delta) H}}=\frac{f_{X}}{f_{D}}
$$

The numerator of this expression is strictly increasing with $H$. Using that $y_{D}$ decreases with $H$ we conclude that the denominator is decreasing with $H$, and so $\Omega(H)$ is strictly increasing. Therefore, given $\Gamma$, if an interior solution for $H$ exists it must be unique. In addition, $\Omega(0)=0$, so that the solution features $H>0$ as long as $\frac{f_{X}}{f_{D}}>0$. The solution for $H$ is finite if $f_{X} / f_{D}<\lim _{H \rightarrow \infty} \Omega(H, H)$.

Defining $\underline{\Gamma}$ as the exporter premium above which $H<\infty$ (i.e., such that that $\left.\lim _{H \rightarrow \infty} \Omega(H, H)=\frac{f_{X}}{f_{D}}\right)$ and $H(\Gamma)$ as the unique solution of $H$ as a function of $\Gamma$ resulting from (80) in that case, income per employed worker $y$ is the following function of $\Gamma$ :

$$
y(\Gamma)= \begin{cases}(1-u)^{\frac{1}{\sigma-1}} & \text { if } \Gamma<\underline{\Gamma} \\ (1-u)^{\frac{1}{\sigma-1}}\left[1+e_{X} \psi(\Gamma-1)\right]^{\frac{\sigma}{\sigma-1}} & \text { if } \Gamma \geq \underline{\Gamma}\end{cases}
$$

where the fraction of employment in exporters is

$$
e_{X}=\frac{\left(1+\kappa_{e}\right) e^{-\mu H}}{1+\kappa_{e} e^{-\mu H}}
$$

The relationship (81) implies that $\frac{d y(\Gamma)}{d \Gamma} \geq 0$ when $\Gamma>\underline{\Gamma}$. In turn, from (4) and (5), the revenue premium $\Gamma$ is strictly decreasing with income per worker, $\Gamma=\left[1+\frac{A}{(1-u) y}\right]^{1 / \sigma}$. This implies $\frac{d y}{d \Gamma}>0$, where $\lim _{\Gamma \rightarrow 1} y=\infty$ and $\lim _{\Gamma \rightarrow \infty} y=0$. Therefore, there is a unique interior equilibrium. To determine whether the equilibrium indeed features export entry, note that, if it does not, then $\frac{f_{X}}{f_{D}}>\overline{f_{X} / f_{D}} \equiv \lim _{H \rightarrow \infty} \Omega(H)$ at the $\Gamma$ such that no firm exports. Using (4) for $y_{D}$, this condition is equivalent to

$$
\frac{f_{X}}{f_{D}}>\overline{f_{X} / f_{D}}=\frac{1}{\gamma} \frac{\left(\rho+\delta+\lambda_{u} \beta\right)\left(1+\kappa_{e}\right)\left[\left(1+\frac{A}{1-u}\right)^{1 / \sigma}-1\right]}{1-\frac{z / \psi}{(1-u)^{1 /(\sigma-1)}}} .
$$

Therefore, an interior equilibrium exists if and only if $f_{X} / f_{D} \in\left(0, \overline{f_{X} / f_{D}}\right)$.

I now move to the comparative statics. Consider first the case $\beta=0$ and $\lambda_{e}>0$. Then (79) implies $\rho U=z$, and (78) becomes

$$
\Omega(H)=\frac{(\rho+\delta)(\Gamma-1)\left(1+\kappa_{e}\right) \int_{0}^{H} e^{-\gamma x}\left[1+\kappa_{e} e^{-\mu(H-x)}\right]^{-1} d x}{\left(1+(\Gamma-1) e^{-(\rho+\delta) H}\right)-\left(\frac{z}{\psi y_{D}}\right)} .
$$

The numerator is increasing with $\lambda_{e}$. A sufficient condition for the function to be increasing with $\lambda_{e}$ is that $y_{D}$ does not increase too fast with $\lambda_{e}$. When that happens, the value of unemployment falls relatively to domestic market size, leading to entry. We now show that this is the case if $\sigma$ is sufficiently large or if $z=b y$. Multiplying numerator and denominator by $\frac{y_{D}}{z}$, the numerator is increasing with $\lambda_{e}$, and the denominator is decreasing if

$$
\frac{\partial y_{D}}{\partial \lambda_{e}} \frac{1}{y_{D}}=\frac{1}{\sigma-1} \frac{(\Gamma-1)}{1+e_{X}(\Gamma-1)} \frac{1}{\delta} \frac{e_{X}\left(1-e_{X}\right)}{1+\kappa_{e}}<(\rho+\delta) \frac{(\Gamma-1) e^{-(\rho+\delta) H}}{1+(\Gamma-1) e^{-(\rho+\delta) H}}
$$

where the first equality follows from using (4) and (81). Given the initial $e_{X}$ and $H$, this condition holds for $\sigma$ sufficiently large. Another sufficient condition is $z=b y$. In that case, using (4) and (81),

$$
\frac{z}{y_{D}}=\frac{b y}{y_{D}}=b\left[1+e_{X}(H) \psi(\Gamma-1)\right]=b \frac{1+\left[\kappa_{e}+\psi(\Gamma-1)\left(1+\kappa_{e}\right)\right] e^{-\mu H}}{1+\kappa_{e} e^{-\mu H}},
$$

which is increasing with $\lambda_{e}$, so that the denominator of (84) is decreasing with $\lambda_{e} \cdot{ }^{63}$ The condition $b \in\left[0, \psi \frac{y_{D}}{y}\right)$

\footnotetext{
${ }^{63}$ Our previous proof of uniqueness given $\Gamma$ proceeded under the assumption that $z$ is an exogenous parameter.
} 
ensures that the value of jobs is always positive and that an equilibrium with positive entry therefore exists.

Consider now the case $\lambda_{e}=0$ and $\beta>0$. Then, (78) becomes

$$
\Omega(H)=\frac{(\rho+\delta)(\Gamma-1)\left(1+\kappa_{e}\right) \frac{1-e^{-\gamma H}}{\gamma}}{1-\rho \frac{U}{\psi y_{D}}+(\Gamma-1) e^{-(\rho+\delta) H}}=\frac{f_{X}}{f_{D}},
$$

where, using (79),

$$
\frac{\rho U}{\psi y_{D}}=\frac{\rho+\delta}{\rho+\delta+\lambda_{u} \beta}\left(\frac{z}{\psi y_{D}}\right)+\frac{\beta \lambda_{u}}{\rho+\delta+\lambda_{u} \beta}\left[1+(\Gamma-1) e^{-(\rho+\delta) H}\left(1+(\rho+\delta) \frac{1-e^{-\mu H}}{\mu}\right)\right] .
$$

As a special case of Proposition 1 in the general model, we see that $\lambda_{u}$ impacts equilibrium outcomes only through $U / y_{D}$. If this term is increasing in $\lambda_{u}$, then $H$ decreases with $\lambda_{u}$. A higher $\lambda_{u}$ places a higher weight on the value of employment relative to unemployment. A sufficient condition for this term to be increasing is:

$$
\frac{z}{\psi y_{D}}<1+(\Gamma-1) e^{-(\rho+\delta) H}\left(1+(\rho+\delta) \frac{1-e^{-\mu H}}{\mu}\right) .
$$

The right hand side is bounded below by 1 , hence this condition is satisfied if $z<\psi y_{D}$.

\section{Appendix to Section 5 (Calibration)}

\section{C.1 Data Sources and Summary Statistics}

I use summary statistics extracted from confidential microdata. Exports data comes from official customs data at the firm-year level. These data were merged with firm employment data from administrative records by the Employment and Business Dynamics Observatory (OEDE) of the Ministry of Labor and Social Security of Argentina (http://www.trabajo.gob.ar/estadisticas/oede/index.asp). All firms are required to report their formal employees on a monthly basis. In each of six two-month periods within each year between 1998 and 2007, every formal worker aged 18 to 64 is linked to the firm where he/she is reported as earning the highest wage. Workers earning below the minimum wage are excluded.

The data includes the universe of firms that report employment above the minimum wage in any period during these years. A worker employed in a firm in a period is considered a new hire if he/she is not employed in the firm in the previous period. To compute the fraction of new hires entering from other formal jobs in any sector of the economy for each firm-year, the shares are first computed for each pair of consecutive periods within year, and then averaged across periods within firm-year. Similar steps are followed to compute the fraction of new hires from the manufacturing sector entering from jobs in exporting firms.

Each firm-year observation is classified as exporter if the firm exports at least USD 10,000. Firm age is the difference between the current year and the year of birth in the tax record. The number of workers per firm is the average employment across periods within year. All figures are based on firms from the manufacturing sector. Exiting firms of any export status (i.e., firms present in a given year who do not report employment in the next) are excluded. Firms who do not report formal employment but who report exports are excluded, as well as industries with less than one-hundred firms in any year. The resulting sample represents, on average, $97 \%$ of the formal employment and $82 \%$ of all firms who either export or formally report the wages of their employees in the manufacturing sector.

Assuming $z=b y$, uniqueness given $\Gamma$ would also be guaranteed for $\Gamma<\frac{1+\kappa_{e} / b}{1+\kappa_{e}}$. 


\begin{tabular}{l|c|c} 
Statistic & $\mathbf{1 9 9 8 - 2 0 0 2}$ & $\mathbf{2 0 0 3 - 2 0 0 7}$ \\
\hline Aggregate Export Shares & & \\
$\quad$ Fraction of exporting firms & $5.8 \%$ & $10.9 \%$ \\
$\quad$ Employment share of exporters & $52.1 \%$ & $52.8 \%$ \\
Firm Size Distribution & 19.5 & 21.7 \\
$\quad$ Average Firm Size & $78.7 \%$ & $75.5 \%$ \\
$\quad$ Share of firms with 0-14 workers & $18.3 \%$ & $21.0 \%$ \\
Share of firms with 15-99 workers & $1.7 \%$ & $2.0 \%$ \\
$\quad$ Share of firms 100-199 workers & $0.8 \%$ & $0.9 \%$ \\
$\quad$ Share of firms with 200-399 workers & $0.6 \%$ & $0.6 \%$ \\
$\quad$ Share of firms with 400+ workers & $17.5 \%$ & $17.3 \%$ \\
Job-to-job Hiring & $16.3 \%$ & $15.7 \%$ \\
$\quad$ Average share of job-to-job hires, all firms & $28.1 \%$ & $30.3 \%$ \\
Average share of job-to-job hires, non-exporters & & \\
Average share of job-to-job hires, exporters & 11.3 & 11.7 \\
Average Firm Age (years) & 20.4 & 20.8 \\
$\quad$ Non-exporters & &
\end{tabular}

Table 6: Summary Statistics, 1998-2002 and 2003-2007

\section{C.2 Numerical Algorithm}

The algorithm to solve the model consists of an outer loop on $\left\{P_{v}(v), y_{D}, y_{X}, u, \lambda_{e}, \lambda_{u}, U\right\}$ and an inner loop on the distribution of firm choices, $\{h(\varepsilon)\}$, and the aggregate tightness $q_{u}$. In the corresponding steps of each iteration, the functions $P_{v}(v)$ and $h\left(\psi, f_{X}\right)$ are interpolated using cubic splines on a grid with 25 equally-spaced job values in $\left[v_{\min }, v_{\max }\right]$ and productivity levels in $\left[\psi_{\min }, \psi_{\max }\right]$. The value function $v(x ; \psi)$ is interpolated using a grid of 15 equally spaced times to investment in log-units in $[0,40]$. restricting 40 years to be the maximum age to enter exporting.

1. Starting from a guess for $\left\{P_{v}(v), y_{D}, y_{X}, u, \lambda_{e}, \lambda_{u}, U\right\}$ or from the outcomes of the last iteration, construct the value functions $v(x ; \psi)$ for each $\psi$ using (10), the optimal search effort $s^{*}(v)$ using (53), and the value of all new hires using (54).

2. Guess a value for $q_{u}$ or use the last iteration outcome. Then, use (17), (19), (75), and (76) to solve for $h(\varepsilon)$ (in the extension to multiple investment options described in (A.5), this step involves solving for the $\left\{h_{j}(\varepsilon)\right\}_{j=1}^{K}$ entry times to all markets using (29)-(30)); adjust $q_{u}$ such that the free entry condition (74) holds; and iterate on the last two steps until convergence of $\left\{h(\varepsilon), q_{u}\right\}$.

3. Compute $\bar{s}$ using the rules $s^{*}(v(h(\varepsilon)-a ; \varepsilon))$, and solve for the aggregate search $\bar{s} M$ using the solution for $q_{u}$ from step 2 .

4. Compute the distribution $P_{v}(v)$ using (56) and support for the grid for values such that $v_{\min }=v\left(\infty ; \psi_{\min }\right)$ and $v_{\min }=v\left(0 ; \psi_{\max }\right)$; income per worker $y$ from (22) and then $\left\{y_{D}, y_{X}\right\}$ using (4) and (5) (in the extension to multiple investment options described in (A.5), this step involves computing income per worker using a step function with the $\left\{y_{j}\right\}_{j=1}^{K}$ revenue levels, and recomputing those revenue levels using (35)-(37)); unemployment and equilibrium contact rates $\left\{u, \lambda_{e}, \lambda_{u}\right\}$ using (1)-(2); and the value of unemployment $U$ using (8).

5. Move back to point 1 for the next iteration. 


\title{
Labor Market Frictions, Firm Growth, and International Trade
}

\author{
Appendices for Online Publication
}

Pablo D. Fajgelbaum (UCLA)

\section{A Additional Figures and Tables}

Figure A.1: Job-Finding Rates and Employment Regulation

(a) $\lambda_{e}$ (Ridder and van den Berg, 2003) vs. EPL and RE

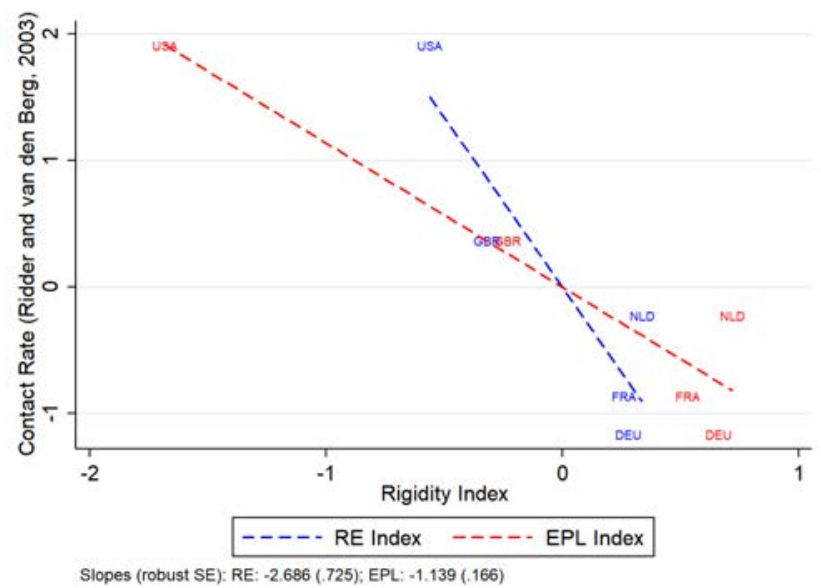

(c) $\lambda_{u}$ and $\lambda_{e}$ (Jolivet et al., 2006) vs. EPL

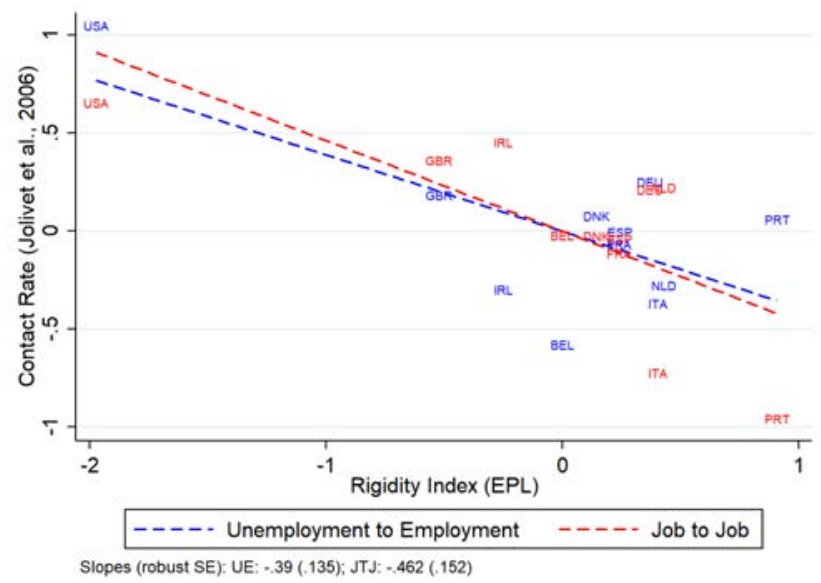

(b) $\lambda_{u}$ (Hobijn and Şahin, 2009) vs. EPL and RE

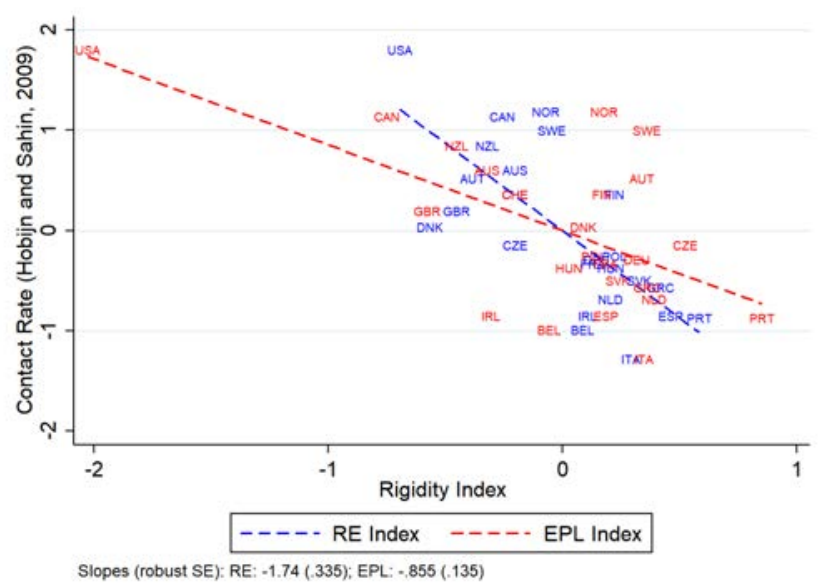

(d) $\lambda_{u}$ and $\lambda_{e}$ (Jolivet et al., 2006) vs. RE

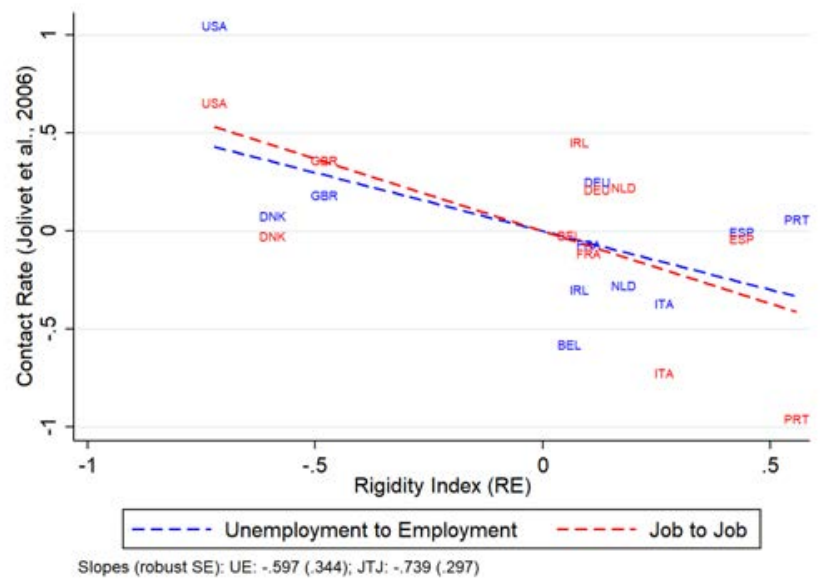

Note: each panel reports the correlation between job-finding rates estimated in the respective paper and indexes of labor market rigidity. RE stands for the Rigidity of Employment Index (World Bank) and EPL stands for the Employment Protection Legislation Index (OECD). EPL takes a value from 0 (less rigid) to 6 (more rigid) and RE takes value from 0 (less rigid) to 100 (more rigid). The variables are reported in logs and demeaned. In each panel, the value of the EPL and RE indexes correspond to an average over the available values of the index in the available years in the dataset. 
Figure A.2: Rigidity of Employment Index and Income Per worker

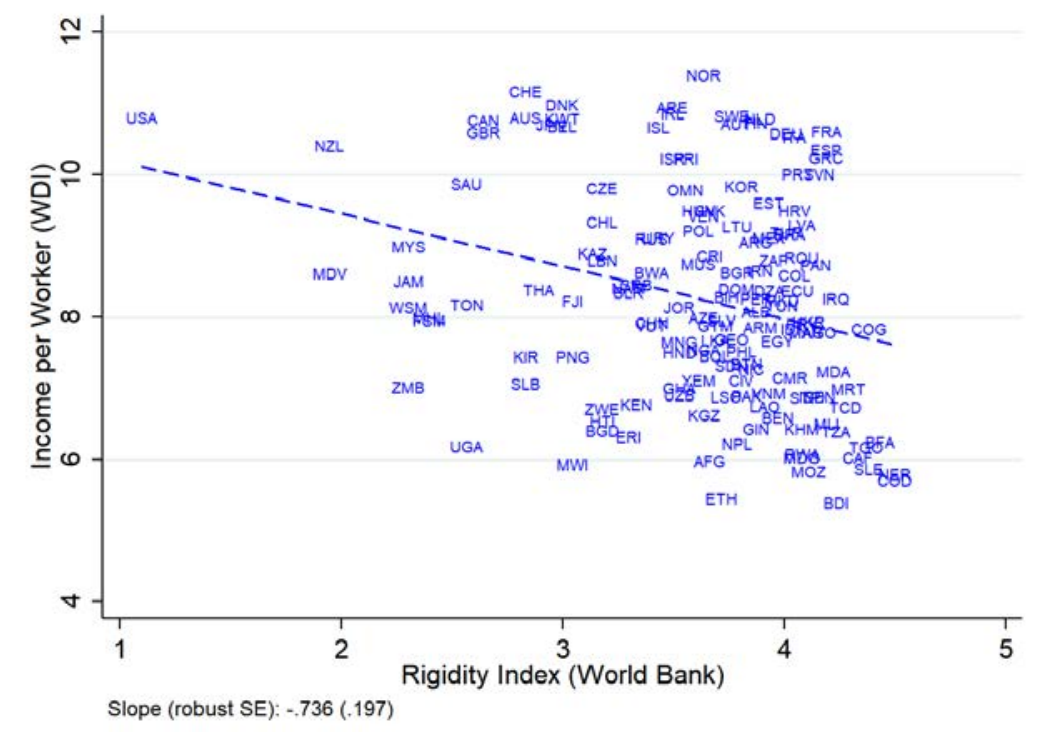

Note: the figure shows income per worker from for the year 2005 from the World Development indicators against the Rigidity of Employment index for the same year from the Doing Business database of the World Bank. The correlation between both variables is -0.28 . If the U.S. is excluded the slope falls to -0.69 (s.e. 0.22 ) and the correlation becomes -0.25 . 
Figure A.3: Export Participation and Firm Growth by Firm Productivity

(a) Age of Export Entry (Years)

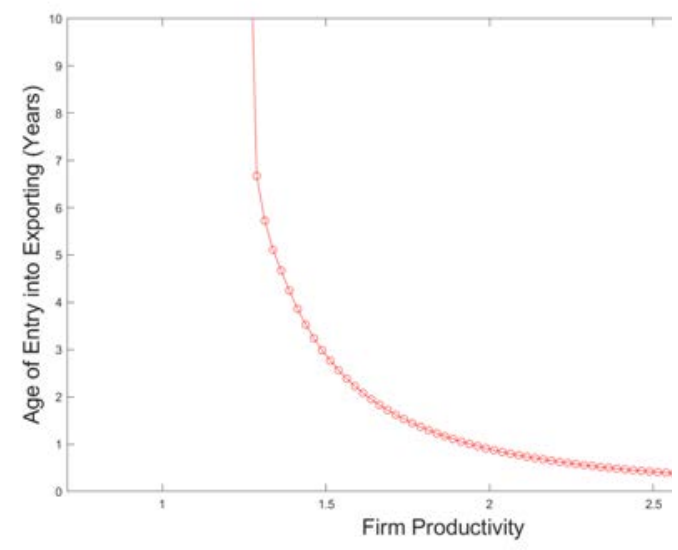

(c) Firm Size by Age for Different Productivity Levels

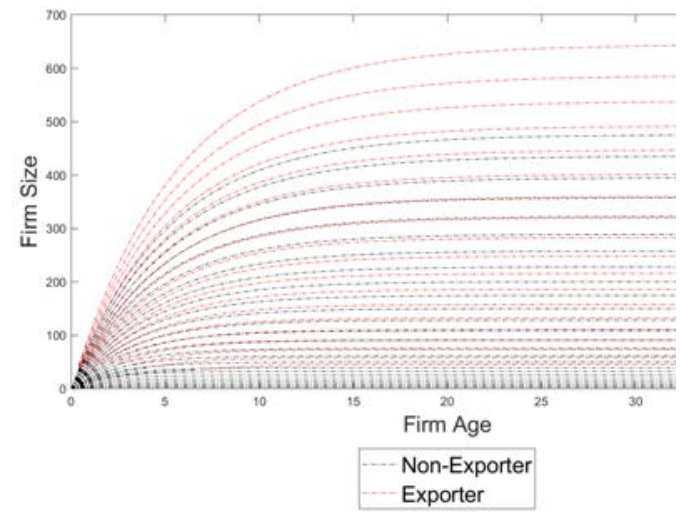

(b) Fraction of Exporters by Productivity

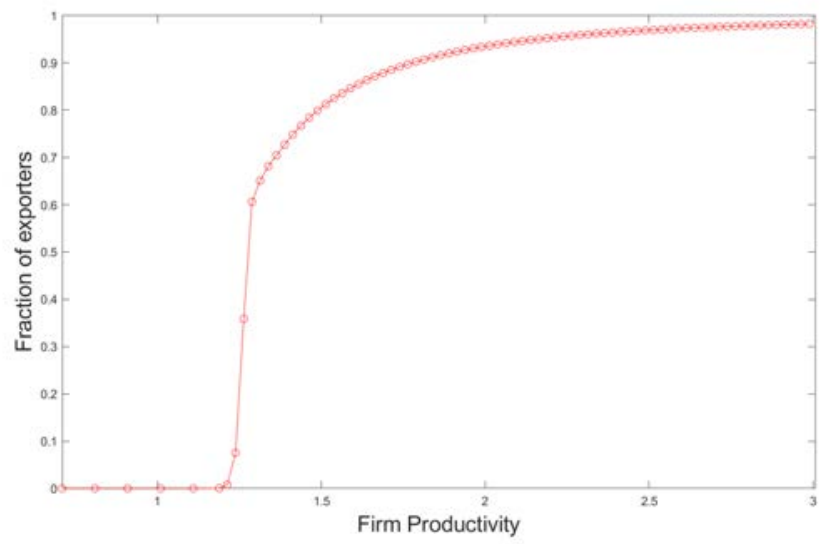

(d) Firm Size by Productivity

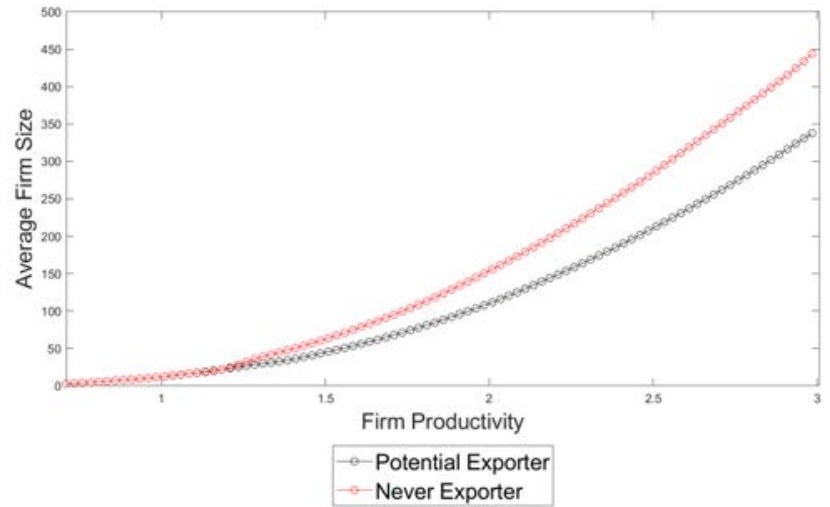


Figure A.4: Wage and Value Trajectories

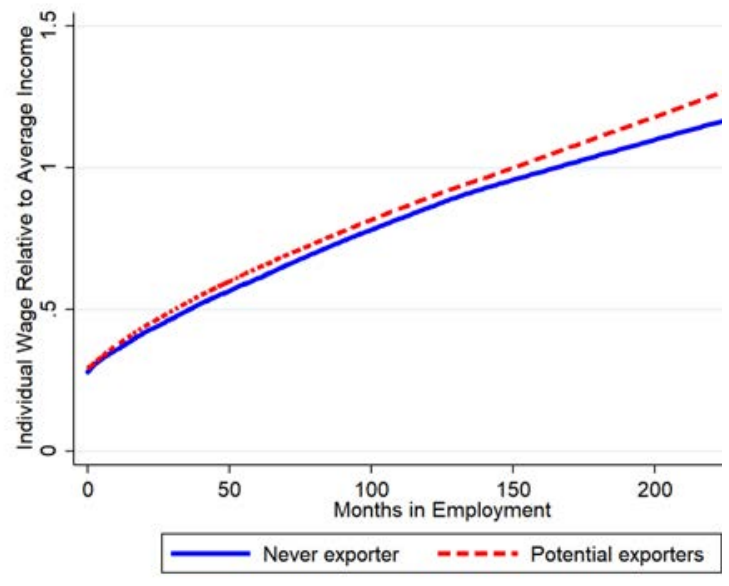

(a) Wage Trajectories (all firms)

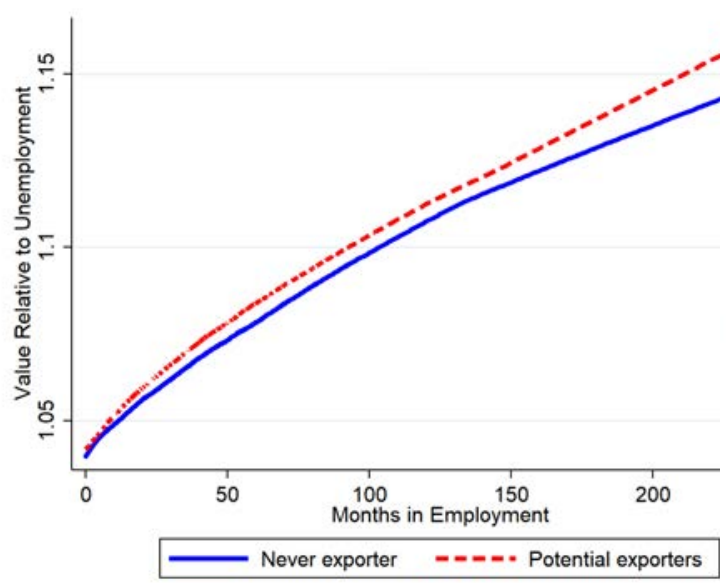

(c) Value Trajectories (all firms)

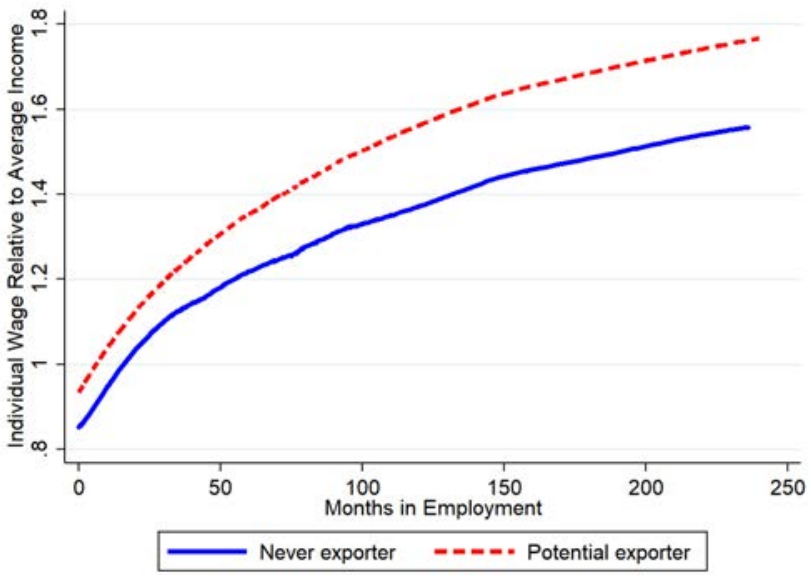

(b) Wage Trajectories (high productivity firms)

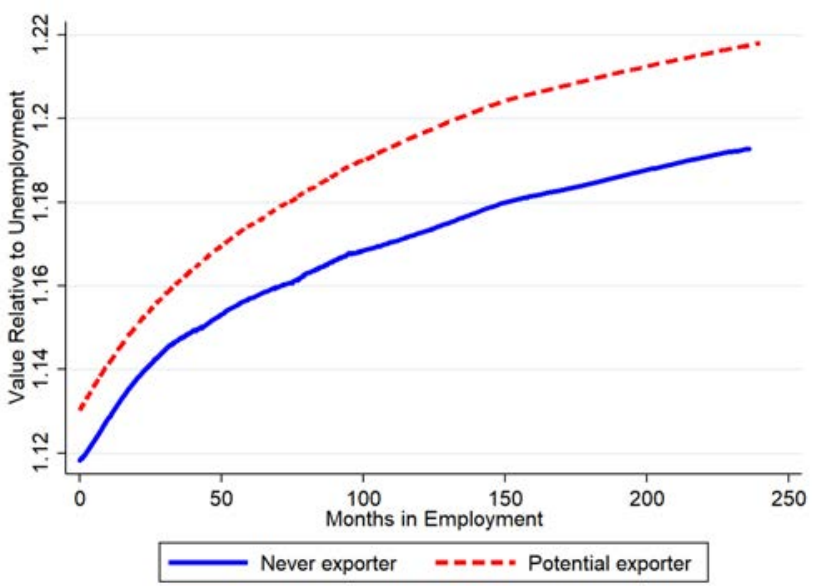

(d) Value Trajectories (high productivity firms)

Note: the figures show the fitted values from locally weighted linear least squares regressions of wages or values on months spent employed (potentially, across many jobs) in simulated employment spells under $\beta=0.44$. The left panel includes all trajectories, and the right panel limits the simulated data to trajectories entirely spent in firms in the top $1 \%$ of the productivity distribution. The top panel shows individual wages relative to income per worker in the economy, and the bottom panel show the value to the worker relative to the value in unemployment. For the details of the computation of the wage and value functions see Footnote 46. 
Figure A.5: Firm Size Distribution, Export Participation by Age, and Firm Growth

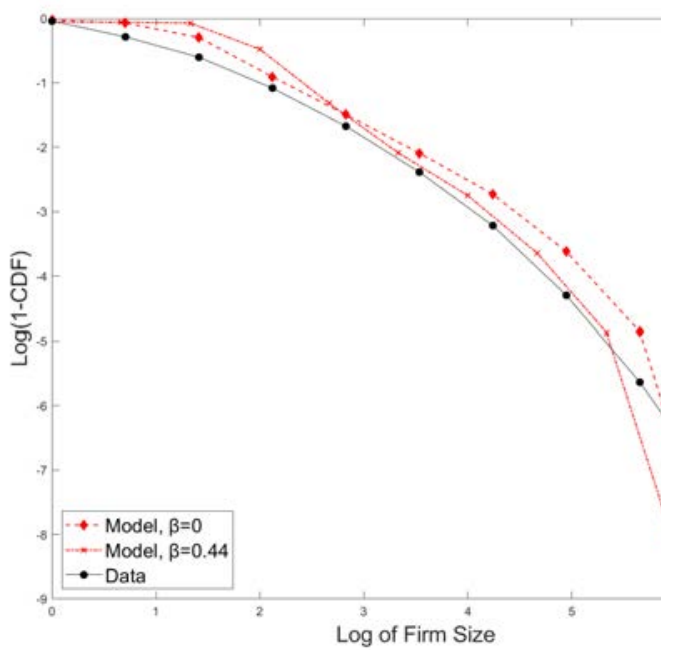

(a) Firm Size Distribution

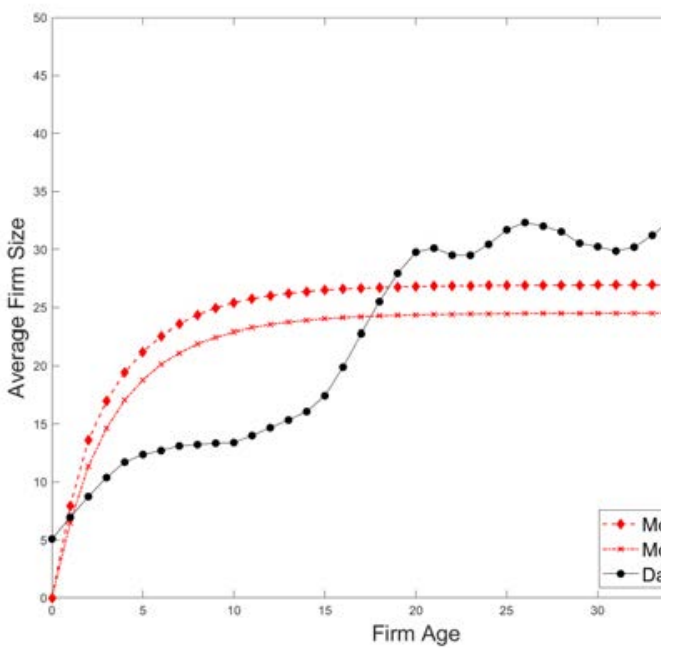

(c) Average Firm Size by Age, All Firms

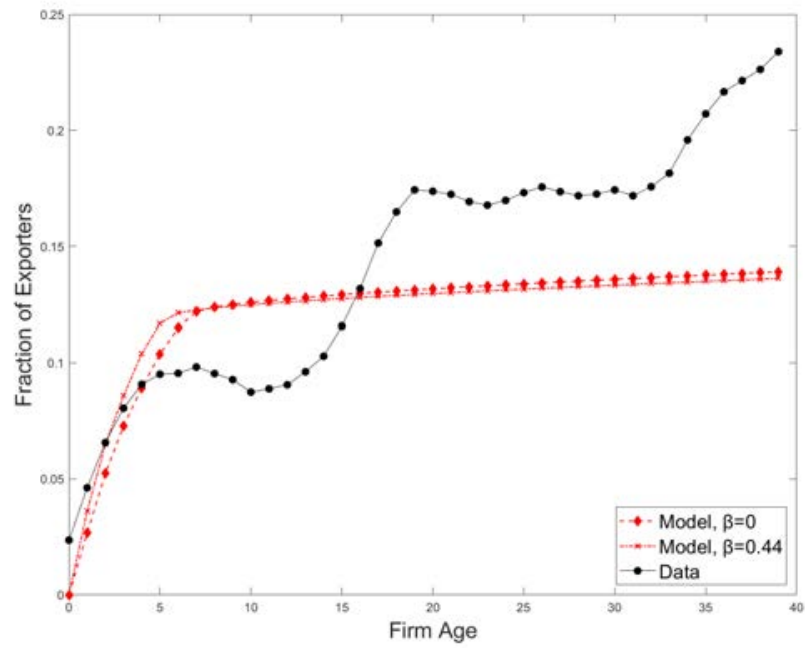

(b) Export Participation by Age

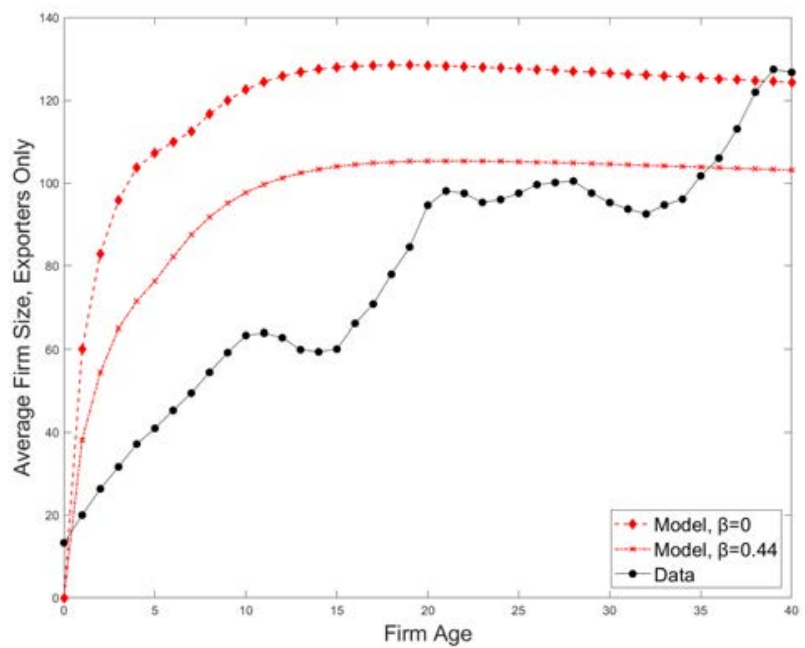

(d) Average Firm Size by Age, Exporters 
Figure A.6: Impact of Lowering Frictions, Additional Outcomes

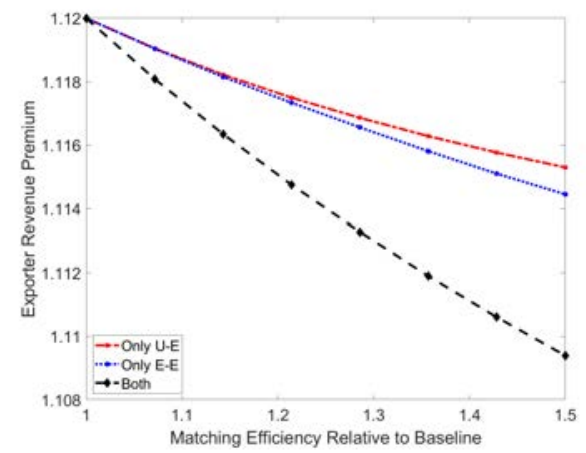

(a) Exporter Revenue Premium $\Gamma(\beta=0)$

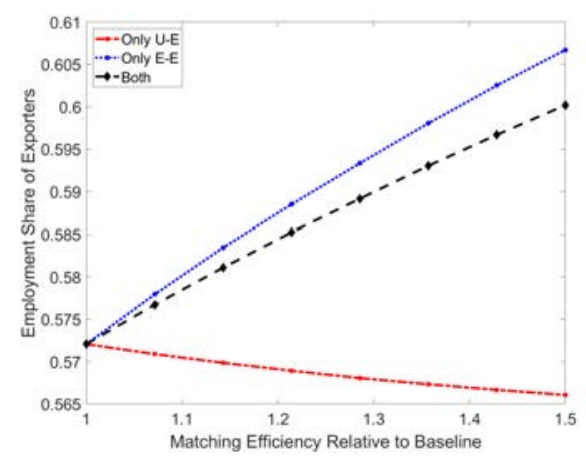

(c) Exporter Employment Share $(\beta=0)$

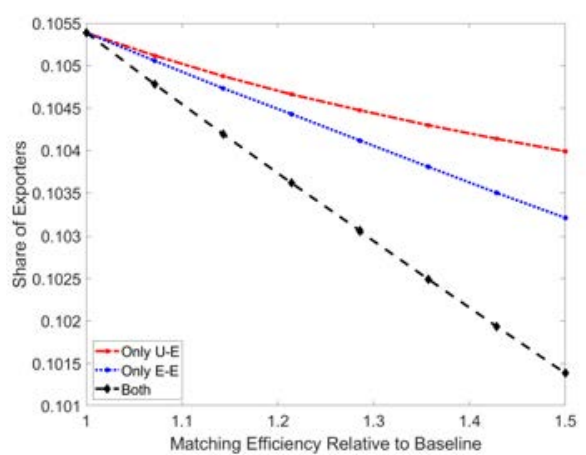

(e) Share of Exporters $(\beta=0)$

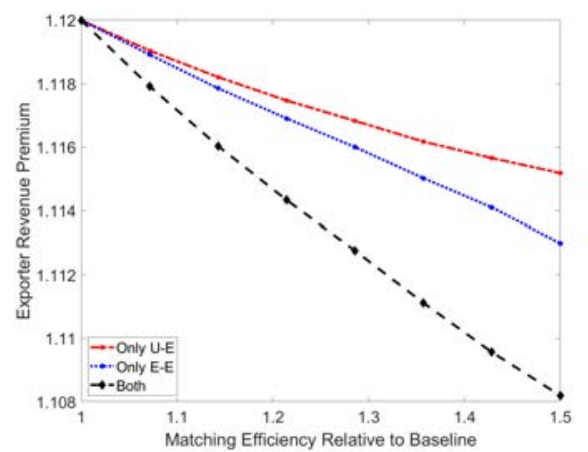

(b) Exporter Revenue Premium $\Gamma(\beta=0.44)$

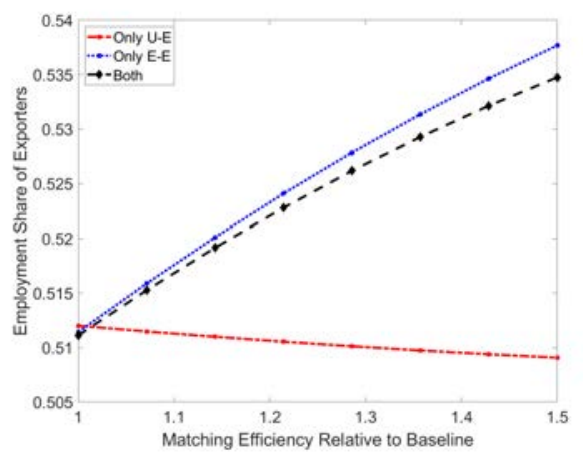

(d) Exporter Employment Share $(\beta=0.44)$

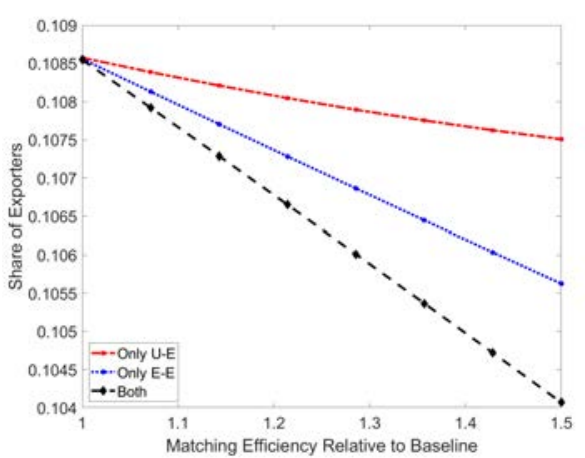

(f) Share of Exporters $(\beta=0.44)$ 
Figure A.7: Revenue Per Worker in Model with Multiple Export Destinations

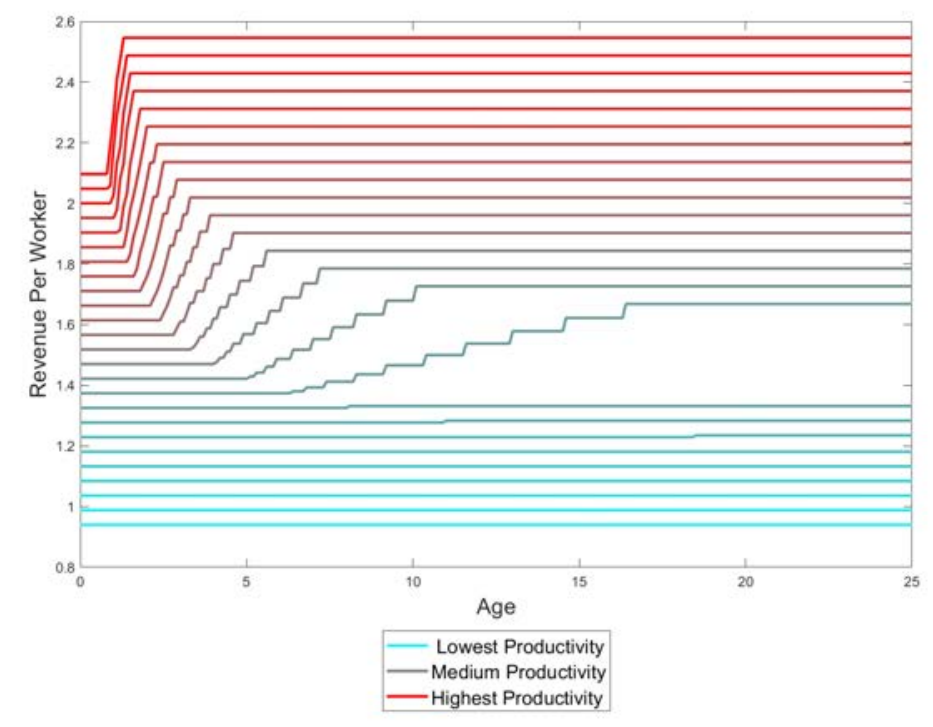

Note: this figure shows the growth in the revenue per worker of firms with different productivity as these firms enter multiple export destinations. The parametrization corresponds to the model with multiple investments developed in Section 6.4. 


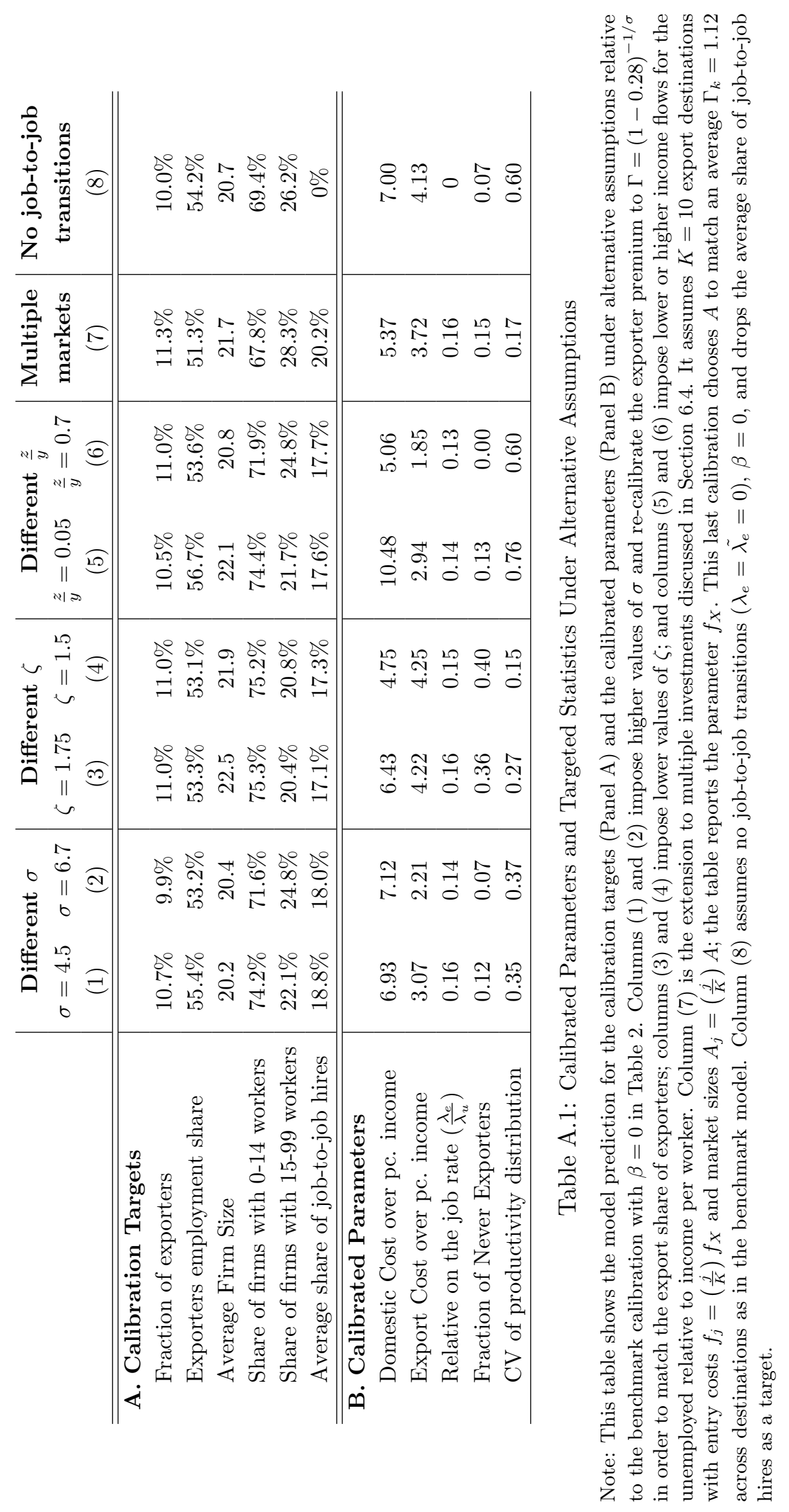




\begin{tabular}{|c|c|c|c|c|c|c|c|c|c|}
\hline & \multicolumn{3}{|c|}{ Growth in $y$} & \multicolumn{3}{|c|}{$\Delta$ Share of Hires Job-to-job } & \multicolumn{3}{|c|}{$\Delta$ Unemployment } \\
\hline & Only $\lambda_{u}$ & Only $\lambda_{e}$ & Both & Only $\lambda_{u}$ & Only $\lambda_{e}$ & Both & Only $\lambda_{u}$ & Only $\lambda_{e}$ & Both \\
\hline \multicolumn{10}{|l|}{ Benchmark } \\
\hline$\beta=0$ & $0.6 \%$ & $3.5 \%$ & $4.2 \%$ & $0.2 \%$ & $1.1 \%$ & $1.3 \%$ & $-1.9 \%$ & $0.5 \%$ & $-1.5 \%$ \\
\hline$\beta=0.44$ & $0.6 \%$ & $3.7 \%$ & $4.4 \%$ & $0.1 \%$ & $1.8 \%$ & $1.9 \%$ & $-1.9 \%$ & $0.3 \%$ & $-1.7 \%$ \\
\hline \multicolumn{10}{|l|}{ Higher $\sigma$} \\
\hline$\sigma=4.5$ & $0.4 \%$ & $3.9 \%$ & $4.4 \%$ & $0.1 \%$ & $0.5 \%$ & $0.7 \%$ & $-1.9 \%$ & $0.7 \%$ & $-1.3 \%$ \\
\hline$\sigma=6.7$ & $0.3 \%$ & $3.8 \%$ & $4.1 \%$ & $0.0 \%$ & $0.6 \%$ & $0.7 \%$ & $-1.8 \%$ & $0.7 \%$ & $-1.3 \%$ \\
\hline \multicolumn{10}{|l|}{ Lower $\zeta$} \\
\hline$\zeta=1.75$ & $0.8 \%$ & $3.6 \%$ & $4.4 \%$ & $0.1 \%$ & $0.6 \%$ & $0.6 \%$ & $-1.9 \%$ & $0.7 \%$ & $-1.3 \%$ \\
\hline$\zeta=1.5$ & $0.7 \%$ & $2.2 \%$ & $3.0 \%$ & $0.1 \%$ & $0.8 \%$ & $0.8 \%$ & $-1.9 \%$ & $0.6 \%$ & $-1.3 \%$ \\
\hline \multicolumn{10}{|l|}{ Different $z$} \\
\hline$\frac{z}{y}=0.05$ & $0.8 \%$ & $7.0 \%$ & $7.9 \%$ & $0.2 \%$ & $1.2 \%$ & $1.3 \%$ & $-1.9 \%$ & $0.4 \%$ & $-1.5 \%$ \\
\hline$\frac{z}{y}=0.7$ & $0.3 \%$ & $3.9 \%$ & $4.5 \%$ & $0.2 \%$ & $1.8 \%$ & $2.0 \%$ & $-1.9 \%$ & $0.3 \%$ & $-1.7 \%$ \\
\hline \multicolumn{10}{|l|}{ Fixed $\frac{z}{y}$} \\
\hline$\beta=0$ & $0.7 \%$ & $4.4 \%$ & $5.2 \%$ & $0.1 \%$ & $0.5 \%$ & $0.6 \%$ & $-1.9 \%$ & $0.7 \%$ & $-1.3 \%$ \\
\hline$\beta=0.44$ & $0.6 \%$ & $3.7 \%$ & $4.4 \%$ & $0.1 \%$ & $1.8 \%$ & $1.9 \%$ & $-1.9 \%$ & $0.3 \%$ & $-1.7 \%$ \\
\hline \multicolumn{10}{|l|}{$\chi(x)=x^{1 / 2}$} \\
\hline$\beta=0$ & $0.7 \%$ & $4.3 \%$ & $5.1 \%$ & $0.1 \%$ & $0.5 \%$ & $0.6 \%$ & $-1.9 \%$ & $0.7 \%$ & $-1.3 \%$ \\
\hline$\beta=0.44$ & $0.6 \%$ & $3.7 \%$ & $4.4 \%$ & $0.1 \%$ & $1.8 \%$ & $1.9 \%$ & $-1.9 \%$ & $0.3 \%$ & $-1.6 \%$ \\
\hline
\end{tabular}

Table A.2: Impact of $25 \%$ reduction in Frictions Under Alternative Parametrizations

Note: This table shows the model predictions corresponding to a $25 \%$ increase in matching efficiencies under the alternative parametrizations of Table A.1. The "fixed $z / y$ " case uses the parameters from the benchmark calibration but assumes $z=b y$, where $b$ is fixed at the value of $\frac{z}{y}$ in the calibrated model. The last two rows show the counterfactuals under the same parametrization as in the benchmark calibration but assuming a Cobb-Douglas aggregate matching function with weights $\frac{1}{2}$ on workers and firms. 


\section{B Link to Arkolakis et al. (2012)}

Arkolakis et al. (2012) show that, in a class of gravity models, the real income change $\Delta \ln y$ caused by a change in trade costs can be measured as $(\Delta \ln y)^{A C R}=-\frac{1}{\sigma-1} \Delta \ln \lambda$, where $\Delta \ln \lambda$ is the change in the domestic share of expenditures associated with this change in trade costs, and $\sigma$ is the elasticity of substitution parameter, corresponding to product differentiation by origin in an Armington model. Empirically, $\sigma-1$ is the elasticity of trade with respect to trade costs. My model does not fall in that class, but I can verify whether their formula works well numerically. For this, I simulate shocks $\Delta \ln \tau$ in my model to generate data on $\Delta \ln \lambda$. Then, I implement the steps that a researcher working on these data through the lens of the Arkolakis et al. (2012) model would do. Specifically, given knowledge of the trade cost shock $\Delta \ln \tau$, one can obtain an estimate $\hat{\sigma}$ of $\sigma$ using a log-linear gravity equation, and use this estimate along with the observed data on $\Delta \ln \lambda$ to compute the real income gains $(\Delta \ln y)^{A C R}$.

I follow these steps, and then compare $(\Delta \ln y)^{A C R}$ to the real income gain $\Delta \ln y$ implied by my model. I generate a reduction in trade costs leading to an increase of $5 \%$ in the foreign market potential $A_{j}$. Given the definition of the foreign market potential $A_{j}$ in (36) and the value of $\sigma=2.98$ assumed in my calibration, this shock corresponds to a change in trade costs of $\Delta \ln \tau=-2.46 \%$. Using the calibrated model, this shock generates a change in the import share of expenditures of $\Delta \ln \lambda=-1.39 \%$ (from $79.3 \%$ to $78.2 \%$ ) and an increase in real income of $\Delta \ln y=0.69 \%$.

Through the lens of a 2-country gravity model, the parameter $\sigma$ would be estimated from a log-linear gravity equation using the relationship $1-\hat{\sigma}=\frac{\Delta \ln (1-\lambda)}{\Delta \ln \tau}$. My model-generated data implies $\Delta \ln (1-\lambda)=5.17 \%$ (an increase in the export share share from $20.7 \%$ to $21.8 \%$ ), leading to $\hat{\sigma}=3.09$. This number is very close to the product differentiation parameter $\sigma=2.98$ that I imposed in the calibration, suggesting that my model generates close to a $\log$-linear gravity equation. As a result, I obtain $(\Delta \ln y)^{A C R}=-\frac{1}{3.09-1}(-1.39 \%)=0.66 \%$, which is very close to the value of $\Delta \ln y=0.69 \%$ implied by my model. Figure A.8 re-does this previous analysis under a range of values of $\Delta \ln \tau$ including larger and smaller shocks. I also plot an alternative calculation of the Arkolakis et al. (2012) formula where $\sigma$ is fixed to the 2.98 value from my calibration instead of being re-computed each time from model-simulated data. This formula with a fixed value of $\sigma$ does not perform as well, reflecting that the parameter $\sigma-1$ is not the elasticity of trade to trade costs in my model.

Figure A.8: Real Income Gain in the Model and Implied by Arkolakis et al. (2012)

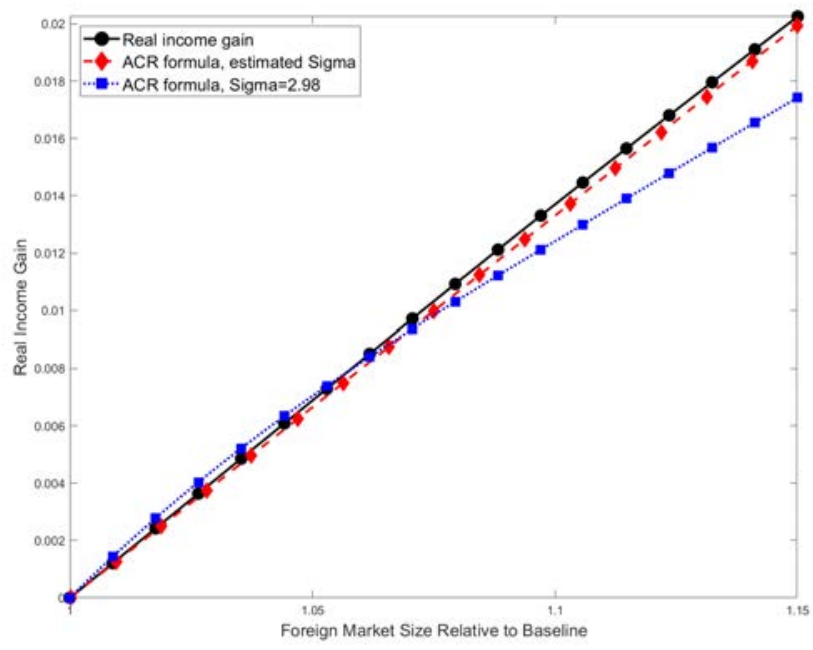




\section{Relationship Between Labor Market Rigidity and Exports}

I consider the relationship between country-level indexes of labor market rigidities and exports using datasets with variation in exports across countries, industries and firms. Country level data is obtained from the World Development Indicators (WDI), industry level data is obtained from UN Comtrade, and firm-level data is obtained from the World Bank's Enterprise Survey. I use two index measures of labor market rigidities, the Strictness of Employment Protection Legislation index (EPL), constructed by the OECD, and the Rigidity of Employment index (RE), introduced in the Doing Business report by the World Bank. These indexes combine measurable features of labor market legislation that relate to the costs of hiring and firing workers. ${ }^{64}$ Version 1 of the EPL index is available for 72 OECD and non-OECD countries with a coverage of thirty years (1985-2015) for OECD countries and one to six years (2010-2015) for non-OECD countries. The RE index is available for 193 countries from 2003-2009 and $2013-2017.65$

At the country level, I consider the following relationship,

$$
\ln \left(Y_{c t}\right)=\beta_{0}+\beta_{1} \ln \left(L M R_{c t}\right)+\gamma_{c}+\gamma_{t}+X_{c t}+\varepsilon_{c t}
$$

where variables are indexed for country $c$ in period $t$. The dependent variable $Y_{c t}$ are real country-level exports. Both the EPL and RE indexes are used as measure of labor market rigidity $\left(L M R_{c t}\right)$. The additional controls, $X_{c t}$, include the logarithms of GDP and population. The regression includes country and period fixed effects, and the standard errors are clustered at the country level. ${ }^{66}$ Due to country fixed effects, the coefficient $\beta_{1}$ captures the correlation between labor market rigidity and exports within countries over time. At the industry level I run a similar specification,

$$
\ln \left(Y_{i c t}\right)=\beta_{0}+\beta_{1} \ln \left(L M R_{c t}\right)+X_{c t}+\gamma_{i}+\gamma_{c}+\gamma_{t}+\varepsilon_{i c t},
$$

where $Y_{i c t}$ are exports of industry $i$ in country $c$ at time $t$ and where now the regression includes industry-level fixed effects. Industries are measured at the HS2 level of aggregation, with 97 industries included in the data. The industry-level regression addresses that labor market rigidities may drive specialization patterns in more open sectors. Finally, at the firm level I run

$$
\ln \left(y_{j i c t}\right)=\beta_{0}+\beta_{1} \ln \left(L M R_{c t}\right)+X_{c t}+s i z e_{j t}+\gamma_{i}+\gamma_{c}+\gamma_{t}+\varepsilon_{j c t},
$$

where $y_{j i c t}$ are exports of firm $j$ in industry $i$ from country $c$ at time $t$ relative to sales. ${ }^{67}$ Firms are sorted into 51 sectors and 3 size categories. Each firm appears at most twice in the survey, precluding the computation of firm fixed effects. However, I can include the firm-level size as a control. Therefore, the regression captures the relationship between rigidity and exports across countries within groups of firms of similar size.

\footnotetext{
${ }^{64}$ I use the indicator for individual and collective dismissals for workers with a regular contract from the EPL, which captures twelve items that can be categorized into Procedural Inconveniences, Notice and Severance Pay, Difficulty of Individual Dismissal, and Collective Dismissals. Each of this items is converted into a cardinal scale from 0 to 6 , increasing in strictness, and then aggregated into the common index. The RE index is based on hiring and firing laws and regulations data published by the International Labour Organization. Similar to the EPL, it summarizes different sub-indices: Difficulty of Hiring (including measures on the flexibility and duration of fixed-term contracts), Rigidity of Hours (including five components regarding restrictions such as the length of the workday) and Difficulty of Firing (reflecting various costs associated with firing, such as whether redundancy is grounds for dismissal). The RE index is calculated as the average of all sub-indices and scaled from 0 to 100 .

${ }^{65}$ The index was discontinued in 2010, but the answers to each component of the index are also available since 2013. Hence for 2013-2017 I reconstruct the index applying the methodology used in the original index.

${ }^{66}$ The overlap between the WDI and OECD datasets results in data availability for 70 countries in periods that range from 1985 to 2015 . Using the $\mathrm{RE}$ index, the overlap yields 163 countries for periods that range from 2003 to 2009 and 2013 to 2017.

${ }^{67}$ The EPL covers mostly developed countries and the Enterprise Survey covers mostly developing countries. Hence, only the World Bank's ER index is used for this regression. On average, the survey includes 300 firms in each country, with survey frequency weights used in the regression to add up to the total population. In total there are 76 countries in the survey over the years in which the RE measure is available.
} 
Table A.3 shows the estimated value of $\beta_{1}$ from the country level regression (A.1) and the industry level regression (A.2) under the two employment protection measures. The first column of Table A.4 shows the estimate of $\beta_{1}$ from the firm level regression (A.3). The coefficient on labor market rigidity is negative and statistically significant in all cases except in the case of the RE index at the industry level. This relationship is broadly suggestive of a negative relationship between labor market rigidities and exports, but cannot be given a causal interpretation. ${ }^{68}$ Further including an interaction term with firm size as in the second column of Table A.4 yields a negative point estimate, suggesting a higher correlation between rigidity and exports of larger firms. The point estimate becomes positive and non-significant within the group of small firms.

Table A.3: Country and Industry Level

\begin{tabular}{lcccc}
\hline \hline & $(1)$ & $(2)$ & $(3)$ & $(4)$ \\
& Country Level & Country Level & Industry Level & Industry Level \\
\hline EPL & $-0.458^{* * *}$ & & $-0.536^{* *}$ & \\
& $(0.127)$ & & $(0.192)$ & \\
RE & & & & -0.0281 \\
& & $-0.0420^{*}$ & & $(0.0250)$ \\
\hline Observations & 850 & $(0.0204)$ & & 27721 \\
Adjusted R-squared & 0.964 & 0.909 & 0.662 & 0.819 \\
Controls & YES & YES & YES & YES \\
Time FE & YES & YES & YES & YES \\
Country FE & YES & YES & YES & YES \\
Industry FE & N/A & N/A & YES & YES \\
\hline \hline
\end{tabular}

Note: Data for 70 countries from 1985 to 2015 for EPL and for 173 countries from 2003 to 2009 and 2013 to 2017 for RE. Dependent variable and controls are from WDI (country level) or UN Comtrade (industry level). EPL is from OECD database, and RE is from the Doing Business reports. Standard errors between parentheses are clustered at the country level in the country-level regression and at country-industry level in the industry-level regression.

Table A.4: Firm Level

\begin{tabular}{lccc}
\hline \hline & $(1)$ & $(2)$ & $(3)$ \\
& All firms & All firms & Only small firms \\
\hline RE & $-0.185^{* * *}$ & $-0.162^{*}$ & 0.00136 \\
& $(0.0514)$ & $(0.0709)$ & $(0.122)$ \\
RE*Size & & $-0.229^{* * *}$ & \\
& & $(0.0544)$ & \\
\hline Observations & 266819 & 266819 & 112307 \\
Adjusted R-squared & 0.187 & 0.189 & 0.233 \\
Time FE & YES & YES & YES \\
Country FE & YES & YES & YES \\
Industry FE & YES & YES & YES \\
Size FE & YES & YES & NO \\
\hline \hline
\end{tabular}

Note: Data for 76 countries from the World Bank Enterprise Survey panel datasets from 2003 to 2009 and 2013 to 2017. Controls are from WDI and RE is from the Doing Business reports. Standard errors between parentheses are clustered at the country-industry level.

\footnotetext{
${ }^{68}$ The coefficient remains negative with more flexible controls, but the estimates become noisier. E.g., country level regressions using the EPL index remain negative and significant using 1-year lags instead of contemporaneous changes, although it becomes insignificant under the RE measure. Industry-level regressions are negative and significant at $10 \%$ using industry-time and industry-country fixed effects with both the EPL and RE measures. The coefficient in the firm-level regression remains negative but not significant using a balanced panel for the countries present from 2009-2013 only.
} 